\title{
Atherothrombosis and Oxidative Stress: Mechanisms and Management in Elderly
}

\author{
Francesco Violi, Lorenzo Loffredo, ${ }^{1}$ Roberto Carnevale, ${ }^{1,2}$ Pasquale Pignatelli, and Daniele Pastori ${ }^{1}$
}

\begin{abstract}
Significance: The incidence of cardiovascular events (CVEs) increases with age, representing the main cause of death in an elderly population. Aging is associated with overproduction of reactive oxygen species (ROS), which may affect clotting and platelet activation, and impair endothelial function, thus predisposing elderly patients to thrombotic complications.

Recent Advances: There is increasing evidence to suggest that aging is associated with an imbalance between oxidative stress and antioxidant status. Thus, upregulation of ROS-producing enzymes such as nicotinamide adenine dinucleotide phosphate (NADPH) oxidase and myeloperoxidase, along with downregulation of antioxidant enzymes, such as superoxide dismutase and glutathione peroxidase, occurs during aging. This imbalance may predispose to thrombosis by enhancing platelet and clotting activation and eliciting endothelial dysfunction. Recently, gut-derived products, such as trimethylamine N-oxide (TMAO) and lipopolysaccharide, are emerging as novel atherosclerotic risk factors, and gut microbiota composition has been shown to change by aging, and may concur with the increased cardiovascular risk in the elderly.

Critical Issues: Antioxidant treatment is ineffective in patients at risk or with cardiovascular disease. Further, anti-thrombotic treatment seems to work less in the elderly population.

Future Directions: Interventional trials with antioxidants targeting enzymes implicated in aging-related atherothrombosis are warranted to explore whether modulation of redox status is effective in lowering CVEs in the elderly. Antioxid. Redox Signal. 27, 1083-1124.
\end{abstract}

Keywords: atherothrombosis, oxidative stress, antioxidants, gut microbiota

\section{Table of Contents}

I. Introduction

1084

II. Oxidative Stress and Aging $\quad 1084$

III. Atherothrombosis in Elderly: Clinical Studies $\quad 1085$

$\begin{array}{lr}\text { A. Hypertension } & 1086\end{array}$

B. Diabetes mellitus 1086

C. Metabolic syndrome 1086

D. Atrial fibrillation 1086

$\begin{array}{ll}\text { E. Peripheral artery disease } & 1087\end{array}$

F. Interaction between cardiovascular risk factors in the elderly 1087

IV. Gut Microbiota and Atherothrombosis 1087

V. Atherosclerosis and Oxidative Stress in Animals and Humans 1087

VI. Pro-Oxidant Pathways 1090
A. Myeloperoxidase
1090

Reviewing Editors: Christine Boesch, Gabriel Gojon, Pascal Goldschmidt-Clermont, Giovanni Li Volti, Daniel Meijles, Sampath Parthasarathy, and Eric Thorin

\footnotetext{
${ }^{1}$ I Clinica Medica, Department of Internal Medicine and Medical Specialties, Sapienza University of Rome, Roma, Italy.

${ }^{2}$ Department of Medical-Surgical Sciences and Biotechnologies, Sapienza University of Rome, Latina, Italy.
} 
B. Lipoxygenases $\quad 1090$

C. NADPH oxidase 1091

VII. Oxidative Products 1091

A. F2-isoprostanes

B. Oxidized LDL 1092

VIII. Atherosclerosis and Antioxidant Status 1093

A. Antioxidant enzymes 1094

1. NO synthase $r$

2. Superoxide dismutase 1094

3. Glutathione peroxidase 1094

\begin{tabular}{lr} 
4. Paraoxonase & 1095 \\
\hline
\end{tabular}

$\begin{array}{lr}\text { 5. Heme-oxygenase } & 1095\end{array}$

B. Direct antioxidants 1095

$\begin{array}{lr}\text { 1. Glutathione } & 1095\end{array}$

2. Vitamin E $r$

3. Vitamin C 1097

C. Indirect antioxidants 1097

1. Hydrogen sulfide 1097

$\begin{array}{lr}\text { 2. Polyphenols } & 1097\end{array}$

IX. Clotting Activation 1097

X. Platelet Activation 1099

XI. Endothelial Dysfunction 1101

XII. Antiplatelet and Anticoagulant Treatment 1104

XIII. Observational and Interventional Trials with Antioxidants in Humans 1104

XIV. Future Perspectives and Conclusions 1106

\section{Introduction}

C ARDIOVASCULAR DISEASES (CVD) occurring in arterial and venous circulation, such as myocardial infarction (MI), ischemic stroke, and venous thromboembolism, are the main cause of morbidity and mortality in Western countries. Their incidence rates increase with age, representing the main cause of death in the elderly population (90). As a further increase in the number of elderly people is expected in the next two to three decades, the management of CVD in this population has a relevant socioeconomic impact.

Progressive development of the atherosclerotic process during aging and its late thrombotic complications are two key phases contributing to artery occlusion in coronary and cerebral districts. Among factors predisposing to MI and stroke, platelets play a pivotal role as they contribute to acute artery occlusion occurring at the site of plaque rupture/erosion by adhering to the exposed sub-endothelium. Then, they concur to thrombus growth via platelet aggregation propagation (75). Clotting system activation and endothelial dysfunction are other important mechanisms implicated in the occurrence of CVD, as they represent a backbone for both artery and venous thrombosis (76). Experimental and clinical studies documented a progressive increase of platelet function, clotting activation, and endothelial dysfunction in the elderly population, supporting their role in the progression of atherothrombosis.

Another age-related process is the imbalance between oxidative stress and antioxidant status. Thus, an increased function of the enzymes responsible for the production of reactive oxygen species (ROS) by aging was reported, along with a parallel decrease of antioxidant pathways, ultimately leading to a pro-oxidant phenotype in elderly subjects. These modifications may also negatively influence platelet and clotting activation and endothelial function, eventually concurring to cardiovascular complications.

In this comprehensive review, we analyzed the mechanisms of atherothrombosis in the aging process focusing on: (i) imbalance between oxidative stress and antioxidant status as factors favoring atherosclerosis and thrombosis in an elderly population, (ii) alterations in platelet and clotting activation and endothelial function in relation to oxidative stress modifications by aging, and (iii) current and future therapeutic antioxidant and anti-thrombotic strategies in the elderly.

\section{Oxidative Stress and Aging}

The main biological consequence of aging is a functional decline in cells, tissues, and organs functions (319). Under normal conditions, cells can go through a limited number of divisions on reaching the end of their replicative lifespan (137). This phenomenon is defined as replicative senescence (RS) and largely depends on alterations in DNA replication that eventually affect chromosomal stability and genome function (187). The RS is mediated by several signaling cascades that are linked to the activation of tumor suppressing proteins, such as $\mathrm{p} 53 / \mathrm{p} 21$, and results in shortening of telomeres (316) that are located at chromosome ends to prevent DNA damage (316). Moreover, cell exposition to different agents damaging DNA, such as ROS, UVA, and UVB, results in reduced mitotic ability and increased signs of senescence. This second phenomenon is termed as stressinduced premature senescence (SIPS) (316).

Thus, the aging process is the result of physiological RS and external SIPS that concur together in accelerating the natural progression of aging (187). In accordance, senescent markers, including Discoidin Domain Receptor family member 1 kinases, 
senescence-associated $\beta$-galactosidase, $\mathrm{p} 53 / \mathrm{p} 21$, and telomere dysfunction, were detected in various tissues from elderly individuals (316).

Although a unique comprehensive theory for the initiation and progression of cell senescence and aging is far from being elaborated, several systems, including mitochondrial dysfunction, protein glycation, deregulation of immune system, hormonal changes, gene modifications, dysfunction telomere attrition, and redox stress, have been identified so far (111).

Oxidative damage represents the most well-documented subset among aging-associated damage. Although its impact on cellular function is only one of the proposed mechanisms of senescence, it seems to be an attractive one as it connects several different mechanisms such as modifications in the regulation of gene expression and mitochondrial dysfunction $(50,122)$.

The theory of ROS overproduction as the main mechanism involved in aging by inducing cumulative damage was first proposed in 1956 (135). According to this hypothesis, an increase in pro-oxidant pathways would promote the aging process, which conversely would be delayed by an improvement in antioxidant defenses.

The validity of this hypothesis was explored in experimental models where the effect of endogenous antioxidant enzymes, such as superoxide dismutase (SOD), catalase, glutathione peroxidase (GPx), and thioredoxin, was investigated. An increase in lifespan was observed in flies overexpressing copper-zinc SOD (CuZnSOD), an enzyme that converts superoxide anion $\left(\mathrm{O}_{2}{ }^{-}\right)$into hydrogen peroxide $\left(\mathrm{H}_{2} \mathrm{O}_{2}\right)$, and catalase, which changes $\mathrm{H}_{2} \mathrm{O}_{2}$ into water $(262$, 363). Moreover, reduced levels of GPx, an enzyme that reduces lipid hydroperoxides to their corresponding alcohols and $\mathrm{H}_{2} \mathrm{O}_{2}$ to water, and of thioredoxin that possesses a similar activity, were observed in an animal model of aging (64). Transgenic and knockout mouse models of antioxidants provided conflicting evidence (328). For example, knockout mice models of GPx1 and SOD were associated to reduced lifespan $(79,96)$, whereas transgenic mice overexpressing SOD and catalase showed an unmodified lifespan (275).

Growing evidence suggests a role for pro-oxidant systems in the aging process. Pro-oxidant enzymes producing ROS, such as nicotinamide adenine dinucleotide phosphate (NADPH) oxidase (Nox), myeloperoxidase (MPO), and uncoupled nitric oxide synthase (NOS), mediate important biological functions by regulating the activity of several intracellular pathways involved in cell growth, apoptosis, survival, metabolism, and migration, all of which are altered during the aging process.

Among $\mathrm{ROS}, \mathrm{O}_{2}^{-}$plays a fundamental role, as it reacts with nitric oxide (NO), thus lowering its activity and/or concentration (199). Reduced NO bioavailability influences migration and proliferation of vascular smooth muscle cells (VSMCs), which is one of the early atherosclerotic changes (199). Moreover, $\mathrm{O}_{2}{ }^{-}$upregulates the nuclear factor kappalight-chain-enhancer of activated B cells (NF- $\kappa \mathrm{B})$, which, in turn, induces the production of atherogenic cytokines such as tumor necrosis factor $\alpha(\mathrm{TNF} \alpha)$, interleukin 6 , monocyte chemoattractant protein (MCP)-1, and adhesion molecules (254).

A specific interplay between ROS, gene transcription, and subsequent signal transduction seems to be implicated in aging. Thus, ROS induce phosphorylation of the redox- sensitive transcription factor p53 by activating p38 mitogenactivated protein kinase (MAPK) (34) and Polo-like kinase 3 (409). The p53 factor enhances ROS signaling, presumably via upregulation of the $\mathrm{p} 67^{\mathrm{phox}}$ subunit of the Nox system (154). Once activated, p53 is able to modulate RS by controlling some specific genes involved in cell cycle arrest. The role of p53 in premature aging has been demonstrated by several mouse models where persistent p53 activation promoted senescence or irreversible cell cycle arrest (372). Interestingly, human endothelial cells undergo p53/p21cipdependent cell cycle arrest via Nox2-derived $\mathrm{O}_{2}{ }^{-}$production (201).

Other oxidative-linked effectors of longevity, such as Klotho gene, may influence aging-related atherosclerotic process. Thus, Klotho-null mice phenotypes display similarities with premature human aging, including accelerated atherosclerosis (188). Once activated, Klotho protein induces MnSOD and SOD2 biosynthesis, thereby increasing the antioxidant cell defense $(176,303,412)$. Moreover, Klotho influences the intracellular signaling pathways involved in oxidative stress responses and aging via inhibition of $\mathrm{p} 53$ / p21cip (81).

The gene regulator histone deacetylase sirtuin (SIRT) is also implicated in the aging process. SIRT is present in seven isoforms and encompasses a nicotinamide adenine dinucleotidedependent enzymatic activity associated with aging (92). In particular, the isoform SIRT1 is localized in the nucleus and plays an important role in preserving vascular health; Sirt1-Tg/ $\mathrm{ApoE}^{2 / 2}$ mice showed upregulated endothelial NOS (eNOS) activity and reduced atherosclerotic plaque formation as compared with wild type (421). In support of this, treatment of $\mathrm{ApoE}^{2 / 2}$ mice with a specific SIRT1 activator resulted in a significant reduction of oxidized low-density lipoprotein (oxLDL) concentration and plaque formation (350).

ROS are also involved in the activation of mitochondrialmediated patterns that are implicated in reducing lifespan and accelerating atherosclerosis progression. Thus, ROS elicit mitochondrial adaptor protein p66shc phosphorylation, which, in turn, regulates intracellular pathways that are involved in ROS production and apoptosis (236). In particular, $\mathrm{H}_{2} \mathrm{O}_{2}$ induces serine phosphorylation on p66shc through protein kinase C, resulting in increased apoptosis (290). Thus, animals on a chronic high-fat diet disclosed an aortic cumulative early lesion area by $\sim 21 \%$ in wild-type mice and only by $3 \%$ in p66shc ${ }^{(-/-)}$mice. Further, in p66shc $\mathrm{s}^{(-)}$mice, a significant reduction of systemic and tissue oxidative stress along with a $30 \%$ prolongation in lifespan was observed (236, 253).

A synthetic scheme of the mechanisms reported earlier is reported in Figure 1.

\section{Atherothrombosis in Elderly: Clinical Studies}

Observational studies in the general population or in patients with CVD documented a progressive increased incidence of acute vascular events by aging (90). In the elderly, a higher prevalence of atherosclerotic risk factors, including arterial hypertension, diabetes mellitus (DM), and metabolic syndrome (MetS), might partly account for this phenomenon (50). Of note is that there is no standardized definition of "old population," as changes occurring by aging are not linear and often depend on several factors, including environment, 


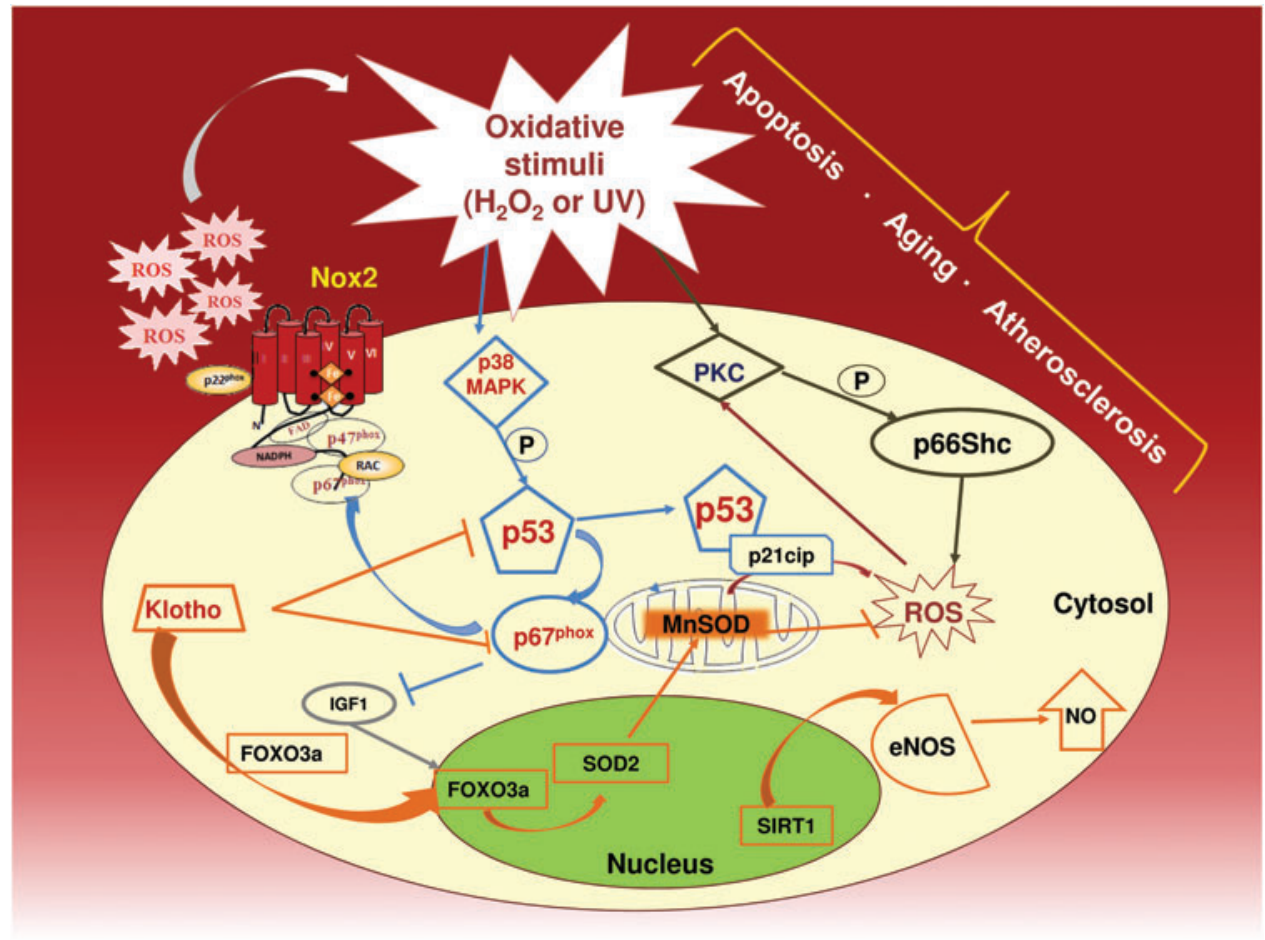

FIG. 1. Schematic representation of oxidative stress role in the aging process. ROS, gene transcription, and subsequent signal are implicated in the aging process. ROS can induce phosphorylation of the redox-sensitive transcription factor p53 by activating p38 MAPK and Protein-chinase C (PKC). p53, in turn, enhances ROS signaling via upregulation of the p67phox subunit of the Nox system. ROS are also involved in the activation of mitochondrial-mediated patterns implicated in reducing lifespan and accelerating atherosclerosis progression. Thus, ROS elicit mitochondrial adaptor protein p66shc phosphorylation, which, in turn, regulates intracellular pathways that are involved in ROS production and apoptosis. Oxidative-linked effectors of longevity, such as Klotho gene, protect from the aging process. Klotho protein activation induces MnSOD and SOD2 biosynthesis, thereby increasing the antioxidant cell defense; it influences the intracellular signaling pathways involved in oxidative stress responses and aging via inhibition of p53/p21cip. The gene regulator histone deacetylase SIRT is also implicated in the aging process. The isoform SIRT1, localized in the nucleus, plays an important role in preserving vascular functions, by upregulating eNOS and NO. eNOS, endothelial NOS; MAPK, mitogen-activated protein kinase; NO, nitric oxide; Nox, NADPH oxidase; ROS, reactive oxygen species; SIRT, sirtuin; SOD, superoxide dismutase. To see this illustration in color, the reader is referred to the web version of this article at www.liebertpub.com/ars

individual behaviors, social position, and ethnicity. The "WHO World report on ageing and health" states that "by age 60, the major burdens of disability and death arise from age-related losses in hearing, seeing and moving, and noncommunicable diseases, including heart disease, stroke, chronic respiratory disorders, cancer and dementia' (26). However, chronological age with a cut-off set at 65 and 75 years is the most used method to define old age, but the need for "multidimensional/functional" definition remains (341).

\section{A. Hypertension}

The prevalence of hypertension increases with age, ranging from $7.3 \%$ in people aged $18-39$ years, to $65.0 \%$ among those $\geq 60$ years in the United States (257). Further, about one third of U.S. adults aged $\geq 80$ years are treated with $\geq 3$ classes of antihypertensive medication (247), suggesting a more severe phenotype of hypertension in elderly patients.

\section{B. Diabetes mellitus}

The overall prevalence of DM in the United States is progressively increasing from $8.4 \%$ (1988-1994) to $12.1 \%$
(2005-2010). The corresponding figures for subjects aged $\geq 65$ years are $18.6 \%$ and $28.5 \%$, respectively (62). Similarly, in European countries, DM prevalence is $10 \%$ and $15-20 \%$ in subjects $<60$ and $>70$ years, respectively $(11,126)$.

\section{Metabolic syndrome}

MetS is characterized by the coexistence of at least three of the following atherosclerotic risk factors: (i) central obesity, (ii) atherogenic dyslipidemia (i.e., low high-density lipoprotein [HDL] and high triglycerides), (iii) hypertension, and (iv) elevated fasting glucose (4). The prevalence of MetS among U.S. men ranges from $20.3 \%$ in subjects 20-39 years of age to $51.5 \%$ for subjects $\geq 60$ years of age in the NHANES 2003-2006. Among U.S. women, prevalence ranges from $15.6 \%$ in subjects $20-39$ years of age to $54.4 \%$ for those $\geq 60$ years of age (98).

\section{Atrial fibrillation}

Aging is associated with an increased prevalence and incidence of atrial fibrillation (AF) that is expected to increase in the next years worldwide. Age is not only a predictor of AF 
but also an established risk factor for CVD and cerebrovascular disease (CD) $(266,267,343,386)$ in patients with paroxysmal or persistent/permanent AF. Thus, by the seventh decade of life, the incidence of athero-thromboembolism in AF patients sharply increases compared with the younger population (205).

\section{E. Peripheral artery disease}

Peripheral artery disease (PAD) is an uncommon finding in people $<50$ years, but its prevalence sharply rises with aging. In the Heinz Nixdorf recall study, which included 4814 subjects, the prevalence of symptomatic/asymptomatic PAD in men aged $45-49$ years was $3.0 \%$, rising to $18.2 \%$ in those aged $70-75$ years. In women, the percentage rose from $2.7 \%$ to $10.8 \%$ in the same age categories (181). Similarly, in the Framingham Heart Study, the incidence of intermittent claudication rose from 0.4 per 1000 in men aged 35-45 years to 6.0 per 1000 in those aged $\geq 65$ years $(170)$.

\section{F. Interaction between cardiovascular risk factors in the elderly}

The presence of multiple risk factors is common in elderly patients (403) and contributes to the aging-related atherothrombosis burden. The prevalence of multimorbidity, defined as $\geq 2$ concomitant chronic diseases, significantly increases by aging and may be detected in $>70 \%$ of patients $\geq 75$ years (28). For instance, DM is associated with other atherosclerotic risk factors; in particular, hypertension, elevated LDL, and obesity may coexist in $75-85 \%, 70-80 \%$, and $60-70 \%$ of diabetic patients, respectively (152). The cumulative risk of experiencing a cardiovascular outcome in multimorbidity patients overcomes the risk conferred by each condition alone (97). Taking into account the frequent combination of multiple risk factors in the elderly, this could be considered one of the important factors contributing to the high risk of CVD in the elderly (129).

\section{Gut Microbiota and Atherothrombosis}

Gut microbiota is emerging as a novel player in the process of atherosclerosis as it is implicated in the development of atherosclerotic risk factors such as diabetes and hypertension (166). However, there is also mounting evidence that products of intestinal microbiota may cross the intestinal barrier, reach the circulatory system, and directly contribute to atherothrombosis. For instance, recent studies on this topic discovered that intestinal microbiota produces trimethylamine $\mathrm{N}$-oxide (TMAO), which may be implicated in the process of atherosclerosis and thrombosis $(300,360)$.

Other products of gut microbiota such as lipopolysaccharide (LPS) may concur to atherosclerosis, possibly via chronic inflammation and thrombosis (235). About 100 trillion of gut bacteria contribute to an enteric reservoir of $>1 \mathrm{~g}$ of LPS, which can be found in human circulation from healthy subjects in a range of $15-200 \mathrm{pg} / \mathrm{ml}$ (313). A recent prospective study showed that circulating LPS was predictive of cardiovascular events (CVEs) in a population affected by AF (265).

An important but not-yet-solved issue is whether changes of gut microbiota occurring with aging may be potentially implicated in atherothrombosis. Indeed, from newborns to elderly gut, microbiota is characterized by continuous modifications, which alter its metabolism. From a phase of instability and low complexity, which characterizes newborns until the age of 3 years, gut microbiota gets more stable in adults with essentially saccharolytic bacteria activity (317). Conversely, in the elderly population, gut microbiota gets again unstable with an activity shifted toward a prevalent proteolytic metabolism. It is unclear, however, whether these changes are due to different dietary patterns or to intrinsic changes of gut microbiota of the elderly population. Whatever is the mechanism, it would be interesting to appreciate whether in the elderly gut microbiota is more prone to deliver metabolic molecules, such as TMAO or LPS, which are implicated in atherothrombosis (Fig. 2).

\section{Atherosclerosis and Oxidative Stress in Animals and Humans}

Retention and accumulation of LDL particles within the vessel wall is a critical step of the early atherosclerotic process. In fact, LDL accumulation causes migration of inflammatory cells such as monocytes/macrophages, which then uptake and oxidize LDL via an oxidative stressmediated mechanism (109). In this regard, kinetic analysis of LDL across the artery wall demonstrated that retention of LDLs in the sub-intima space depends on LDL permeability and on the ability of LDL to leave (efflux) the artery wall (358). Concentration of LDL in the circulation is likely to be an important element contributing to LDL permeability and degradation in the artery wall. Bartels et al. (21) studied this issue in cholesterol-fed, LDL receptor (LDLR)-deficient mice treated with an anti-ApoB antisense oligonucleotide versus mismatch control antisense oligonucleotide for 1-4 weeks before an injection of iodinated LDL particles. Animals treated with an anti-ApoB antisense oligonucleotide showed $\sim 90 \%$ reduction of plasma LDL, which was associated with $50 \%$ and $85 \%$ reduction of aortic permeability and degradation, respectively, of newly entered LDL particles after 1 week of treatment. Conversely, 4 weeks of treatment were necessary to observe a reduction in foam cell content, plaque size, and aortic LDL pool size. Interestingly, plasma LDL cholesterol lowering was associated with $70 \%$ reduction of sub-luminal foam cells and $\sim 90 \%$ reduction of messenger RNA (mRNA) expression of inflammatory genes. The enhanced permeability of LDL into atherosclerotic plaque is almost evident in the elderly population with established atherosclerosis. This was documented by an injection of iodinated autologous LDL in elderly patients $24 \mathrm{~h}$ before undergoing endoarterectomy for critical carotid stenosis. The analysis of carotid specimens demonstrated that LDL localized into macrophages and that this phenomenon was prevented by pre-treatment with vitamin $\mathrm{E}$, suggesting that LDL is rapidly uptaken and oxidized by foam cells of atherosclerotic plaque (155).

Chronic deposition and accumulation of LDL causes an injury response, which results in the recruitment of macrophages, dendritic cells, and lymphocytes at the site of atherosclerotic lesion. As for sterile inflammation, this process may undergo resolution with classical tissue repair or, in case of defective resolution, progress to advanced lesion (330). Advanced atherosclerotic plaque is characterized by a central necrotic core, composed by macrophages and 


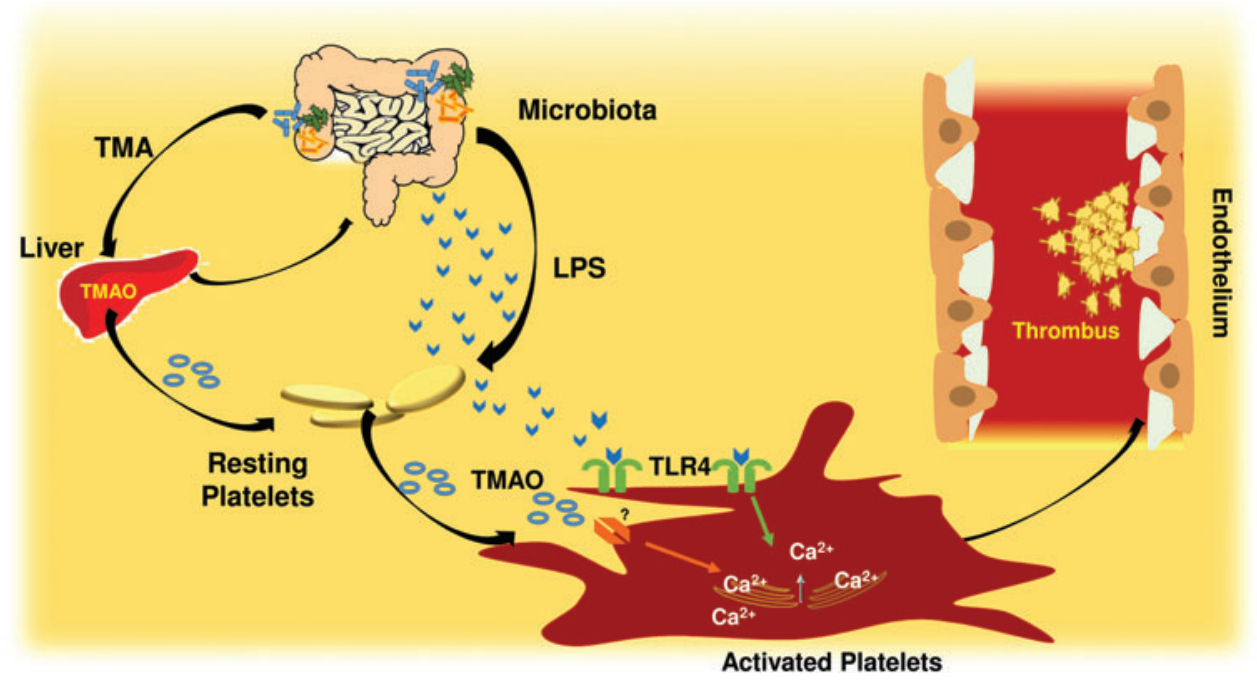

FIG. 2. Gut microbiota and atherothrombosis. The products of intestinal microbiota may across the intestinal barrier, reach the circulatory system, and contribute to atherothrombosis. For instance, trimethylamine (TMA) is oxidized by the liver in TMAO, which increases platelet aggregation and thrombus growth. Other products of gut microbiota such as LPS may also be involved in the atherothrombotic process via chronic inflammation and thrombosis mediated by binding TLR4 on the platelet surface. LPS, lipopolysaccharide; TMAO, trimethylamine N-oxide. To see this illustration in color, the reader is referred to the web version of this article at www.liebertpub.com/ars

VSMC. Impaired clearance of necrotic cells, a process called efferocytosis, causes accumulation of inflammatory material that further exacerbates atherosclerotic lesion, eventually leading to its rupture or erosion (358). Persistent inflammatory stimulus due to continuous accumulation of LDL in the sub-intima coupled with impaired efferocytosis and presence of an inflammatory phenotypes leads to progression of inflammation and the atherosclerotic process (358).

In this context, oxidative stress has an important role as it is a stimulus for further macrophage accumulation and activation, and for the production of oxidant products that perpetuate tissue damage (345). For instance, isoprostanes, which were found in human atherosclerotic plaque (294), induce mitogenesis of VSMCs, proliferation of fibroblasts and endothelial cells, and overexpression of endothelin 1 in mouse aortic endothelial cells (293). Moreover, blockade of thromboxane (Tx) receptor improves the anti-atherogenic effect of Tx inhibition in LDLR-deficient mice (71). Other effects of oxidative stress include expression of adhesion molecules such as vascular cell adhesion molecule (VCAM)1, intercellular adhesion molecule (ICAM)-1 and E-selectin, and the MCP-1, which promote monocyte adhesion, migration, and accumulation in the sub-endothelium (68) and activation of inflammatory cytokines such as $\mathrm{TNF} \alpha$. In this regard, it is interesting that in $\mathrm{p} 47^{\text {phox }}$ knockout mice, $\mathrm{TNF} \alpha$ failed to induce expression of ICAM-1 in coronary microvascular endothelial cells (200). In other studies, ROS elicited expression of VCAM-1, which serves as a scaffold for leukocyte migration and a trigger for endothelial signaling via inducing Nox 2 activation (67). Oxidative stress is closely related to activation of pro-oxidant pathways such as Nox, MPO, uncoupled eNOS, and lipoxygenases (LOXs) and is counteracted by antioxidant enzymes, including SOD, catalase, GPx, paraoxonase (PON), and NOS. These endogenous antioxidants protect against athero-genesis by scavenging
ROS, facilitating endothelium-dependent vasorelaxation, inhibiting inflammatory cell adhesion to the endothelium, and altering vascular cellular responses, such as VSMC and endothelial cell apoptosis, VSMC proliferation, hypertrophy, and migration (114) (Table 1 and Fig. 3).

Defective tissue repair with impaired damage resolution is a relevant key element for atherosclerotic progression that is not yet poorly understood $(124,171)$. Clearance of inflammatory cells and necrotic materials along with vascular regeneration are hampered in atherosclerosis and, more in particular, in aging-related atherosclerosis. Lesion resolution depends on several factors, including formation of (i) bioactive lipids such as lipoxins, resolvins, protectins, and maresins, called specialized pro-resolvin proteins; (ii) proteins such as interleukin 10, transforming growth factor-beta, and annexin A1; and (iii) bioactive gas such as NO, hydrogen sulfide $\left(\mathrm{H}_{2} \mathrm{~S}\right)$, and carbon monoxide (357). The presence of cell phenotypes with resolving capacity such as regulatory $\mathrm{T}$ cells and resolving-type macrophages is also relevant (357).

An important role in vascular tissue repair seems to be played by mononuclear cells with a specific phenotype, namely progenitor cells (PCs), which originate primarily from bone marrow (BM) and differentiate into hematopoietic stem cells, including endothelial progenitor cells (EPCs). Several age-related modifications of BM have been described (311). Thus, the hematopoietic active BM (red BM) gradually undergoes adipose replacement (yellow BM), becoming less active during the aging process. Also, BM cellularity is strictly correlated with age (123), together with a reduced availability and ability to migrate of EPCs, and possibly other BM cells that are necessary for successful arterial repair in the elderly (218). Thus, in 123 women with nonobstructive coronary artery disease (CAD), the number of circulating PC $\left(\mathrm{CD}_{4} 4^{+}, \mathrm{CD}_{4} 4^{+} / \mathrm{CD}_{133}{ }^{+}\right.$, and $\left.\mathrm{CD} 34^{+} / \mathrm{CXCR}^{+}\right)$was inversely correlated with age (233). 
Table 1. Animal Models of Interplay Between Oxidative Stress and Atherosclerosis

\begin{tabular}{|c|c|c|c|}
\hline & Genetic model/pharmacologic agent & Phenotype & References \\
\hline \multicolumn{4}{|l|}{ Oxidant enzymatic systems } \\
\hline MPO & Humanized MPO-knockout mice (mice & Reduction in lipid peroxidation & $(38,423)$ \\
\hline & express human MPO-463G/A alleles) & Accelerated atherosclerosis & (58) \\
\hline iNOS & $\mathrm{ApoE}^{-/-} / \mathrm{eNOS}^{-} /$ & Decreased atherosclerosis & $(182,242)$ \\
\hline LOX & $12 / 15-\mathrm{LO}^{-1-} / \mathrm{ApoE}^{-/-}$ & Decreased atherosclerosis & \\
\hline Nox 2 & $\mathrm{ApoE} \mathrm{E}^{-/-} / \mathrm{Nox} 2^{\mathrm{y} /-}$ & $\begin{array}{l}\text { Decreased vascular ROS levels, } \\
\text { increased NO bioavailability, and } \\
\text { decreased atherosclerosis }\end{array}$ & $(168)$ \\
\hline $\begin{array}{l}\mathrm{p} 47^{\text {phox }}(\text { Nox } 1 / 2 \mathrm{NADPH} \\
\text { oxidase activity) }\end{array}$ & ApoE $E^{-/-} / \mathrm{p} 47^{\text {phox-l- }}$ & $\begin{array}{l}\text { Decreased vascular ROS levels and } \\
\text { atherosclerosis }\end{array}$ & $(20)$ \\
\hline \multicolumn{4}{|c|}{ Antioxidant enzymatic systems } \\
\hline eNOS & $\mathrm{ApoE}^{-/-} / \mathrm{eNOS}^{-/-}$ & $\begin{array}{l}\text { Accelerated atherosclerosis, aortic } \\
\text { aneurysm, and ischemic heart } \\
\text { disease }\end{array}$ & $(183)$ \\
\hline nNOS & nNOS-deficient $\mathrm{ApoE}^{-/-}$mice & Accelerated atherosclerosis & $(184)$ \\
\hline Catalase & $\mathrm{ApoE}^{-/-} / \mathrm{hCatTg}^{0 / 7}$ & Decreased lipid peroxidation and & $(413)$ \\
\hline SOD1 and catalase & ApoE ${ }^{-/-} / \mathrm{hSOD}^{\circ} \mathrm{Tg}^{0 /+} / \mathrm{hCatTg}^{0 /+}$ & atherosclerosis & \\
\hline SOD2 & $\mathrm{ApoE}^{-/-} / \mathrm{SOD} 2^{+/-}$ & $\begin{array}{l}\text { Increased mitochondrial ROS levels } \\
\text { and mitochondrial DNA damage; } \\
\text { increased atherosclerosis }\end{array}$ & $(18)$ \\
\hline GPx1 & $\mathrm{ApoE}^{-/-} / \mathrm{GPx}^{-/-}$ & $\begin{array}{l}\text { Increased vascular ROS levels and } \\
\text { atherosclerosis }\end{array}$ & $(365)$ \\
\hline GPx4 & hGPx4Tg/ApoE ${ }^{-/-}$ & $\begin{array}{l}\text { Decreased eicosanoids and } \\
\text { atherosclerosis }\end{array}$ & $(130)$ \\
\hline PON1 & $\mathrm{PON}^{-/-} \mathrm{ApoE}^{-/-} / \mathrm{PON}^{-/-}$ & Increased atherosclerosis & $(331,332)$ \\
\hline PON2 & PON2-deficient $\mathrm{ApoE}^{-/-}$ & $\begin{array}{l}\text { Increased mitochondrial oxidative } \\
\text { stress }\end{array}$ & $(85)$ \\
\hline PON3 & $\mathrm{hPON} \mathrm{Tg}^{0 /+} ; \mathrm{ApoE}^{-/-} / \mathrm{hPON} \mathrm{Tg}^{0 /+}$ & Decreased atherosclerosis & $(333)$ \\
\hline
\end{tabular}

eNOS, endothelial NOS; GPx, glutathione peroxidase; iNOS, inducible NOS; LOX, lipoxygenase; MPO, myeloperoxidase; NADPH, nicotinamide adenine dinucleotide phosphate; nNOS, neuronal NOS; NO, nitric oxide; Nox, NADPH oxidase; PON, paraoxonase; ROS, reactive oxygen species; SOD, superoxide dismutase.

FIG. 3. Change of prooxidant and anti-oxidant molecules and enzymes during aging. Pro-oxidant and antioxidant enzymes/ molecules implicated in atherosclerotic plaque formation and their modification by aging. VSMCs, vascular smooth muscles cells. To see this illustration in color, the reader is referred to the web version of this article at www .liebertpub.com/ars

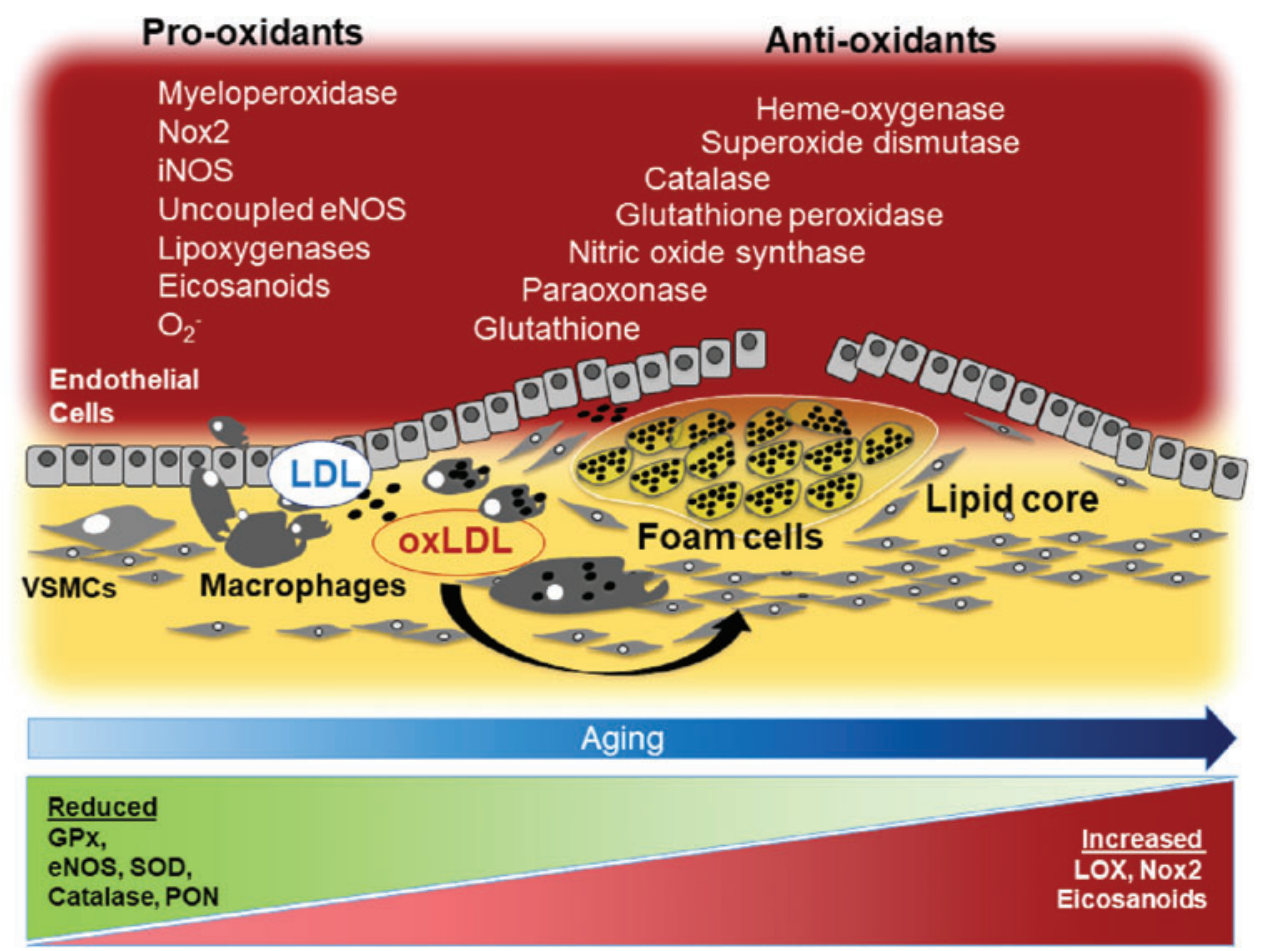


Indirect evidence of the potential role played by $\mathrm{PC}$ in vascular disease has been provided by Hill et al., who showed lower circulating PC in patients at risk of CVD with an inverse correlation between PC and artery dysfunction (144). Other reports in patients at risk of CVD supported these findings and also underscored that PC lowering is more marked in an elderly population with concomitant atherosclerotic risk factors than in apparently healthy subjects in whom such PC decline by aging is not evident (136). Experimental studies are in agreement with this negative interplay between PC and aging as depicted by experiments reporting lower $\mathrm{BM}$-derived $\mathrm{PC}$ in aging $\mathrm{ApoE}^{-/}$mice, along with a positive impact of chronic treatment with $\mathrm{BM}$-derived PC in the atherosclerosis progression (301). However, the clinical relevance of these findings in human atherosclerosis is still speculative and needs to be further investigated. In particular, prospective studies are necessary to assess whether BM-derived PC are actually decreasing by aging independently or not by classic atherosclerotic risk factors, and their potential role to halt atherosclerotic progression.

In contrast with this hypothesis, a recent work showed that clonal hematopoiesis of indeterminate potential (CHIP), which is a common aging-related phenomenon characterized by the presence of an expanded somatic blood-cell clone in people without hematologic disease, which may lead to an increase in circulating myeloid cells, was significantly associated with the risk of coronary events in 4726 participants with coronary heart disease (CHD) and 3529 controls, and with accelerated atherogenesis in a murine model of atherosclerosis (159).

\section{Pro-Oxidant Pathways}

\section{A. Myeloperoxidase}

MPO is an enzyme belonging to the mammalian heme peroxidase superfamily, which is detectable in neutrophils, monocytes, and macrophages. MPO produces various compounds with pro-oxidant properties, such as hypochlorous acid, chloramine, tyrosyl radicals, and nitrogen dioxide, contributing to oxidative stress by oxidizing LDL and lowering NO activity and biosynthesis (57, 423). Moreover, MPO activation generates eicosanoids and bioactive lipids and atherogenic forms of both LDL and HDL. Indeed, studies using MPO knockout mice demonstrated that this enzyme plays an important role in the formation of products derived from the oxidation of arachidonic acid (AA) that are involved in the inflammatory response (423) and in lipid peroxidation $(38,423)$.

Although the role of MPO as a pro-oxidant and proinflammatory enzyme is well demonstrated, its contribution to atheroma progression is a matter of debate. In fact, in $\mathrm{ApoE}^{(--)}$mice, genetic deletion of MPO had no impact on atherosclerotic lesion (37), whereas specimens from human aortic plaques expressed increased MPO (219) and MPOderived compounds (404). Interestingly, "humanized" MPO/atherosclerosis animal models demonstrated an accelerated plaque development in $\operatorname{LDLR}^{(-/)}$transgenic mice expressing human MPO-463G/A alleles $(58,396)$.

Clinical studies performed in patients with CHD $(143,234$, $361,422)$ or $\operatorname{PAD}(6,40)$ showed a predictive role for elevated MPO. Conversely, few data regarding its role in aging have been reported. Son et al. found that in rats MPO activity increases by $70 \%$ and $85 \%$ at 18 and 24 months, respectively, compared with the 6-month-old rats (344). MPO was also more elevated in cardiac tissue after $24 \mathrm{~h}$ from myocardial injury in old compared with young rats (101). Data from the prospective cohort study Aging and Longevity Study in the Sirente Geographic Area (SIRENTE Study), which included 363 people aged $\geq 80$ years, showed an enhanced mortality risk in individuals in the highest MPO tertile as compared with the lowest one (145).

A recent study in patients with acute MI reported an increased MPO activity along with a reduced glutathione (GSH) concentration in 45 patients aged $\geq 65$ years compared with 34 patients aged $<65$ years.

\section{B. Lipoxygenases}

LOXs are non-heme iron-containing dioxygenases that oxidize polyunsaturated fatty acids released from the cell membrane under inflammatory conditions into hydroperoxy fatty acid derivatives (88). LOXs form a heterogeneous class of lipid peroxidizing enzymes that seem to be involved in the pathogenesis of atherosclerosis (115). LOXs, in particular 5LOX and 12/15 LOX, were found to be overexpressed in advanced atherosclerotic lesions $(17,120)$, where they can contribute to leukocyte recruitment through the generation of two classes of AA-derived lipid mediators, namely leukotrienes and lipoxins (141). In particular, 5-LOX catalyzes the transformation of free AA into leukotriene B4, a potent chemo-attractant and leukocyte activator. However, inconclusive data were obtained with respect to the pathophysiological relevance of this leukotriene signaling in atherosclerosis. Thus, leukotriene B4 antagonist was able to decrease monocyte-derived foam cell translocation into the plaque (3), in a double knockout mice model $\mathrm{BLT}^{(-/-)}$and ApoE ${ }^{(-l-)}$, whereas deletion of BLT1, the leukotriene B4 receptor, was associated to reduced lesion formation during the early stages of plaque development, but was not effective at more advanced stages (352).

$12 / 15$-LOX catalyzes the oxidation of AA, resulting in the formation of the pro-oxidant 12-/15-hydroxyeicosatetraenoic acids. Moreover, 12/15-LOX oxidizes polyunsaturated acyl chains in phospholipids and cholesteryl esters, two relevant LDL components $(27,134)$. Experiments in knockout models supported the relevance of $12 / 15-\mathrm{LOX}$ in the atherosclerotic process. Thus, $12 / 15-\mathrm{LOX}^{(-/)}$mice on a high-fat diet disclosed reduced ox-LDL, plasma, and urinary isoprostanes levels, and atherosclerotic lesion initiation was significantly delayed in the double-knockout mice compared with ApoE $^{(--)}$mice (70). Consistent with this, overexpression of human $15-\mathrm{LOX}$ in the vascular endothelium of $\mathrm{LDLR}^{(-)}$ mice was associated with increased early atherosclerosis (133).

Although data on animal models are promising, there are only few studies regarding the involvement of LOX in human CVD. Only recently, in a case-cohort study including 57,053 participants aged 50-64 years, polymorphisms of 5-LOX pathway, resulting in LOX5 gain of function, were associated with incident MI (117).

LOXs seem also to be affected by animal and human aging. Thus, 5-LOX mRNA and protein levels were significantly increased in the cerebral nervous system of 25 
month- compared with 3 month-old mice (216). Similarly, in humans, expression of the 5-LOX gene and the activity of 5-LOX were increased in elderly subjects, suggesting a role for this enzyme in neurological diseases associated with aging (104).

\section{NADPH oxidase}

Nox is an enzymatic system composed by several subunits, and different isoforms have been described so far. Nox is responsible for the formation of $\mathrm{O}_{2}^{-}$(383) that induces LDL oxidation, expression of VCAM-1, MCP-1, and endothelial monocyte adhesion and infiltration (118).

The impact of the different Nox isoforms in human atherosclerosis is still a matter of debate (379). Thus, Nox1 and Nox 5 are known to essentially elicit $\mathrm{O}_{2}{ }^{-}$formation and to contribute to proliferation of humans VSMC (379). Nox4 yields $\mathrm{H}_{2} \mathrm{O}_{2}$ formation and only scarcely stimulates $\mathrm{O}_{2}{ }^{-}$ production (379); Nox4 also possesses vasodilating properties via eNOS activation (323). Among ROS generated by Nox2, $\mathrm{O}_{2}^{-}$and $\mathrm{H}_{2} \mathrm{O}_{2}$ seem to play a relevant role in redox signaling of atherogenic processes. These two molecules appear to have different impact on vascular function as $\mathrm{O}_{2}{ }^{-}$is devoted to controlling endothelial dilatation whereas $\mathrm{H}_{2} \mathrm{O}_{2}$ may have not only vasodilation but also pro-inflammatory properties (114). Thus, in a model of carotid ligation, overexpression of the Nox 2 subunit $\mathrm{p} 22^{\text {phox }}$ was associated with a marked increase of atheroma and a concomitant overproduction of $\mathrm{H}_{2} \mathrm{O}_{2}$ (173). This finding was confirmed in experiments in which the use of an $\mathrm{H}_{2} \mathrm{O}_{2}$ scavenger, such as catalase, reduced the formation of atheroma (173).

An experimental study demonstrated that atherosclerotic plaque formation was significantly mitigated in animals treated with apocynin, a molecule that reduces subunit $\mathrm{p} 47^{\text {phox }}$ translocation to the membrane catalytic Nox2 (206, 298). Apocynin dose dependently decreased total monocyte accumulation, platelet adhesion, and atherosclerotic progression (206). The relationship between Nox 2 and atherosclerotic lesion progression has been supported by Judkins et al., who studied a double knockout model of accelerated atherosclerosis represented by $\mathrm{Nox} 2^{(-/ \mathrm{y})} / \mathrm{ApoE}^{(-/-)}$mice (168). They found a significantly lower vascular ROS production, increased NO bioavailability, and reduced early lesion development compared with $\mathrm{ApoE}^{(-1-)}$ mice (168). Similar results were also obtained in $\mathrm{ApoE}^{(-1-)} / \mathrm{p} 47^{\text {phox(-l-) }}$ mice (20). These data were further confirmed by Quesada et al., who found a significant regression of atherosclerotic plaque in mice fed with a high-fat diet and given a specific Nox2 inhibitor (298). Finally, in mice overexpressing endothelial Nox2, an early increase of endothelial activation and macrophage accumulation within the sub-endothelium were observed compared with controls, whereas aged animals showed similar atherosclerotic burden and progression (89).

In human, overexpression of some Nox subunits was associated with a marked increase of atheroma (173). Azumi et al. demonstrated that $\mathrm{p} 22^{\text {phox }}$ subunit was overexpressed in the vessel wall of atherosclerotic coronary arteries using coronary sections from autoptic specimens (15). This observation was confirmed by Guzik et al. (131), who found enhanced superoxide production in coronary arteries from patients with CHD in association with upregulation of p $22^{\text {phox }}$ and Nox2, suggesting that both these subunits con- tribute to oxidative stress in human coronary atherosclerotic lesions (131).

Experiments performed in subjects affected by chronic granulomatous disease (CGD), which is characterized by hereditary deficiency of Nox 2 subunits, allowed to investigate the role of this Nox in human atherosclerosis. The most common form of CGD is related to Nox 2 hereditary deficiency, but other subunits such as $\mathrm{p} 47^{\mathrm{phox}}$ may be lacking. To investigate the role of Nox 2 in the physiology and pathophysiology of cardiovascular system, we developed an immuno-assay that measures the extra membrane peptide of the enzyme released in the medium on Nox2 activation, called soluble Nox2-derived peptide (sNox2-dp) (278). Blood analysis demonstrated that $\sim 90 \%$ of sNox2-dp stems from activation of leukocytes, lymphocytes/monocytes, and platelets (278).

The interplay between Nox and atherosclerosis was also investigated in female carriers of Nox 2 deficiency (384). The study showed a significant reduction of the carotid intimamedia thickness (IMT), which is another surrogate marker of atherosclerosis, in carriers compared with controls (215). Using a more sophisticated diagnostic approach, that is, magnetic resonance imaging and computed tomography, Sibley et al. (337) supported these preliminary reports by demonstrating that CGD patients, compared with control subjects, had a $22 \%$ lower internal carotid artery wall volume with a similar reduction detected in both the $\mathrm{p} 47^{\text {phox- }}$ and gp91 ${ }^{\text {phox }}$-deficient subtypes (337).

The relationship between Nox 2 and aging has been investigated in $\mathrm{ApoE}^{(-/-)}$mice, which showed an upregulation of Nox 2 in atherosclerotic plaque compared with controls; Nox2 was upregulated in endothelial cells and macrophages of atherosclerotic lesion and associated with elevated ROS levels. Of particular interest was the fact that upregulation of Nox 2 and elevation of ROS were age dependent, with a significant increase from 12 to 19 weeks (168).

The relationship between aging and Nox 2 has been prospectively investigated in AF, who were followed up for about 40 months; Nox 2 activity increased coincidentally, with aging-related GPx3 downregulation suggesting an imbalance between oxidant and antioxidant status (268); and the imbalance between Nox 2 and GPx3 was significantly evident at the age of 75 years, coincidentally with an abrupt risk of CVEs.

\section{Oxidative Products}

\section{A. F2-isoprostanes}

F2-isoprostanes are a family of eicosanoids with proatherogenic and pro-thrombotic properties. The eicosanoid 8-iso-prostaglandin $\mathrm{F}_{2 \alpha}$ (8-iso- $\mathrm{PGF}_{2 \alpha}$ ) derives from the nonenzymatic oxidation of AA, and it is involved in the late phase of platelet activation and thrombus growth (280). The production of 8 -iso- $\mathrm{PGF}_{2 \alpha}$ is partly a result of activation of Nox2 (53), as shown by impaired formation of 8-iso-PGF $2 \alpha$ in CGD patients (384). Urinary excretion of 8 -iso- $\mathrm{PGF}_{2 \alpha}$ is a validated and accepted reliable biomarker of in vivo oxidative stress, which has been investigated in healthy subjects and in patients at risk or with CVD (53). Increased values of urinary 8-iso-PGF ${ }_{2 \alpha}$ (23) and serum sNox2-dp levels have been detected in subjects with CHD, hypertension, type $2 \mathrm{DM}$, MetS, $\mathrm{AF}$, and PAD. Plasma or urinary excretion of 8 -iso-PGF ${ }_{2 \alpha}$ has 
been extensively investigated in patients with acute or chronic CAD and, with very few exceptions, the levels have been found to be elevated in patients compared with controls (Table 2). Production of 8 -iso- $\mathrm{PGF}_{2 \alpha}$ was more pronounced in patients with acute versus stable CHD and correlated with the number of affected vessels, suggesting a relationship between oxidative stress and coronary atherosclerotic burden $(65,392)$.

The predictive role of 8 -iso- $\mathrm{PGF}_{2 \alpha}$ levels has been tested in a nested case-cohort study including 141 CHD cases, 109 stroke cases, and 142 controls (306). The highest quartile of urinary 8 -iso- $\mathrm{PGF}_{2 \alpha}$ compared with the lowest ones had an odds ratio of 1.8 to develop fatal CVD in a median 10-year follow-up.

LeLeiko et al. (197) measured serum F2-isoprostanes in 108 patients presenting with acute coronary syndrome (ACS) and in 101 control patients. ACS patients had higher serum F2-isoprostanes compared with controls and were predictive of cardiovascular recurrences.
More recently, in 1002 anticoagulated elderly AF patients followed up for about 3 years, median levels of urinary 8-iso$\mathrm{PGF}_{2 \alpha}(160 v s .100 \mathrm{pg} / \mathrm{mg}$ creatinine, $p<0.001)$ and sNox2dp $(13 v s .9 \mathrm{pg} / \mathrm{ml}, p<0.001)$ were significantly higher in patients with CVEs compared with those without CVEs during the follow-up (284).

The relationship between F2-isoprostanes and aging has been scarcely investigated. Apparently, the production of 8-iso-PGF $2 \alpha$ increases with age as a significant positive correlation was found between age and 8-iso-PGF $2 \alpha$ (247). Even if this would be consistent with an overproduction of isoprostanes in the elderly, further studies are necessary to support this single finding.

\section{B. Oxidized $L D L$}

ox-LDLs play a pivotal role in the process of atherosclerosis. On reaching the sub-endothelium, LDL undergo oxidation via ROS produced by pro-oxidant enzymes such as Nox2, MPO, or xanthine-oxidase and are taken up by

Table 2. Clinical Studies Investigating F2-Isoprostanes in Cardiovascular and Cerebrovascular Disease

\begin{tabular}{|c|c|c|c|}
\hline Author/year & Setting/patients' typology & Biomarker & Main results \\
\hline $\begin{array}{l}\text { Cipollone et al./ } \\
2000(65)\end{array}$ & $\begin{array}{l}\text { Unstable angina }(n=32) \\
\text { stable angina }(n=32) ; \\
\text { variant angina }(n=4) \\
\text { healthy subjects }(n=40) .\end{array}$ & Urinary 8 -iso- $\mathrm{PGF}_{2 \alpha}$ & $\begin{array}{l}\text { Unstable angina }(339 \mathrm{pg} / \mathrm{mg} \text { creatinine }) \\
\text { stable angina }(236 \mathrm{pg} / \mathrm{mg} \text { creatinine, } \\
p<0.001) \text {; control subjects }(192 \mathrm{pg} / \mathrm{mg} \\
\text { creatinine, } p<0.0001) .\end{array}$ \\
\hline $\begin{array}{l}\text { Schwedhelm } \\
\text { et al./2004 } \\
\text { (324) }\end{array}$ & $\begin{array}{l}\text { CHD }(n=93) ; \text { controls } \\
\quad(n=93)\end{array}$ & $\begin{array}{l}\text { Urinary } 8 \text {-iso-PGF }{ }_{2 \alpha} \text { and } \\
\text { 2,3-dinor-5,6-dihydro- } \\
\text { 8-iso-PGF } 2 \alpha\end{array}$ & $\begin{array}{l}\text { Urinary } 8 \text {-iso-PGF }{ }_{2 \alpha} \text { and } 2,3 \text {-dinor-5,6- } \\
\text { dihydro- } 8 \text {-iso-PGF } \text { - }_{2 \alpha} \text { differed, from } 77 \\
\text { to } 139 \mathrm{pmol} / \mathrm{mmol} \text { creatinine and from } \\
120 \text { to } 193 \mathrm{pmol} / \mathrm{mmol}^{-} \text {in controls and } \\
\text { cases, respectively, } p<0.001 \text {. }\end{array}$ \\
\hline $\begin{array}{l}\text { Shishehbor et al./ } \\
\quad 2006(336)\end{array}$ & $\begin{array}{l}\text { CAD, } n=54 ; \text { controls } \\
\quad(n=50)\end{array}$ & Plasma F2-isoprostanes & $\begin{array}{l}\text { CAD } 9.0 v s . \text { controls } 6.0 \mu \mathrm{mol} / \mathrm{mol} \\
\quad p<0.001 .\end{array}$ \\
\hline $\begin{array}{l}\text { Woodward et al./ } \\
2009(405)\end{array}$ & $\begin{array}{l}\text { CHD }(n=227) ; \text { controls } \\
\quad(n=420) .\end{array}$ & Plasma F2-isoprostanes & $\begin{array}{l}\mathrm{CHD}=1146 \mathrm{p} M \\
\quad \text { controls }=1250 \mathrm{p} M, p=\mathrm{NS}\end{array}$ \\
\hline $\begin{array}{l}\text { Kim et al./2008 } \\
(175)\end{array}$ & $\begin{array}{l}\text { CAD }(n=799) ; \text { controls } \\
\quad(n=925) .\end{array}$ & Urinary 8 -epi-PGF $2 \alpha$ & $\begin{array}{l}\mathrm{CAD}=1332.9 v s . \text { controls }=1123.6 \mathrm{pg} / \mathrm{mg} \\
\text { creatinine }, p<0.001 .\end{array}$ \\
\hline $\begin{array}{l}\text { Vassalle et al./ } \\
2004 \text { (376) }\end{array}$ & $\begin{array}{l}\text { CAD }(n=38) ; \text { controls } \\
\quad(n=30)\end{array}$ & $\begin{array}{l}\text { Plasma levels of } 8- \\
\text { epiPGF } 2 \alpha\end{array}$ & $\begin{array}{l}\text { CAD }=351.1 \text { vs. controls }=194.2 \mathrm{pg} / \mathrm{ml}, \\
p<0.001 . \text { Plasma of } 8 \text {-epiPGF } 2 \alpha \\
\text { correlated with the number of affected } \\
\text { vessels (one vessel } 288.3 \mathrm{vs} . \text { multi } \\
\text { vessels } 380 \mathrm{pg} / \mathrm{ml}, p<0.001 \text { ). }\end{array}$ \\
\hline $\begin{array}{l}\text { Wang et al./ } \\
2006(392)\end{array}$ & $\begin{array}{l}241 \text { Consecutive patients } \\
\text { undergoing coronary an- } \\
\text { giography. }\end{array}$ & $\begin{array}{l}\text { Plasma levels of 8-iso- } \\
\text { PGF }_{2 \alpha}\end{array}$ & $\begin{array}{l}\text { 8-iso-PGF } \mathrm{H}_{2 \alpha} \text { levels were higher in patients } \\
\text { with }(n=169) \text { than those without } \\
(n=72) \text { CAD }(337.7 v s .263 .8 \mathrm{pg} / \mathrm{ml} \text {, } \\
\text { respectively }<0.001) .8 \text {-iso-PGF } 2 \alpha \\
\text { levels were correlated with age } \\
(\mathrm{r}=0.29, p<0.001) \text { and the numbers } \\
\text { of affected vessels }(p<0.001) .\end{array}$ \\
\hline $\begin{array}{l}\text { Gross et al./2005 } \\
\quad(125)\end{array}$ & 2850 Young healthy adults. & $\begin{array}{l}\text { Plasma-free F2- } \\
\text { isoprostanes }\end{array}$ & $\begin{array}{l}\text { The odds ratio for the presence of coro- } \\
\text { nary artery calcification was } 1.24 \text { per } \\
92.2 \mathrm{p} M(32.7 \mathrm{ng} / \mathrm{L}) \text { of F2-isoprostanes } \\
\text { (1 SD). }\end{array}$ \\
\hline $\begin{array}{l}\text { Iuliano et al./ } \\
2001 \text { (157) }\end{array}$ & $\begin{array}{l}12 \text { CAD patients undergoing } \\
\text { coronary angiography. }\end{array}$ & Plasma F2-isoprostanes & $\begin{array}{l}\text { After PTCA, iso-PGF } 2 \alpha \text {-III increased, } \\
\text { from } 40 \text { to } 125 \mathrm{pg} / \mathrm{ml}(p<0.001) \text { and } \\
\text { iso-PGF } 2 \alpha \text {-VI from } 115 \text { to } 295 \mathrm{pg} / \mathrm{ml} \\
(p<0.001) \text {. }\end{array}$ \\
\hline $\begin{array}{l}\text { Ward et al./2011 } \\
\text { (397) }\end{array}$ & $\begin{array}{l}44 \text { Acute ischemic stroke } \\
\text { patients and } 44 \text { matched } \\
\text { controls }\end{array}$ & Plasma F2-isoprostanes & 3754 Compared with $1947 \mathrm{p} M, p<0.02$ \\
\hline
\end{tabular}

8-iso-PGF $2 \alpha, 8$-iso-prostaglandin $\mathrm{F}_{2 \alpha} ; \mathrm{CAD}$, coronary artery disease; CHD, coronary heart disease; NS, not significant; SD, standard deviation. 
macrophages via scavenger receptors, thus promoting the formation of foam cells (351). Ox-LDL have been evaluated in several studies, including patients with different degrees of CHD. A cross-sectional study (148), which included 63 patients with ACS, 35 nontransplanted patients with angiographic stable angina, 28 heart transplant patients with posttransplant CAD, 79 heart transplant patients without CAD, and 65 control subjects, showed that ox-LDL levels were significantly higher in patients with CAD compared with those without. The association between ox-LDL levels and CAD severity was also corroborated in patients with ACS, who displayed higher levels of ox-LDL compared with patients with stable CAD. Prospective studies investigating the prognostic role of ox-LDL provided positive (147, 163, 302, $334,370,406)$ and negative $(2,36,177,402)$ results.

Holvoet et al. (147) studied 3033 subjects, 1147 with and 1886 without MetS, and found elevated values of ox-LDL in patients with MetS $(1.45 \pm 0.82 \mathrm{mg} / \mathrm{dl})$ compared with those without MetS $(1.23 \pm 0.67 \mathrm{mg} / \mathrm{dl}, p<0.0001)$. ox-LDL levels were associated with an increased rate of MI during the follow-up (relative risk 2.25 for the highest quintile). The incidence of CHD events was registered in a 6-year follow-up among 18,140 men from the HPFS (Health Professionals Follow-up Study) and in an 8 year follow-up among 32,826 women from the Nurses' Health Study. Subjects experiencing CHD showed higher values of ox-LDL compared with controls in both men and women. The highest quintile of ox-LDL was significantly associated with an increased risk of CHD in a multivariate model (406). In the prospective case-control study in which 44,725 men and women from the World Health Organization Multinational MONICA (Monitoring of Trends and Determinants in Cardiovascular Disease) project and the Västerbotten Intervention Program were enrolled, there was no difference in the levels of
IgG, IgA, and IgM autoantibodies against copper-ox-LDL or malonaldehyde-LDL between patients experiencing $\mathrm{CD}$ and controls (2). In the Framingham offspring study, IgG antibodies to ox-LDL were measured in 1192 men and 1427 women who were followed for 8 years for the occurrence of CHD and CVEs (402). Although IgG were significantly correlated with age in both men and women, no association with events was found. Finally, in 36 patients undergoing carotid endoarterectomy, ox-LDL levels were higher in comparison with 20 controls and were significantly higher in unstable versus stable carotid plaques (338).

Different methodology used in the earlier reported clinical studies may account for these conflicting results. Indeed, some studies used antibodies against ox-LDL, whereas some others made a direct measurement of ox-LDL, with or without adjustment for lipid profile. A more reliable methodology to measure ox-LDL is likely necessary to further investigate the role of ox-LDL in atherothrombosis.

\section{Atherosclerosis and Antioxidant Status}

Cellular protection against oxidative products is provided by a complex network of antioxidant systems, which can be classified according to their activity (i.e., enzymatic and nonenzymatic antioxidants) or to their behavior into redox reactions (i.e., direct and indirect antioxidants) (Fig. 4) (87, 295). However, it should be noted that this classification does not reflect the more complicated functional interplay existing between direct and indirect antioxidants. For instance, some antioxidants are both direct and indirect and can be referred to as "bifunctional." Moreover, cytoprotective proteins may participate in the synthesis/regeneration of direct antioxidants, which are, in turn, required for the catalytic functions of cytoprotective proteins $(87,295)$.
FIG. 4. Antioxidant molecules involved in aging process. Antioxidant molecules are classified into direct (blue arrows) and indirect (green arrows) antioxidants. During aging, a decrease of these antioxidant molecules is observed (both direct and indirect) with a consequence oxidative imbalance favoring oxidative stress. To see this illustration in color, the reader is referred to the web version of this article at www .liebertpub.com/ars

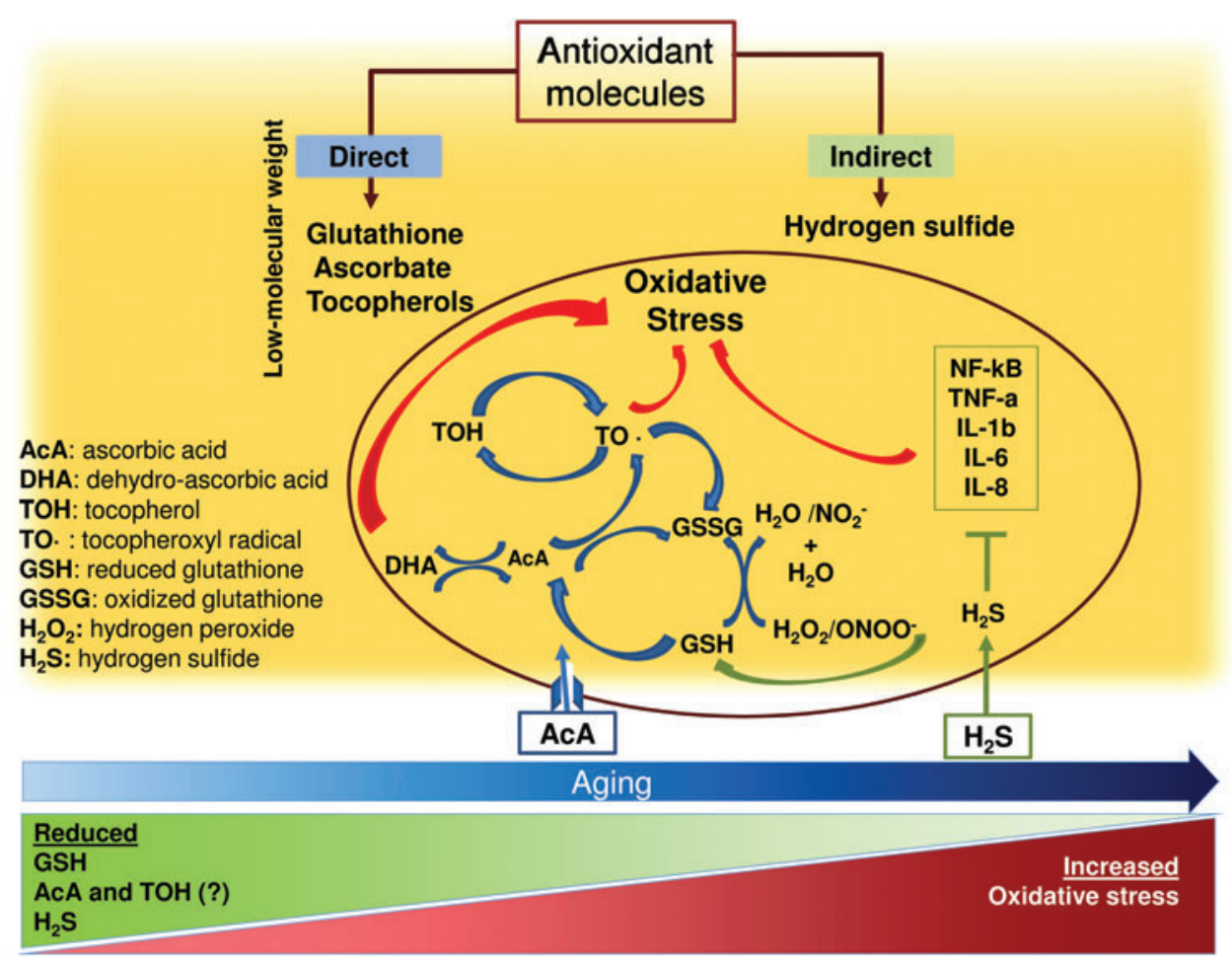




\section{B. Antioxidant enzymes}

1. NO synthase. The NOS family generates NO from conversion of L-arginine to L-citrulline; it includes homodimeric oxidoreductases in which the heme-containing oxygenase domain is linked via a calmodulin-binding linker peptide to an NADPH cytochrome $\mathrm{P} 450$ reductase-like diflavin domain (224). On activation, the FAD unit of the flavoprotein domain transfers electrons from NADPH to the Flavin Mono Nucleotide, which reduces heme iron and results in $\mathrm{O}_{2}$ activation followed by oxidation of the guanidino $\mathrm{N}$ atom of L-arginine, forming at last $\mathrm{NO}$ and citrulline. There are three NOS isoforms in the cardiovascular system, one inducible NOS (iNOS) and two constitutive, namely eNOS and neuronal NOS (nNOS). Under normal conditions, eNOS exerts antiatherogenic effects in the vascular wall by inhibiting cell growth, leukocyte adhesion, and platelet aggregation. Thus, in eNOS-deficient $\mathrm{ApoE}^{(--)}$mice on a Western-type diet, an increased coronary atherosclerosis was observed (183). Conversely, in several CVD, such as DM and hypercholesterolemia, eNOS can produce the oxidant species $\mathrm{O}_{2}{ }^{-}$instead of $\mathrm{NO}(307,312)$ because of absence/reduction of its substrate L-arginine by arginase 1 upregulation. The shift from $\mathrm{NO}$ to $\mathrm{O}_{2}^{-}$production is named NOS uncoupling (61). The role of arginase 1 in uncoupled eNOS-related atherosclerosis was investigated in an animal model where administration of arginase 1 inhibitor, $S$-(2-boronoethyl)-1cysteine, increased circulating $\mathrm{NO}$, inhibited $\mathrm{O}_{2}{ }^{-}$generation, and attenuated plaque development (312). Similarly, nNOS is protective against atherosclerosis as documented by Kuhlencordt et al. (184), who reported increased atherosclerotic plaque formation and decreased survival in nNOS-deficient ApoE $^{(-/-)}$mice.

The iNOS isoform is synthesized in response to proinflammatory agonists such as cytokines and, differently from eNOS and nNOS, seems to play a pro-atherogenic role. Thus, iNOS activation leads to a sustained production of NO, which corresponds to $\sim 100$-fold the amount produced by constitutive eNOS. Large quantities of NO could combine with $\mathrm{O}_{2}^{-}$to form peroxynitrite, an adduct with enhanced oxidizing capability. iNOS is detectable in human atherosclerotic lesions (46), where it contributes to peroxynitrite formation and, eventually, LDL oxidation. In fact, LDL isolated from aortic atherosclerotic intima had 90-fold higher levels of peroxynitrite compared with healthy subjects. The pro-atherogenic role of iNOS was documented in $\mathrm{ApoE}^{(--)} /$ iNOS $^{(-)}$mice, which showed a significantly reduced atherosclerotic lesion area and lipid peroxidation compared with ApoE $\mathrm{E}^{(-/-)}$mice $(182,242)$.

The activity of NOS profile seems to be modified in the elderly. Thus, a recent study, evaluating age-related progressive organ dysfunction in 338 healthy subjects (age ranging from 3 to 92 years), demonstrated that eNOS protein level was significantly decreased in elderly people as compared with adults (174). However, the impact of this change on atherosclerosis progression and CVEs is still unknown.

2. Superoxide dismutase. SOD family encompasses three isoforms, namely SOD1, SOD2, and SOD3, which are cytoplasmic, mitochondrial, and extracellular isoforms, respectively. All isoforms seem to protect against atherosclerosis. Thus, overexpression of SOD1 and catalase or catalase alone decreased plasma and aortic F2-isoprostane levels and retarded atherosclerotic lesion development in $\mathrm{ApoE}^{(-/-)}$ mice (413). On the contrary, SOD2 deficiency induced mitochondrial DNA damage and accelerated atherosclerosis in ApoE $E^{(--)}$mice (18). SOD1 and SOD2 deficiency resulted in VSMC hyperplasia and hypertrophy mediated by different kinases (217). Previous studies showed that SOD1 ${ }^{(-/-)}$mice are prone to develop various aging-related pathologies, concomitantly with an increase of oxidative damage in organs (398). In accordance with this, SOD1 and SOD2 prevented DNA damage during aging in experimental models. Of note, in aging mice, damage related to SOD downregulation was counteracted by atorvastatin treatment, resulting in delayed age-related cardiac alterations (i.e., cardiac hypertrophy) and inhibition of inflammatory cytokines (132). The relationship between SOD activity and aging was also investigated in humans. In lymphocytes from healthy subjects, a progressive decrease across decades of age of antioxidant enzyme activity such as SOD, catalase, and GPX has been reported (119). Further, in samples of human brain tissues, a significant decrease in SOD and GPx activities with increasing age was detected, suggesting a role for impaired antioxidant status in the onset of neurologic disorders such as Parkinson and Alzheimer diseases (377). SOD3 seems to be involved in protecting LDL particles from oxidation. Thus, in rabbit as well as human endothelial cells, recombinant SOD3 decreases LDL oxidation $(196,359)$. In patients with CAD, low levels of plasma SOD3 were independently associated with a history of MI (394).

3. Glutathione peroxidase. Even if there is a growing body of evidence to suggest that GPx has anti-atherosclerotic property (308), differences among the eight isoforms belonging to the GPx family do exist. However, all GPx isoforms share the ability to detoxify peroxides, with GSH acting as an electron donor in the reduction reaction, producing GSH disulfide (110). GPX1 is prevalently localized in red blood cells, GPx2 is in the gastrointestinal tract, and GPx3 is the only circulating isoform. GPx4 exists as a cytosolic, mitochondrial, and nuclear isoform derived from alternative splicing of a single gene. In human, GPx4 acts as a phospholipid hydroperoxidase protecting cells from lipid peroxidation. It also plays a role in primary $\mathrm{T}$ cell response to infections by protecting $\mathrm{T}$ cells from ferroptosis, a cell death secondary to an iron-dependent accumulation of lipid ROS. Finally, GPx4 serves as a structural function in mature sperm cells. The isoforms 5-8 are less characterized.

GPx1 and GPx4 play a role in preventing atherosclerosis progression, and GPx 1 seems to also possess antithrombotic properties (308). Thus, in ApoE ${ }^{(--)}$GPx1-deficient mice, increased aortic ROS, decreased NO, and increased atherosclerosis burden were observed (365). In accordance with experimental studies, GPx1 activity is either decreased or absent in human carotid atherosclerotic lesions, and its absence is associated with lesion severity (195). In another human study that investigated platelet activity in two brothers with cerebral vein thrombosis, Freedman et al. found a decreased activity of GPx3 along with an increased platelet reactivity compared with controls (113). The addition of exogenous GPx restored NO-mediated platelet function. Further, overexpression of GPx4 reduced aortic F2-isoprostane 
levels, lowered IL1-induced VCAM-1 expression, and delayed lesion progression in experimental animal models $(19,130)$.

The relationship between GPx isoforms and CVEs has been investigated in few studies. In a cohort of 636 patients with suspected CHD, an inverse relationship between GPx1 activity and risk of CVEs during a follow-up of 4.7 years was reported (33). Further, a recent prospective cohort study that included 909 AF patients reported a significantly lower value of GPx3 and SOD in patients experiencing a CVE in a mean follow-up of 43.4 months (268). The same study also reported that GPx3 was the antioxidant enzyme that progressively decreased by aging, with an abrupt reduction at age of 70 years. Of note, such a reduction was associated with an overproduction of $\mathrm{TxB}_{2}$, suggesting an interplay between impaired detoxification of ROS and platelet activation (268).

4. Paraoxonase. PON is an antioxidant enzyme that exists in three isoforms (PON1, PON2, PON3) and possesses atheroprotective effects. The antioxidant activity of PON1 has been detected in vitro, where it inhibited LDL and HDL oxidation $(12,13)$, and in PON1-knockout mice, which displayed higher levels of oxidized phospholipids and increased aortic atherosclerosis compared with wild type $(331,332)$. Two common polymorphisms of PON1 (i.e., 55 and 192) were shown to be associated with human atherosclerosis and heart disease.

PON2 attenuated triglyceride accumulation into macrophages and foam cell formation via the inhibition of redoxsensitive microsomal diacylglycerol acyltransferase 1 (310). PON2-deficient ApoE ${ }^{(-1-)}$ mice developed enhanced mitochondrial oxidative stress and exacerbated atherosclerosis when fed with chow and Western diet (85).

Similar to PON1, PON-3 prevents oxidative modification of LDL; humanized PON3 transgenic mice fed with an atherogenic diet exhibited decreased atherosclerotic lesion areas compared with nontransgenic animals (333).

Serum PON1 concentration decreased in the atherosclerotic $\mathrm{ApoE}^{(-/-)}$mice during aging and was inversely correlated to the development of atherosclerotic lesions (13). This finding was corroborated by a human study demonstrating that PON1 concentration was lower in old (60-89 years) compared with young (20-30 years) subjects (63). Similarly, Milochevitch and Khalil found that plasma PON1 was inversely correlated to age in a group of subjects ranging 26-77 years (238). Increased age was also negatively correlated with PON activities, specifically with the PON1-192 variant. In the same study, higher expression of this polymorphism was found in centenaries, suggesting a role for PON1 in successful aging (223).

5. Heme-oxygenase. Heme-oxygenase (HO) is a microsomal enzymatic system involved in the degradation of heme $(186,248,368)$. The HO system regulates hemeprotein levels and protects cells from the deleterious hemeinduced iron-dependent reactions, leading to ROS generation and lipid peroxidation $(186,417)$. HO reduces cellular free heme by splitting the tetrapyrrole heme ring to biliverdin, free ferrous iron, and carbon monoxide. Biliverdin is subsequently metabolized to the antioxidant molecule bilirubin by biliverdin reductase (248). The mechanism by which bilirubin reacts with ROS is not completely understood, although its hydrophobic tetrapyrrole structure has been reported to inhibit the activation of Nox (189). Recently, bilirubin was reported to suppress atherosclerotic plaque formation in LDLR-deficient mice by disrupting endothelial VCAM-1 and ICAM-1-mediated leukocyte migration through its ROSscavenging property (389).

Of the two $\mathrm{HO}$ isoforms described, $\mathrm{HO}-1$ is involved in the atherosclerotic process whereas HO-2 seems to play a protective role against anoxic processes at neuronal and cardiac level $(186,248)$. HO-1 has a broad spectrum of inducers such as ROS, cytokines, PGs, and endotoxin (84). HO-1 is highly expressed in macrophages, especially in those contained in the intra-plaque hemorrhage where it plays an athero-protective role. Thus, $\mathrm{HO}-1^{+}$macrophage population is significantly expanded in atherosclerotic plaques in the heme-rich regions (261). When HO-1-deficient macrophages are treated with ox-LDL, generation of ROS is amplified and the secretion of pro-inflammatory IL-6, MCP-1, and the IL- 8 homologue is increased (261). Thus, HO-1 expression in macrophages makes them resistant to foam cell formation and proinflammatory mediators that exacerbate atherogenesis and plaque progression (150).

The importance of HO-1 in vascular biology was highlighted in a child with HO-1 deficiency, in whom endothelial cells were more susceptible to oxidative insults and hememediated LDL oxidation (410). Further, Exner et al. carried out a cohort study to evaluate the relationship between HO-1 gene promoter polymorphisms associated to higher HO-1 expression and the risk for arterial restenosis after percutaneous transluminal angioplasty (100). Patients with short $(<25 \mathrm{GT})$ dinucleotide repeats in the HO-1 gene promoter had significantly less restenosis than patients with longer $(\geq 25$ GT) dinucleotide repeats (100). This finding was corroborated in a large cohort of 812 subjects from the Bruneck Study, which described an inverse association between low HO-1 and atherosclerotic progression along with a trend toward higher levels of oxidized phospholipids on ApoB-100 (272). The behavior of this antioxidant enzyme in the elderly population is still unknown.

\section{B. Direct antioxidants}

Several low-molecular-weight compounds belong to direct antioxidants such as ascorbate, GSH, and tocopherols. They are all involved in redox reactions by scavenging ROS and nitrogen species. Direct antioxidants have peculiar features such as being redox active, consumed or chemically modified on antioxidant reaction, and needing reloading or regeneration.

1. Glutathione. The non-protein thiol GSH (L- $\gamma-$ glutamyl-L-cysteinyl-glycine; GSH) is a tripeptide molecule synthesized in most cells by human glutamate-cysteine ligase (GCL) and GSH synthase. In particular, GCL is composed by catalytic (GCLC) and modifier (GCLM) units and is the limiting phase in the production of GSH. GSH can exist in an oxidized or reduced state (367), and it is used as an enzyme substrate for the GPx, where it is the reductant of hydroperoxides, and for GSH S-transferases, responsible for the conjugation of GSH with electrophilic molecules (110).

GSH levels may vary significantly among different organs, with some of them being responsible for GSH synthesis, whereas some others are essentially exporters. In human 
tissues, GSH levels range from 0.1 to $10 \mathrm{~mm}$, being most concentrated in the liver (up to $10 \mathrm{~mm}$ ) (258).

Although cells have relatively high concentrations of $\mathrm{GSH}$, an increase in synthesis of GSH is clearly part of the adaptive response to oxidative stress (367). Several evidences support the role of GSH in atherosclerotic progression. The GSH content in mice aorta is reduced before and during lesion development (30), and GSH-dependent expression of GPx 1 is reduced in ApoE-deficient mice treated with an atherogenic diet (356). Modulation of GSH levels by treating ApoE-deficient mice with L-2-oxo-4-thiazolidin carboxylate, which supplies cysteine residues, resulted in a $25 \%$ increase in macrophages' GSH and a $25 \%$ decrement in atherosclerotic lesion size (309). To confirm the role of $\mathrm{GSH}$ in atherosclerotic lesion progression, a $\mathrm{ApoE}^{(-/-)} /$ GCLM $^{(-/-)}$knockout mouse model, resulting in an impaired GCL synthesis, was associated with low GSH levels and more rapidly with the development of complex atherosclerotic lesions (49).

A few data associated GSH levels in plasma or red blood cells with CHD. In a case-control study, patients with angiographically proven $\mathrm{CAD}$ or awaiting coronary artery bypass graft (CABG) presented significantly lower red blood cell GSH levels compared with controls $(41,127)$. More recently, an analysis among 134 CVD cases and 435 age- and sex-matched healthy control subjects from the Hisayama Study demonstrated that plasma GSH concentrations were lower in all CVD cases than in controls, particularly in patients affected by severe cerebral infarction (335). Data on the role of GSH in preventing CVD stem from genetic studies involved the GCLC and GCLM units of GCL, as GSH biosynthesis is paralleled by GCL gene expression. Thus, the CT polymorphism of the GCLM gene was associated with an increased risk of MI (251). Similarly, the $129 \mathrm{~T}$ polymorphism of the GCLC gene was associated to reduced levels of GSH and endothelial dysfunction in MI patients compared with controls (178). These data are in contrast with a recent study that did not show significant difference in plasma GSH comparing PAD patients with controls (339).

Two prospective studies investigated whether GSH predicts CVD. GSH appeared independently and inversely associated with recurrent atherothrombotic events in a cohort of 375 survivors admitted for an ACS, followed for a median duration of 2.7 years (108). Similarly, in a sample from the Hunter Community Study free of CVEs, 5-year absolute cardiovascular risk score calculated using the Framingham Risk Equation was independently and inversely associated to plasma GSH levels (220).

GSH concentration appears to decline with advancing age. Thus, in healthy subjects aged 19-85 years, plasma ratio between reduced and oxidized GSH in plasma did not change before 45 years, but later on GSH was oxidized at a nearly linear rate of $0.7 \mathrm{mV} /$ year, suggesting that after 45 years GSH declines rapidly (165). Although these data could be questioned as plasma GSH accounts for only $1 \%$ of total GSH, similar results were obtained while studying GSH from other sources such as erythrocytes and lymphocytes. Thus, in healthy individuals, GSH levels were significantly lower in the erythrocytes of "old" (60-79 years) compared with "mature" group (40-59 years) and with the young reference group (20-39 years), which expressed the highest GSH content (193). Similarly, human lymphocytes display a progressive decrease of GSH by advancing age, with 60-80 year-old subjects having about $50 \%$ less of GSH lymphocyte content compared with 20-40 year ones (375).

The decline of GSH by aging may also have an impact on extracellular levels of other antioxidants, such as alpha tocopherol and ascorbic acid, as GSH is involved in their restoration cycle. Thus, cycles of regeneration of these three antioxidants are strictly correlated (374). For example, in human erythrocytes, ascorbate regeneration from dehydroascorbate is largely dependent on GSH (232), and oxidized vitamin E radical is reduced by both GSH and ascorbic acid, giving formation to the ascorbyl radical (374).

Of note, the bio-availability of cysteine appears to be the rate-limiting factor for synthesis of GSH, which is a sulfurcontaining metabolite. The reduced dietary protein intake occurring by aging could be an additional detrimental factor concurring to age-related GSH decrease (153, 255). Food, such as garlic, onions, and brussels sprouts, contain significant amounts of sulfur, and could be considered as part of a nutritional approach for elderly patients.

2. Vitamin E. Natural vitamin E consists of a family of eight different compounds, four tocopherols and four tocotrienols. All tocopherols and tocotrienols are potent antioxidants with lipoperoxyl radical-scavenging activities, which consist of donating hydrogen atoms from the phenol group on the chromanol ring. Animal studies provided evidence of a role for $\alpha$-tocopherol in modulating arterial lipid content, lipid oxidation, and eventually plaque evolution. Verlangieri and Bush (378) reported a $35 \%$ inhibition of atherosclerotic lesion in cholesterol-fed macaques supplemented with $\alpha$ tocopherol over a 3-year period of follow-up (378). In rabbits with established experimental atherosclerosis undergoing angioplasty, a reduced restenosis and IMT after angioplasty was observed after $\alpha$-tocopherol supplementation (190). Similarly, $\alpha$-tocopherol supplementation inhibited aortic intimal thickening as well as lipid peroxidation in a chicken model (342). Further, in ApoE ${ }^{(-/-)}$mice, $\alpha$-tocopherol supplementation was able to reduce aortic lesions in 4- to 10week-old ApoE ${ }^{(--)}$mice, when fatty streaks are absent or very sparse (274). Similar results were obtained in older animals with established aortic lesion (273). Finally, diet $\alpha$ tocopherol intake led to a reduced deposition of cholesterol in arterial plaques from rabbits fed with atherogenic diet (325), and ex-vivo copper mediated oxidative modification of LDL in the same animal model (401). $\alpha$-tocopherol also possesses anti-inflammatory effect as depicted by its capacity of slowing cell migration into the lesion site. Thus, in aortic lesions of $\mathrm{ApoE}^{(-1-)}$ mice treated with $\alpha$-tocopherol, a reduced level of MCP-1 was observed (274). In addition, $\alpha-$ tocopherol can affect the atherothrombotic evolution by modulating platelet activation; thus, intravenously administered tocotrienols induced a fourfold increase in $\alpha$-tocopherol concentration and inhibited acute platelet-mediated thrombus and agonist-induced platelet aggregation in stenotic canine coronary arteries (299).

The relationship between aging and $\alpha$-tocopherol concentration is controversial. Serum and visceral levels of $\alpha$-tocopherol were found to be decreased by aging in rats (169), whereas another study failed to confirm this relationship (252). In accordance with this last finding, decreased levels of ascorbic acid and GSH, but no differences of $\alpha$ tocopherol by aging, have been reported (292). 
3. Vitamin C. Ascorbic acid (vitamin C) is a hydrophilic vitamin that interferes with several mechanisms involved in the atherosclerotic process mostly by preventing NO degradation (399) and LDL oxidation (161). Ascorbic acid may preserve NO by several mechanisms, including direct reduction of nitrite to NO, release of NO from nitrosothiols, scavenging $\mathrm{O}_{2}^{-}$(231), and sparing endothelial cell-derived NO by recycling tetrahydrobiopterin (139, 231). Ascorbic acid plays a protective role against atherosclerotic burden by decreasing endothelial cells' ability to oxidase LDL (225). This effect is also achieved by influencing $\alpha$-tocopherol metabolism as depicted by in vitro experiments where ascorbic acid restored the reduced form of $\alpha$-tocopherol in human monocyte/macrophages, ultimately preventing LDL oxidation (161). Combined deficiency of vitamin $\mathrm{E}$ and $\mathrm{C}$ increased lipid peroxidation, doubled plaque size, and increased plaque macrophage content by two- to threefold in ApoE $E^{(-I-)}$ mice (16). The progression of the atherosclerotic plaque was also higher in $\mathrm{ApoE}^{(--)}$and gulonolactone oxidase $^{(-1-)}$ mice that prevented animals from synthesizing their own vitamin C (16). Ascorbic acid concentration seems to be affected by the aging process. In animals, serum vitamin $\mathrm{C}$ content was inversely related to age (252). Similarly, in humans, a progressive decrease in serum concentration of ascorbic acid by aging has been described (292).

\section{Indirect antioxidants}

Indirect antioxidants include small-molecule inducers of cytoprotective proteins such as $\mathrm{H}_{2} \mathrm{~S}$ and polyphenols. Differently from direct ones, indirect antioxidants may be redox active and can also activate the NF-E2-related factor 2 (Nrf2)/antioxidant-responsive element (ARE) pathway, resulting in transcriptional induction of a battery of cytoprotective proteins (also known as phase 2 enzymes); the latter act catalytically, are not consumed in their antioxidant action, have longer half-lives, and catalyze several chemical reactions, ultimately leading to detoxification $(87,295)$.

1. Hydrogen sulfide. $\mathrm{H}_{2} \mathrm{~S}$ is a "gaseous signaling molecule," which freely diffuses through cell membranes, targeting proteins, enzymes, transcription factors, and membrane ion channels (295). In mammals, cysteine and methionine, the only two sulfur-containing amino acids, represent the major source of $\mathrm{H}_{2} \mathrm{~S}$ (295), which is generated on the activity of four main enzymes, that is, cystathionine $\gamma$ lyase, cystathionine $\beta$-synthase, cysteine aminotransferase, and 3-mercaptopyruvate sulfurtransferase (222) [reviewed in detail in Caliendo et al. (48)]. $\mathrm{H}_{2} \mathrm{~S}$ has important functions in cardiovascular and immune systems (418). In CVD, $\mathrm{H}_{2} \mathrm{~S}$ acts by (i) promoting endothelial cells' proliferation and migration, (ii) favoring vasodilatation (via interaction or less with $\mathrm{NO}$ ), and (iii) as an anti-inflammatory molecule by the NF$\kappa \mathrm{B}$ pathway. At immune level, $\mathrm{H}_{2} \mathrm{~S}$ seems to be involved in the regulation of $\mathrm{T}$ cells (418).

Recent evidence indicated, in fact, that $\mathrm{H}_{2} \mathrm{~S}$ inhibits LDL oxidation via scavenging hypochlorite and $\mathrm{H}_{2} \mathrm{O}_{2}$ and inhibiting MPO activity (191). $\mathrm{H}_{2} \mathrm{~S}$ can modulate atherosclerotic plaque evolution by suppressing monocytes' adhesion to activated endothelium and reducing plaque volume, as demonstrated in $\mathrm{ApoE}^{(-/-)}$mice treated with $\mathrm{H}_{2} \mathrm{~S}$ donor sodium hydrosulfide (395). Consistent with this, cystathionine $\gamma$-lyase-knockout mice displayed decreased endogenous $\mathrm{H}_{2} \mathrm{~S}$ level, elevated plasma levels of LDL, increased oxidative stress and adhesion molecule expression, and early fatty streak lesions in the aortic root (221).

$\mathrm{H}_{2} \mathrm{~S}$ is also demonstrated to interfere with the atherosclerotic process by diminishing the tissue injury induced by LPS-mediated neutrophil activation via induction of apoptosis and/or scavenging neutrophil-derived hypochlorite (400). $\mathrm{H}_{2} \mathrm{~S}$ also acts by downregulating several proatherogenic cytokines, including NF- $\kappa \mathrm{B}, \mathrm{TNF} \alpha$, IL-1b, IL-6, and IL-8, as demonstrated by in vitro studies (295).

Decreased levels of $\mathrm{H}_{2} \mathrm{~S}$ have been found in different CVD, such as hypertension, heart failure, and type 2 diabetes [see also Wallace et al. (390)].

Aging is associated to reduced levels of $\mathrm{H}_{2} \mathrm{~S}$ in animal models, but data on humans are lacking (42).

2. Polyphenols. Polyphenols are a class of natural, synthetic, and semisynthetic substances characterized by large multiples of phenol units. Polyphenols, in the form of flavonoids, are broadly classified into (i) anthocyanins, namely cyanidin, delphinidin, malvidin contained in raspberry; (ii) flavanols, namely catechin, epicatechin contained in cocoa, red wine, green tea; (iii) flavonols, namely quercetin, fisetin contained in onion, blueberry, red apple, many fruits and vegetables; (iv) flavanones, namely hesperidin; and (v) flavones luteolin in citrus fruits (369).

In addition, resveratrol (3,5,4'-trihydroxy-trans-stilbene) is a non-flavonoid phytoalexin polyphenol mostly contained in plants and red wine [reviewed in detail in Xia et al. (408)].

Antioxidant ability of polyphenols to scavenge free radicals has not been fully elucidated (146). However, polyphenols exert an indirect antioxidant activity by inhibiting Nox, thus increasing NO availability (211). Moreover, polyphenols seem to exert a cytoprotective action; for instance, at neuronal level, polyphenols may be neuroprotective by modulation of the Nrf2/ARE pathway, which regulates phase II antioxidant responses, triggering the simultaneous expression of numerous protective enzymes and scavengers including HO-1 (321). Polyphenols may also have a cardioprotective effect due to their uncoupling properties. Endogenous uncoupling is a physiologic mechanism to lower mitochondrial ROS production, and it is regulated by specific inducible uncoupling proteins. According to the "uncoupling to survive" theory, this mechanism could be important in minimizing oxidative damage to DNA and in slowing aging (35). Thus, "mild mitochondrial uncoupling" has been proposed as a mechanism to reduce upstream ROS production; it has been suggested that "mild mitochondrial uncoupling" could be a more effective therapeutic strategy than removing ROS once they are formed (69).

\section{Clotting Activation}

The risk of thrombosis in the artery and venous circulation typically increases with aging, and it is responsible for an enhanced incidence of CVD and venous thromboembolism in the elderly population (180). Activation of the clotting system is relevant for thrombus growth for both arterial and venous thrombosis. As depicted in Figure 5, the clotting system includes several proteases, which are activated as a 


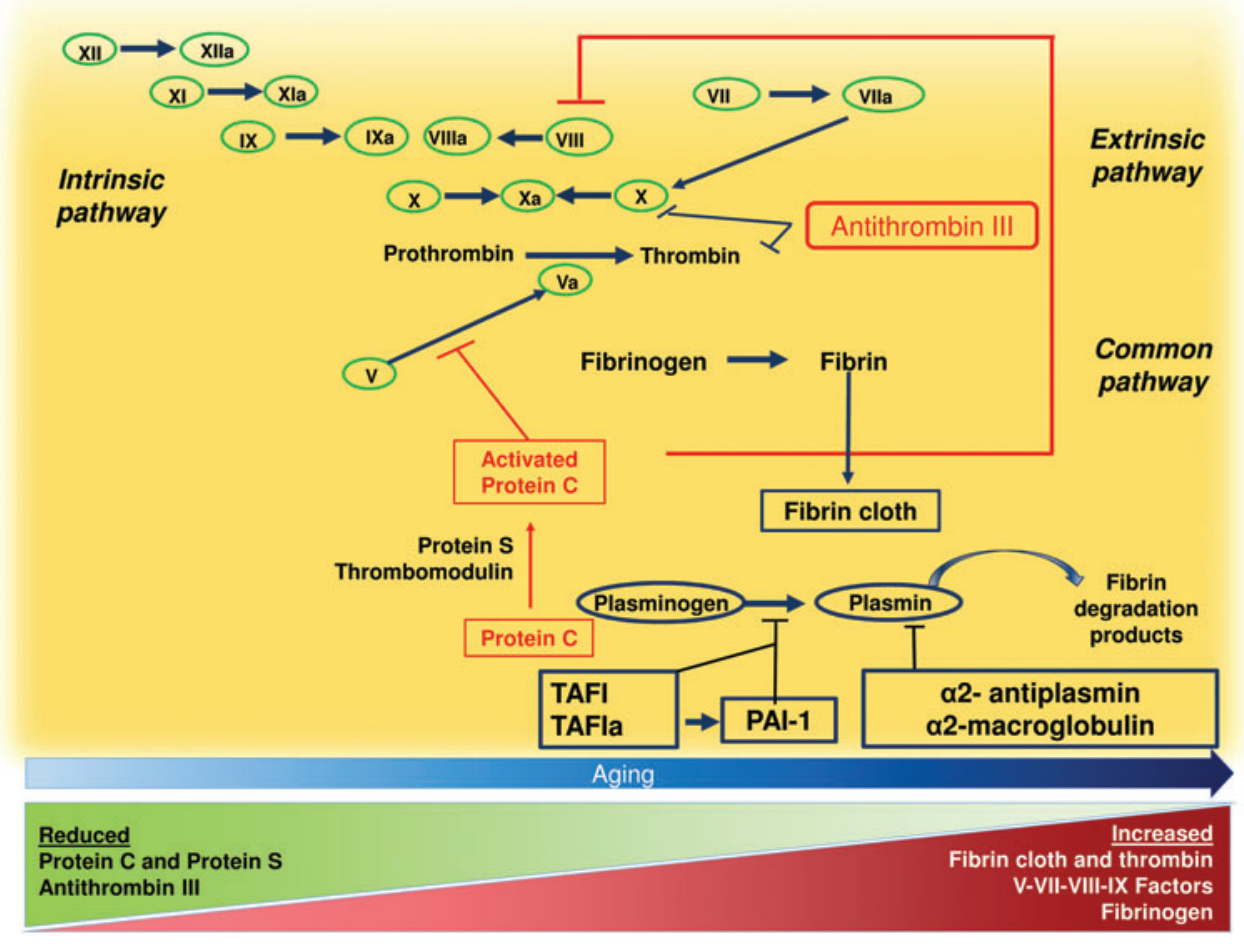

FIG. 5. Clotting activation in aging process. Activation of clotting system plays a central role in both artery and venous thrombosis. Clotting system includes several proteases, which are activated as a "cascade" and ultimately lead to fibrin formation, which serves for vessel closure in case of injury. During aging, a decrease of Protein C, Protein $\mathrm{S}$, and Antithrombin III is observed, and an increase in Fibrin cloth, thrombin, VVII-VIII-IX Factors, and Fibrinogen is observed. To see this illustration in color, the reader is referred to the web version of this article at www .liebertpub.com/ars

"cascade" and lead to fibrin formation, which serves for vessel hemostasis in case of injury.

Several studies analyzed modification of the clotting system by aging using different global coagulation assays or markers of clotting activation $(1,103)$. Analysis of global tests, which were performed prevalently in healthy volunteers, consistently showed a more rapid clotting activation in the elderly compared with the younger population regardless of the assay used. In accordance with these reports, measurement of markers of clotting activation such as the prothrombin fragment $\mathrm{F} 1+2$ demonstrated a significant increase of thrombin generation in the elderly compared with the younger population (24). This was also evident when analyzing activation of specific clotting factors, such as factor IX and $\mathrm{X}$ activation peptides, which were more elevated by aging (103). It should be underscored, however, that the sample size of these studies was small and, hence, it is difficult to adequately appreciate the change of clotting activation across decades of age. Moreover, studies demonstrating that changes of the clotting system by aging are associated with an enhanced thrombotic risk are lacking.

Increased activation of the clotting system by aging might be attributed to changes of coagulation factors, anticoagulants, and the fibrinolytic system. One factor potentially contributing to enhanced clotting activation by aging is the increased concentration of some coagulation factors, such as FV, FVII, FVIII, FIX, and fibrinogen, which, in fact, increase by aging (112). For some of them such as factor VIII and fibrinogen, prospective studies documented an increased risk of thrombosis related to their blood concentration, but it is difficult to draw definite conclusions from these studies as both factor VIII and fibrinogen are acute-phase reactant proteins, which may largely vary depending on the timing of blood sampling. Reduction of natural anticoagulants by aging might be a mechanism accounting for enhanced clotting activation but data regarding this point are unclear and conflicting. Clinical studies investigated whether the activity of some anticoagulants such as antithrombin III (ATIII), protein $\mathrm{C}, \mathrm{S}$, and tissue factor (TF) pathway inhibitor may decrease by aging. However, the clinical impact of these reports is unclear as some studies showed no differences in anticoagulant proteins in elderly compared with younger subjects, whereas some others reported an increase of these anticoagulants in the elderly population (112).

Changes in the activity of the fibrinolytic system may also concur to increase the thrombotic risk by aging but also in this case, results are inconclusive. Using global tests of fibrinolysis activation, such as plasmin-alpha2-antiplasmin complex, it was demonstrated that the fibrinolytic system would be activated by aging in 800 elderly subjects free of clinical CVD in the Cardiovascular Health Study and the Honolulu Heart Program cohort (315). Conversely, plasminogen activator inhibitor 1 (PAI-1) has been shown to increase by aging (411) but, as for factor VIII and fibrinogen, PAI-1 is an acutephase reactant and may not be the expression of an actual inhibition of the fibrinolytic system.

ROS are important promoters of clotting activation as they upregulate TF in leucocytes (47). The role of ROS and, more importantly, the role of Nox in the activation of the clotting system has been investigated in endothelial cells, where TF activation is modulated by ROS formation. Accordingly, an experimental study demonstrated a crucial role for Nox-derived ROS in upregulating endothelial-dependent TF activation, an effect significantly inhibited by cell incubation with antioxidants (140). Further, an experimental study demonstrated that oxidant molecules such as $\mathrm{H}_{2} \mathrm{O}_{2}$ produced by activated leucocytes induced thrombomodulin oxidation and eventually impaired protein C activation (140). This effect was prevented by 
cell incubation with diphenylene iodonium, which is an inhibitor of Nox (140). The effect of antioxidants on thrombus formation has been further investigated in a murine model of genetic deficiency of SOD, where susceptibility of carotid thrombosis was investigated in response to photochemical injury. Thus, animals deficient of SOD displayed faster and larger thrombotic occlusion in artery and venous vessels compared with wild type (77). This effect was dependent on impaired protein $\mathrm{C}$ activation and was restored by treatment with antioxidants such as SOD and catalase. Impaired protein $\mathrm{C}$ activation was attributed to ROS formation, which determined thrombomodulin oxidation with $40 \%$ reduction in thrombomodulin-dependent protein $\mathrm{C}$ activation (77).

Finally, oxidative stress may also promote thrombosis by acting on the fibrinolytic system, where ROS can upregulate PAI-1 in endothelial cells, thus favoring the thrombotic process in animals prone to atherosclerosis (355).

The role of oxidative stress as clotting activation promoter has been investigated both in vitro and in vivo with vitamin $\mathrm{E}$, which has been shown to negatively interfere with intrinsic and extrinsic coagulation pathways and to promote fibrinolysis. This vitamin possesses anticoagulant property via inhibiting oxidation of vitamin $\mathrm{K}$, which serves to activate the prothrombinase complex, that is, factors II, VII, IX, and X (263). Further, an in vitro study demonstrated that vitamin $\mathrm{E}$ downregulates the monocyte expression of $\mathrm{TF}$, indicating that it can interfere with the extrinsic coagulation pathway (105). Finally, in patients with coronary spastic angina, Miyamoto et al. showed that $400 \mathrm{mg} /$ day vitamin E significantly reduced PAI-1 activity after 1-month treatment (241).

\section{Platelet Activation}

Platelets have been long recognized as crucial players for primary hemostasis at sites of vascular injury. The activity of platelets at sites of plaque rupture consists of three different phases: platelet adhesion, platelet activation, and platelet recruitment (Fig. 6).

The initial step of primary hemostasis is platelet adhesion to the extracellular matrix. In particular, platelets roll, adhere, and spread on collagen matrix to form an activated platelet monolayer. This process is mediated by platelet receptors that bind extracellular matrix components, such as von Willebrand factor, collagen, fibronectin, thrombospondin, and laminin, which are exposed to blood on vascular injury. Once firmly adherent, platelets spread and release the content of their granules that contain pro-aggregating and pro-inflammatory molecules. Then, interaction of several agonists with the specific receptors expressed on platelets induces the propagation of platelet activation.

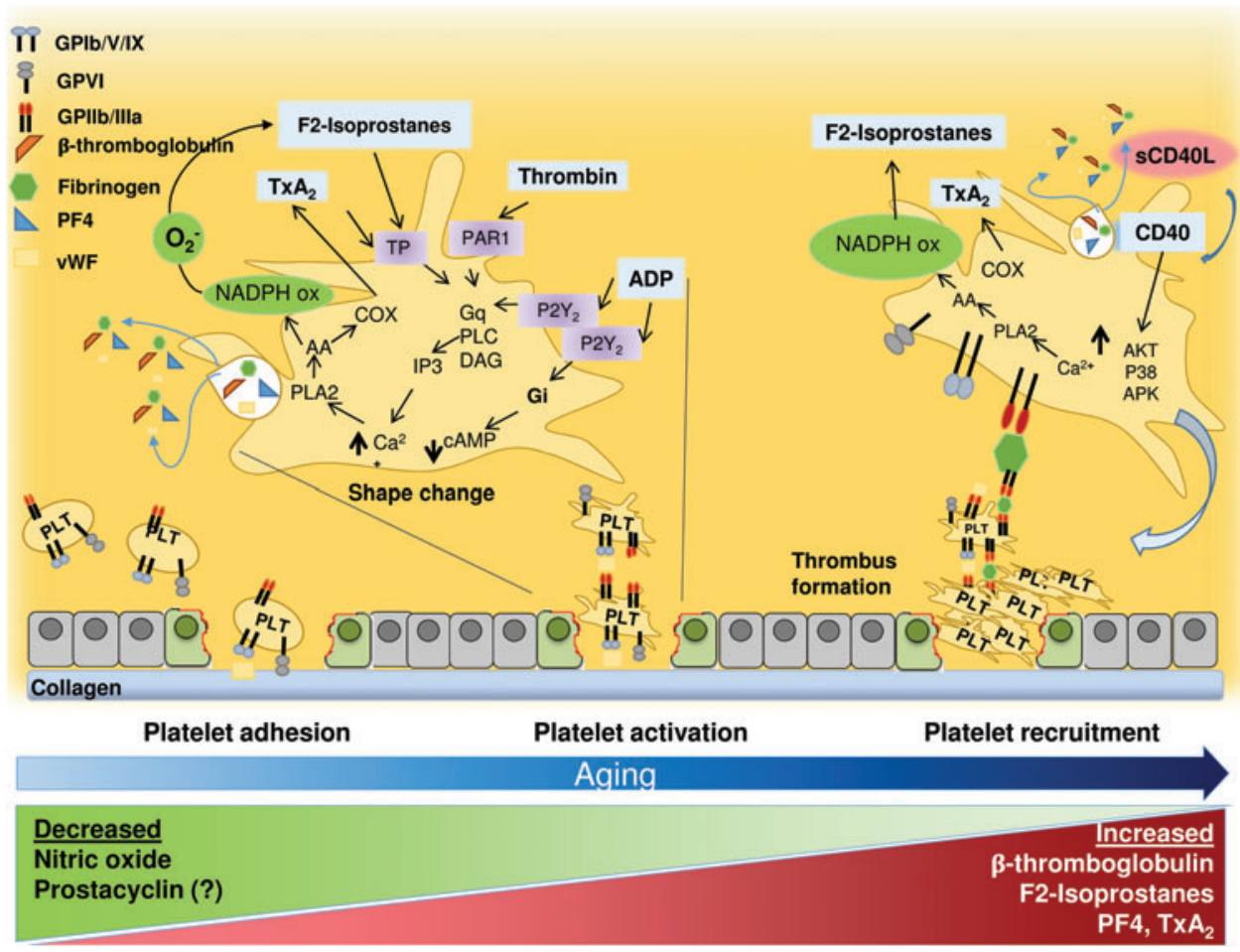

FIG. 6. Platelet activation in aging process. The role of platelets at site of plaque rupture consists of three different phases: platelet adhesion, activation, and platelet recruitment. The initial step of primary hemostasis consists of platelet adhesion to the extracellular matrix. The adhesion of platelets to the damaged vasculature is mediated by platelet receptors that bind extracellular matrix components, such as vWF, collagen, fibronectin, and thrombospondin, which are exposed to blood on vascular injury. In the second phase, platelets spread and release the content of their granules that contain proaggregating and pro-inflammatory molecules. In the third phase, the interaction of several agonists with the specific receptors expressed on platelets induces the propagation of platelet recruitment. During aging, progression is observed in elevated markers of platelet activation such as platelet factor 4 (PF4) and $\beta$-thromboglobulin along with an increase of proaggregating molecules such as F2-Isoprostanes and $\mathrm{TxA}_{2}$. TxA $\mathrm{A}_{2}$, thromboxane $\mathrm{A}_{2}$; vWF, von Willebrand factor. To see this illustration in color, the reader is referred to the web version of this article at www.liebertpub.com/ars 
Platelet eicosanoids are important mediators of platelet aggregation and propagation. Once produced by adherent platelets, $\mathrm{TxA}_{2}$ amplifies platelet adhesion response by binding to $\mathrm{TP} \alpha$ and $\mathrm{TP} \beta$ receptors (the effects in platelets are mediated primarily through the $\alpha$ form) (260). TxA $\mathrm{A}_{2}$ is synthetized from AA through phospholipase $\mathrm{A}_{2}\left(\mathrm{PLA}_{2}\right)$ and cyclooxygenase (COX)-1, and it can activate phospholipase C. This enzyme induces formation of second messenger inositol triphosphate and diacylglycerol that activate intracellular protein kinase $\mathrm{C}$. The production of inositol triphosphate increases cytosolic levels of calcium. Peroxidation of membrane phospholipids leads to the generation of another eicosanoid family named $\mathrm{F}_{2}$-isoprostanes, which modulate platelet activation via $\mathrm{TxA}_{2}$ receptors (246). $\mathrm{F}_{2}$-isoprostanes are produced from AA by a free radical-mediated mechanism (246) that is likely dependent on Nox2 activation (280). Thus, reduced $\mathrm{F}_{2}$-isoprostanes platelet formation was detected in patients with CGD (280). In this clinical model, the reduced production of platelet $\mathrm{F} 2$-isoprostanes was associated to impaired platelet activation that was restored by adding exogenous F2-isoprostanes (280).

The recruitment phase depends on the release of several pro-aggregating substances such as adenosine diphosphate, eicosanoids, or ROS, which spread platelet activation at the site of thrombus growth.

Previous studies consistently showed that platelet activation is enhanced in the elderly population (243). Crosssectional studies demonstrated an enhanced platelet response to common agonists as documented by a lower concentration needed to aggregate platelets in the elderly compared with the younger population (243). In accordance, Sverdlov et al. demonstrated a progressive increase of platelet sensitivity to common agonists in 204 subjects followed for 4 years (353). Further, proteins released by activated platelets such as Betathromboglobulin and platelet factor 4 were elevated in the elderly population compared with the younger one (243). Finally, bleeding time, which explores platelet activation in vivo, was found to be shorter in elderly patients (167). However, a limitation of these studies is that bleeding time reflects not only in vivo platelet activation but also vascular reactivity (112). Urinary excretion of 11 -dehydro- $\mathrm{TxB}_{2}$ is among the most reliable tests of platelet activation in vivo. It is the stable metabolite of $\mathrm{TxA}_{2}$, and urinary excretion of 11dehydro- $\mathrm{TxB}_{2}$ has been used for clinical purpose in patients with atherosclerotic risk factors such as DM, hypertension, and hypercholesterolemia $(66,128,318)$, and in patients with acute and chronic CVD. In these clinical settings, urinary 11dehydro- $\mathrm{TxB}_{2}$ was elevated, suggesting an increased platelet activation in patients at risk or with overt atherosclerosis (93). In a small cross-sectional study performed in 20 healthy subjects, Reilly and FitzGerald found increased urinary excretion of 2,3-donor- $\mathrm{TxB}_{2}$ in elderly ( $>65$ years) compared with younger ( $<65$ years) subjects (304). Differently from previous reports, ex vivo and in vivo tests of platelet function were similar in elderly and young patients. This finding is apparently in contrast with a previous study, which measured serum $\mathrm{TxB}_{2}$ in 177 patients with atherosclerotic risk factors and found no difference according to aging; however, small sample size and number of elderly patients limit data interpretation (5). To address the relationship between platelet activation and aging, we measured 11-dehydro- $\mathrm{TxB}_{2}$ in 833 patients affected by AF, which is associated with several atherosclerotic risk factors and poor vascular outcomes, such as thromboembolic stroke and MI (269). A cross-sectional analysis of life decades demonstrated that urinary 11-dehydro$\mathrm{TxB}_{2}$ increased by aging with a significant elevation at the age of 74 years (269). Of note, during a follow-up of $\sim 5$ years, patients with elevated $\mathrm{TxB}_{2}$ experienced more CVEs compared with those with lower $\mathrm{TxB}_{2}$. Thus, platelet age-dependent ROS production could represent an important mechanism accounting for atherothrombosis in the elderly.

The relationship between ROS and platelet activation was originally demonstrated by Del Principe et al. (83), who found increased platelet calcium mobilization by adding in vitro exogenous $\mathrm{H}_{2} \mathrm{O}_{2}$ to platelets. This finding was later confirmed by another in vitro study where sample treatment with catalase resulted in inhibition of agonist-induced platelet activation and calcium mobilization (286). This finding suggested that also antioxidant compounds or enzymes may modulate platelet function. Thus, direct antioxidants such as vitamin $\mathrm{C}$ and $\mathrm{E}$ significantly inhibited platelet aggregation $(287,289)$. Among the enzymatic pathways implicated in platelet ROS formation and aggregation, Nox2 has a prominent role as shown by the anti-platelet effects elicited by inhibition of Nox 2 activity, which resulted in impaired production of platelet $\mathrm{O}_{2}$, lower calcium mobilization and GPIIb/IIIa activation, and, eventually, inhibition of platelet aggregation. The role of Nox 2 was further investigated (288) in CGD patients, whose platelets displayed impaired platelet activation and thrombus growth (280). Nox2 is able to influence platelet activation through at least three different mechanisms that are relevant in platelet aging, including (i) $\mathrm{O}_{2}{ }^{-}$dismutation to the more stable and proaggregating molecule $\mathrm{H}_{2} \mathrm{O}_{2}$, (ii) inhibition of the antiplatelet activity $\mathrm{NO}$ by $\mathrm{O}_{2}^{-}$, and (iii) nonenzymatic transformation of AA into F2-isoprostanes.

Analysis of platelet $\mathrm{H}_{2} \mathrm{O}_{2}$, which is implicated in platelet aggregation, via calcium mobilization, COX1 activation, and MTORC1, demonstrated an important role for these oxidant species in aging-related platelet aggregation $(286,414)$. Thus, prospective analysis in animals demonstrated that platelet $\mathrm{H}_{2} \mathrm{O}_{2}$ increases by aging coincidentally with an enhanced risk of thrombosis (78). A key factor for platelet $\mathrm{H}_{2} \mathrm{O}_{2}$ overexpression was activation of Nox2, which was, in fact, upregulated in elderly animals. In accordance, animals treated with apocynin, which inhibits $\mathrm{p} 47^{\mathrm{phox}}$ translocation to Nox2, disclosed reduced platelet $\mathrm{H}_{2} \mathrm{O}_{2}$ formation and agerelated thrombosis (78).

It is still to be determined, however, whether overproduction of platelet ROS by aging is a result of upregulation of enzymes producing ROS or reduction of antioxidant status. Recent studies support this latter hypothesis. As mentioned earlier, vasodilating properties by $\mathrm{NO}$ are rapidly lost on its interaction with $\mathrm{O}_{2}^{-}$to give formation of peroxynitrite (52, 382). Peroxynitrite rapidly induces tyrosine nitration of proteins with the same pattern of tyrosine phosphorylation, thus inducing platelet activation (244) Impaired NO generation by inactivation and/or reduced biosynthesis is associated with enhanced platelet aggregation (280). In a prospective study performed in 204 subjects followed up for 4 years, platelet responsiveness to NO was significantly reduced compared with baseline coincidentally with a progressive increase in plasma asymmetric dimethylarginine, which is an inhibitor of NOS (353). Alternatively, reduced 
platelet response to NO may be related to an impaired detoxification of intracellular ROS. The relevance of this phenomenon has been documented in previous reports in animals (162) and humans $(78,297)$ in which the deficiency of GPx was associated with serious thrombotic complications. In support of this, in animals overexpressing GPx1, platelet activation as well as platelet-related thrombosis were significantly inhibited, further reinforcing the hypothesis that impaired $\mathrm{H}_{2} \mathrm{O}_{2}$ detoxification favors occurrence of thrombotic process (78). The role of GPx in aging-related platelet activation has been documented by an observational study in patients with AF followed up for $\sim 40$ months; thus, the activity of GPx3 progressively decreased by aging with a significant decline at the age of 75 (268). The decline of GPx3 was coincident with upregulation of Nox 2 and enhanced platelet activation, suggesting that impaired $\mathrm{H}_{2} \mathrm{O}_{2}$ breakdown could result in enhanced Nox2-derived ROS formation and platelet Tx production (268).

Taken together, these data can lead us to hypothesize that aging is associated with platelet activation via an oxidativestress-mediated mechanism. Reduction of GPx activity and increase of Nox 2 upregulation seem to be important factors promoting platelet-derived thrombus formation. Thus, both may contribute with different mechanisms to enhance platelet eicosanoid formation and lower NO generation via its enhanced degradation or impaired biosynthesis (Fig. 7). Consequently, upregulation of GPx activity and/or down- regulation of Nox 2 may represent a potentially important tool to reduce aging-related platelet activation and, eventually, thrombosis-related CVD.

So far, there are few interventional studies investigating the effect of antioxidants on platelet function, and results are not univocal. Jain et al. demonstrated that $100 \mathrm{IU} /$ day of vitamin E significantly reduced blood $\mathrm{TxB}_{2}$ in patients with type $1 \mathrm{DM}$, suggesting that vitamin $\mathrm{E}$ exerts an antiplatelet activity via inhibition of platelet AA metabolism (158). This finding has been confirmed and extended by Davì et al., who administered $600 \mathrm{mg} /$ day of vitamin E to 85 type 2 DM patients for 2 weeks (74); the authors found a significant decrease of urinary excretion of 11-dehydro- $\mathrm{TxB}_{2}$ in patients compared with controls. Conversely, Patrignani et al. reported no effect of vitamin E supplementation on urinary 8 -iso- $\mathrm{PGF}_{2 \alpha}$ or 11 -dehydro- $\mathrm{TxB}_{2}$ excretion in 46 moderate cigarette smokers (271).

\section{Endothelial Dysfunction}

Endothelium integrity/function has been classically identified as one major determinant factor to maintain vascular homeostasis. Under physiologic conditions, eNOS is responsible for maintaining vasodilation by producing $\mathrm{NO}$; NO activates soluble guanylyl cyclase, which converts guanosine-5'-triphosphate to cyclic guanosine monophosphate and, eventually, decreases smooth muscle tension, causing vasodilatation (116).

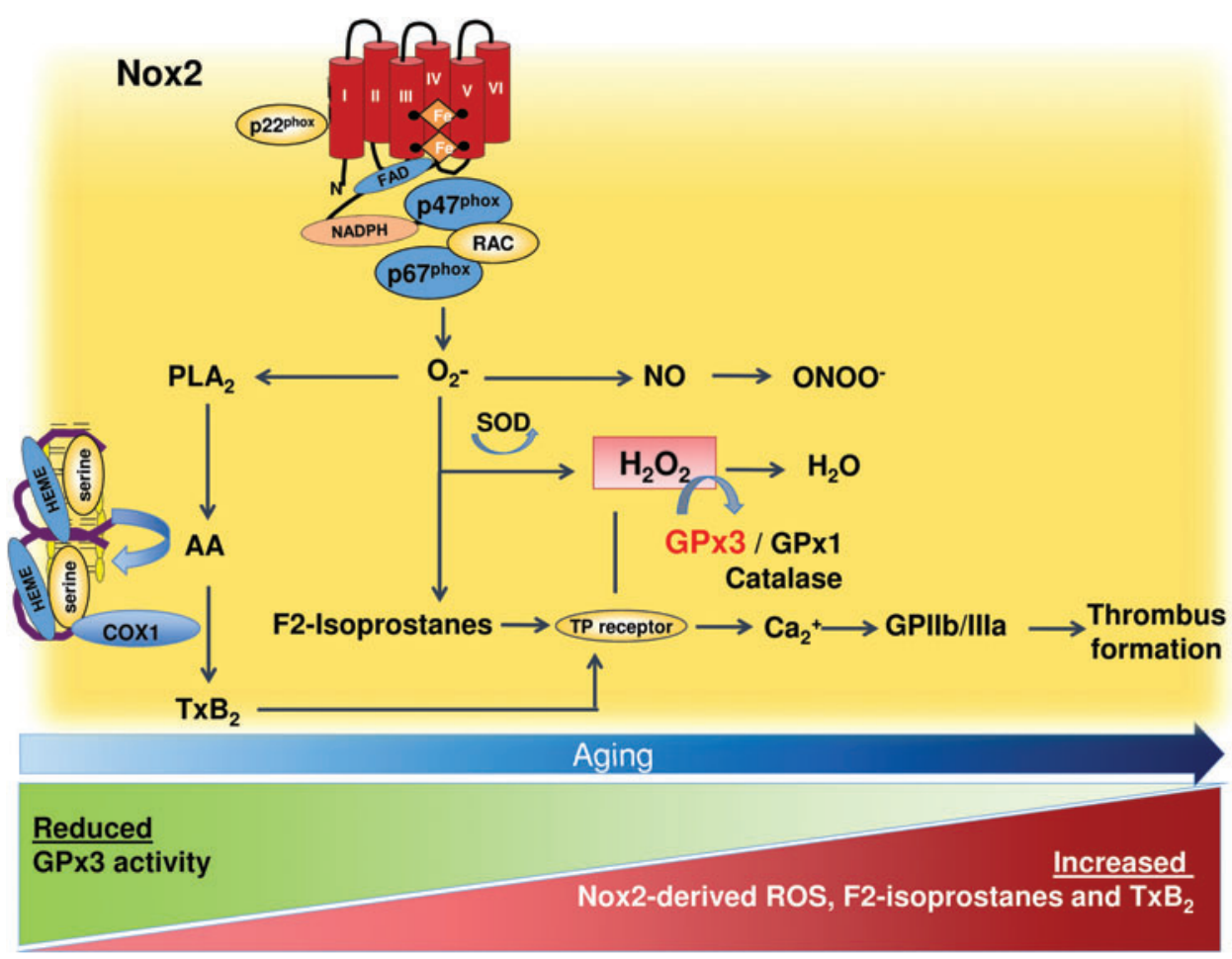

FIG. 7. ROS production and thrombus formation in aging process. Nox 2 activation results in platelet $\mathrm{O}_{2}^{-}$production, with a consequent increased phosphorylation of $\mathrm{PLA}_{2}$, AA release, and $\mathrm{TxB}_{2}$ formation. Platelet $\mathrm{O}_{2}{ }^{-}$also mediates $\mathrm{F} 2-$ isoprostanes and $\mathrm{H}_{2} \mathrm{O}_{2}$ formation that, together with $\mathrm{TxB}_{2}$, induce calcium mobilization, GPIIb/IIIa activation, and, eventually, thrombus formation. Conversely, catalase and GPx3 break down $\mathrm{H}_{2} \mathrm{O}_{2}$. A decrease of GPx3 and an increase of Nox2-derived ROS together with enhanced platelet eicosanoids occur by aging. AA, arachidonic acid; GPx3, glutathione peroxidase 3; $\mathrm{H}_{2} \mathrm{O}_{2}$, hydrogen peroxide; $\mathrm{O}_{2}^{-}$, superoxide anion; $\mathrm{PLA}_{2}$, phospholipase $\mathrm{A}_{2} ;$ TxB $\mathrm{B}_{2}$, thromboxane $\mathrm{B}_{2}$. To see this illustration in color, the reader is referred to the web version of this article at www.liebertpub.com/ars 
The eNOS may be activated by changes in shear forces or by binding of some molecules (such as acetylcholine, adenosine, bradikinine) to membrane receptors, which cause an increase in calcium levels in endothelial cells (240). Increased calcium levels also activate $\mathrm{PLA}_{2}$, which generates AA from membrane-bound phospholipid and, eventually, prostacyclin, a powerful anti-aggregating and vasodilating molecule, via $\mathrm{COX} 2$ activation (Fig. 6).

In addition to NO, endothelial cells produce small oxidant vasoactive molecules, such as $\mathrm{O}_{2}^{-}$(vasoconstrictive) and $\mathrm{H}_{2} \mathrm{O}_{2}$ (vasodilating). Laminar shear stress promotes $\mathrm{H}_{2} \mathrm{O}_{2}$ generation, which, in turn, activates p38 MAPK and, ultimately, NOS, leading to vasodilation (39). As mentioned earlier, the balance between $\mathrm{NO}$ and $\mathrm{O}_{2}{ }^{-}$is crucial, as an increase in $\mathrm{O}_{2}{ }^{-}$has a detrimental effect on NO bioactivity/ biosynthesis or elicits eNOS uncoupling.

Endothelial cells produce $\mathrm{O}_{2}{ }^{-}$prevalently via several Nox isoforms such as Nox1, Nox2, Nox4, and Nox5, which may contribute toward modulating arterial dilatation with different mechanisms $(43,179)$ (Fig. 8). In this regard, we measured flow-mediated dilatation (FMD), which is dependent on endothelial release of $\mathrm{NO}$ and is a surrogate marker of atherosclerosis (364), in CGD patients with Nox2 (X-linked) (385) or $\mathrm{p} 47^{\text {phox }}$ hereditary deficiency (209). CGD patients showed enhanced FMD, which, however, was more marked in Nox2-deficient patients, suggesting a relationship between the degree of ROS formation and artery vasoconstriction $(209,385)$. The mechanism accounting for enhanced artery dilatation was attributed to heightened NO generation, which was also suggested to account for enhanced vasodilation detected in knockout animals for $\operatorname{Nox} 2(59,229)$. The close relationship between endothelial dysfunction and Nox 2 has been studied in several conditions such as dyslipidemia, obesity, smoking (208), hypertension, MetS, DM, PAD (207), and obstructive sleep apnea (82). These classic cardiovascular risk factors provoke endothelial dysfunction since childhood, and the coexistence of Nox 2 upregulation suggests this enzyme as a potential trigger $(210,214,226)$. Indeed, children with hypercholesterolemia, obesity, or obstructive sleep apnea displayed Nox2 upregulation coincidentally with a reduced FMD (210).

Nox4 plays a peculiar role as this isoform produces $\mathrm{H}_{2} \mathrm{O}_{2}$ rather than $\mathrm{O}_{2}{ }^{-}$; hence, differently from Nox2, Nox4 has vasodilating property via eNOS activation (323). Animal studies showed that genetic deficiency of Nox4 was associated with endothelial dysfunction and increased atherosclerosis burden (194).

Other Nox isoforms, such as Nox1 and Nox5, may concur to vasodilation. Nox 1 is mainly located in VSMC where it enhances production of $\mathrm{O}_{2}{ }^{-}$, causing eNOS uncoupling and consequent impaired vasorelaxation (86). The effect of Nox1 on endothelial function was evaluated by studies in mice with genetic deficiency of Nox1 that showed an increased vasodilatory response to acetylcholine (229). In endothelial cells, Nox5 directly produces $\mathrm{O}_{2}^{-}$in response to an intracellular increase of calcium levels, without requiring the activation of other subunits (91). The biological role of Nox5 in vasodilation remains unclear, but $\mathrm{O}_{2}^{-}$produced by Nox5 contributes to determining endothelial dysfunction by inhibition of extracellular NO (245) and, paradoxically, activates eNOS, increasing NO generation (420).

Natural antioxidants such as SOD, catalase, and GPx serve to counteract oxidative stress in the endothelium (114). In particular, SOD3 prevents inactivation of $\mathrm{NO}$ by $\mathrm{O}_{2}{ }^{-}$in the

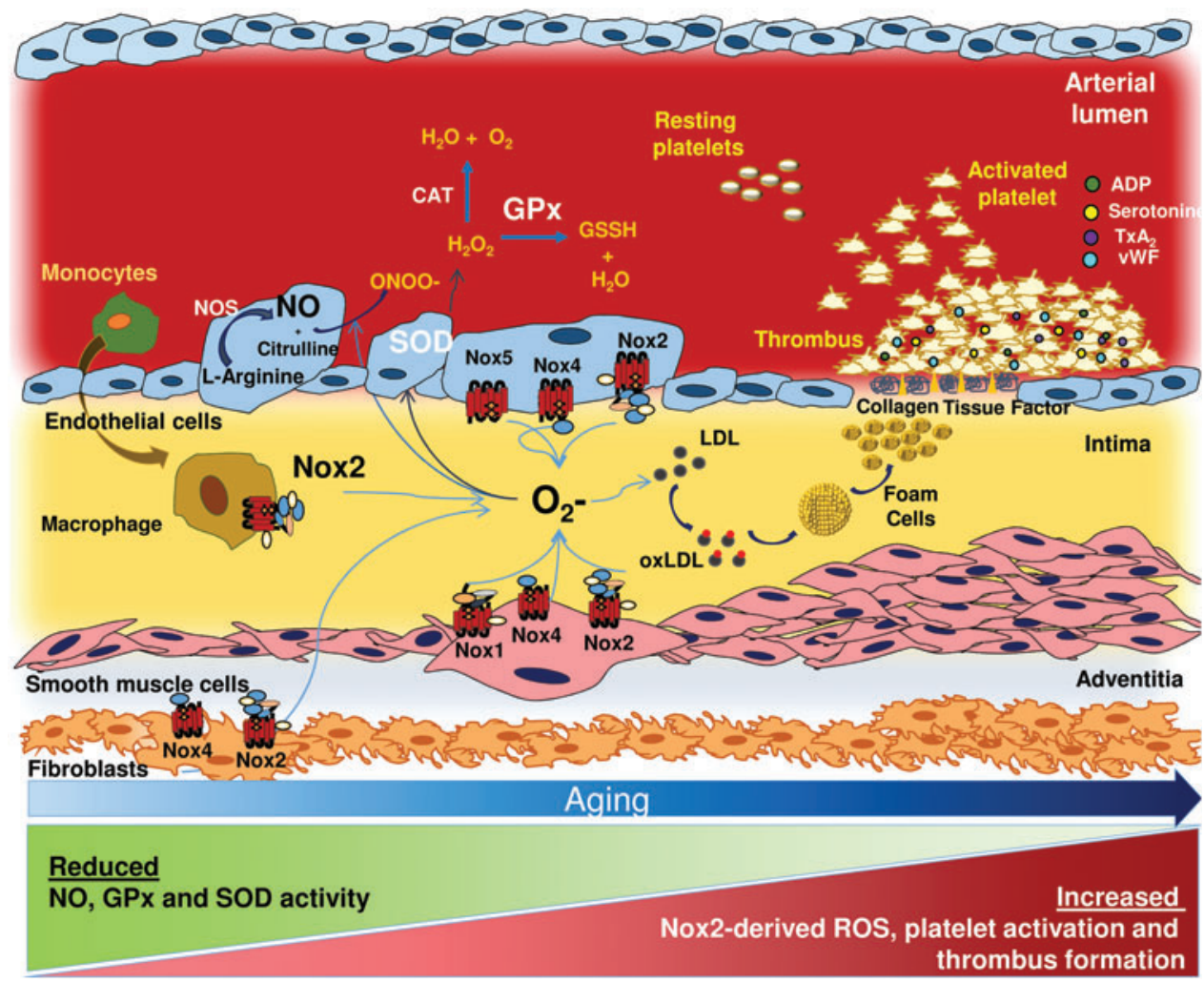

FIG. 8. Endothelial dysfunction in aging process. Endothelial function may be influenced by redox status changes occurring by aging. Endothelial cells produce $\mathrm{O}_{2}{ }^{-}$ prevalently via several Nox isoforms such as Nox1, Nox2, Nox4, and Nox5. The balance between $\mathrm{NO}$ and $\mathrm{O}_{2}{ }^{-}$is crucial, as an increase in $\mathrm{O}_{2}{ }^{-}$ has a detrimental effect on NO bioactivity/biosynthesis or elicits eNOS uncoupling. Impaired inactivation of oxidant species by downregulation of catalase, SOD, and GPx activity can contribute to artery dysfunction. A decrease in NO bioavailability, GPx and SOD activity and an increase in Nox2-derived ROS, platelet activation may favor thrombus formation in elderly patients. To see this illustration in color, the reader is referred to the web version of this article at www.liebertpub.com/ars 
extracellular space; SOD1 preserves NO levels within the endothelium; and SOD2 protects against oxidative stressmediated mitochondrial dysfunction (114).

Aging is characterized by a progressive arterial loss of function and structural changes, which may strongly concur to atherothrombosis. Thus, several studies showed that, compared with young healthy adults, artery dilation is impaired in elderly people $(60,256,326)$. Classic cardiovascular risk factors can accelerate the age-related modifications of the artery, favoring the onset and progression of atherosclerosis and CVD (250). A large cross-sectional study conducted in 5314 Japanese adults showed that endothelial function decreases with age decades (20-70 years) in close relationship with cumulative cardiovascular risk factors (227). In particular, the study found that age, body mass index, systolic blood pressure, DM, smoking and baseline brachial artery diameter were independent predictors of FMD (206).

Functional impairment of age-related artery dilatation may be related to an imbalance between ROS formation and detoxification, which eventually results in vascular oxidative stress. For instance, as Nox 2 is upregulated by aging, it would be arguably an implication of this enzyme in favoring artery dysfunction. Experimental studies are in support of this as evidenced in cholesterol-fed animals knockout for Nox2, which displayed enhanced artery dilation compared with wild type (237). Conversely, antioxidant status seems to be implicated in age-related endothelial dysfunction. Thus, Barton et al. (22) found that plasma endothelin-1 levels increased whereas plasma SOD activity decreased with aging coincidentally with impaired endothelium-dependent artery dilatation and NO release by rat aortic endothelial cells (22). Interestingly, they also found that SOD activity and relaxations to acetylcholine were preserved in femoral arteries, indicating a heterogeneity in endothelial function and oxidative stress related to size and sites of the arteries (22). Further support to the pivotal role of SOD in aging was provided by animal studies showing that SOD mimetics restored endothelial function in elderly mice $(198,362)$. Endothelial dysfunction by aging can also be dependent on GPx regulation (138) as shown in animals knockout for GPx, which displayed impaired NO bioavailability in elderly compared with younger animals and, eventually, vascular dysfunction (259).

Others factors potentially contributing to endothelial dysfunction by aging are related to a link among short length of telomeres, senescence, and endothelial dysfunction (415). The exact mechanism through which telomeres would determine endothelial dysfunction and CVD remains unclear. However, it was suggested that cardiovascular risk factors may accelerate telomere shortening through increased oxidative stress (415). Also, the human abdominal aorta (14) displays typical alterations of senescent cells such as agedependent telomere erosion and consequent reduction of telomere length (14).

Doppler ultrasonography is a first-level examination to assess the atherosclerotic burden; one surrogate marker of atherosclerosis is the carotid artery IMT, which was directly correlated with the occurrence of CVEs, such as stroke and MI (215). There is evidence that carotid IMT increases by aging $(228,373,393)$ as reported by the Bogalusa study, which compared the progression of IMT in childhood and adults with cardiovascular risk factors (202). Autoptic studies showed that aortic IMT increased with aging even in populations at a low risk of atherosclerosis (387) and, in accordance with this, the Baltimore Longitudinal Study on Aging demonstrated a two- to threefold carotid IMT increase from 20 to 90 years of age $(106,192)$. An increase of aging-related carotid IMT in the general population was also confirmed by other studies that estimated a rate of IMT growing $>0.01 \mathrm{~mm} /$ year $(102,149,366)$.

There is evidence that an imbalance between ROS formation and detoxification $(10,416)$ is associated with IMT increase. Thus, a recent nested case-control study by Yoon et al. showed that IMT was associated with oxidative stress markers such as urinary 8-hydroxy-20-deoxyquuanosine, malondialdehyde, and 8-iso- $\mathrm{PGF}_{2 \alpha}$ (416). Further, Ashfaq et al. (10) reported that the ratio between reduced/oxidized form of GSH was an independent predictor of IMT. Upregulation of Nox 2 could be another potential mechanism accounting for a progressive increase of IMT. In patients with CGD, a reduced carotid thickness was detected by ultrasonography and magnetic resonance imaging (337). Further, in children with obesity and hypercholesterolemia or in subjects without clinically overt atherosclerotic disease, Nox 2 activation was significantly associated with carotid IMT (210, 419). However, prospective studies are needed to substantiate the role of Nox 2 as a predictor of IMT progression.

Aging is also associated with arterial structural changes such as an increase of luminal enlargement and wall stiffness (192). Pulse wave velocity (PWV), the velocity of pulse propagation through the arteries, is considered a noninvasive index of vascular stiffness. Cardiovascular risk factors, such as DM, smoking, and hypertension, increase PWV, particularly in the elderly population $(151,204)$. The structural changes of the artery wall, which accounts for increased PWV, are probably dependent on an increase of collagen content, reduction of elastin, and calcification by aging. Thus, an impaired synthesis and accelerated degradation of elastin (250), and a higher deposition of collagen fibrils were observed in aged arteries (250). Changes in the content of collagen fibrils and elastin were studied in the human thoracic aorta by cross-link products (250). From 0-19 to 80 years, an increase of about $100 \%$ of collagen cross-link product and a decrease of about $50 \%$ of elastin cross-link products were observed, confirming a loss of elasticity during aging (250). These changes can be detected in large- and medium-size arteries that become less distensible, with luminal dilatation and being somewhat hypertrophic (320).

Oxidative stress may be implicated in impaired arterial elasticity $(270,407)$ as it directly correlates with enhanced arterial stiffness in healthy subjects $(270,407)$. Further, Nox2 deficiency is associated with reduced impairment of agedependent neovascularization in mice (371).

Taken together, these data suggest that aging is associated with important alterations of endothelial homeostasis (94), which are shifted toward loss of dilatation function and elasticity and enhanced vasoconstriction. Due to the relevant role of oxidative stress in endothelial homeostasis, antioxidants might favorably influence endothelial function. Antoniades et al. demonstrated, for example, that 2-week administration of $2 \mathrm{~g}$ vitamin $\mathrm{C}$ and $800 \mathrm{IU}$ vitamin $\mathrm{E}$ improved forearm blood flow in chronic smokers; this effect seemed to be mediated by an upregulation of NOS (8). 
Similar effects have been detected by polyphenol administration, which increased FMD (203) via Nox2 downregulation and, eventually, enhanced NO bioavailability (211).

Experimental studies with other antioxidants such as polyphenol supported the potential usefulness of these molecules to counteract age-related artery dysfunction. Thus, a chronic intake of polyphenols protected against aginginduced endothelial dysfunction and decline of physical performance via Nox inhibition and upregulation of eNOS in rats $(72,73)$. No human study has so far analyzed the effect of polyphenols on aging and endothelial function.

\section{Antiplatelet and Anticoagulant Treatments}

The modifications induced by aging in platelet function may have clinical and therapeutic consequences, as the increased platelet activation may result in a lower efficacy of antiplatelet in elderly patients compared with younger ones. The effect of aspirin, which inhibits COX1, thus preventing the formation of $\mathrm{TxA}_{2}$, has been investigated in a meta-analysis of randomized clinical trials (7). Despite an apparent similar efficacy of aspirin in the young $(-13 \%)$ and elderly $(-12 \%)$ population, it was speculated that aspirin could be even more effective in the elderly population because the younger population are at a lower absolute risk (7). However, data analysis is not consistent with this interpretation as aspirin efficacy was significant only in patients $<65$ years (hazard ratio [HR] 0.87 , $95 \%$ confidence interval $[\mathrm{CI}]$ 0.78-0.98) compared with those aged $\geq 65$ years (HR: $0.88,95 \%$ CI $0.77-1.01$ ) (7). This different efficacy seems to be also evident for thienopyridines, which are reversible (ticagrelor) or irreversible (clopidogrel and prasugrel) inhibitors of the platelet receptor P2Y12 (Table 3). The Dual Antiplatelet Therapy (DAPT) trial included 9961 patients who underwent a coronary stent placement and were randomly assigned to continue thienopyridine treatment or to receive a placebo in addition to aspirin. The study showed a lower efficacy of antiplatelet therapy in reducing CVEs and CD in patients $<75(n=8929)$ versus $\geq 75$ years $(n=1032)$ (230). Similarly, the CLARITY-TIMI 28 trial (314), which included 1752 ACS patients with ST-segment elevation, showed that clopidogrel was less effective in 1015 patients $\geq 65$ years than in 2466 patients $<65$ years (314).

Similar results were obtained by three recent studies, which explored the clinical efficacy of ticagrelor (Table 3). The PLATO study (391) included 18,624 patients with ACS without ST segment elevation, to compare the efficacy of ticagrelor versus clopidogrel during a follow-up of 30 days. The study showed a favorable effect of ticagrelor in patients $<75$ years $(n=15744)$ in reducing the composite endpoint of $\mathrm{CV}$ death, MI, and stroke, which was not significant in those aged $\geq 75$ years $(n=2878)$.

This different efficacy was also observed in the SOCRATES trial (164), which included 13,199 patients with nonsevere ischemic stroke or high-risk transient ischemic attack treated with ticagrelor versus aspirin in a 90-day follow-up. Patients treated with ticagrelor had significantly lower CVEs, but this positive effect was age related; thus, the trial reported a lower efficacy of ticagrelor in patients $>75$ years $(n=2995)$ versus those $<65$ years $(n=6028)$. Together, these data seem to indicate a sort of "antiplatelet resistance" in the elderly population, which needs to be further investigated.
In addition to antiplatelet drugs, elderly patients are often treated with oral anticoagulants such as vitamin $\mathrm{K}$ antagonists or non-vitamin $\mathrm{K}$ oral anticoagulants (NOACs), which inhibit thrombin or factor Xa. The efficacy and safety of NOACs have been investigated in patients with deep venous thrombosis, AF and ACS with an efficacy at least comparable to warfarin, along with a better safety profile. Such beneficial effects seem to be independent from age and may be explained by the fact that NOACs, in particular the Xa inhibitors, possess not only an anticoagulant but also an antiplatelet effect, which may turn useful in patients with upregulation of platelet and clotting activation as detected in the elderly AF population (283).

\section{Observational and Interventional Trials with Antioxidants in Humans}

The efficacy of antioxidants for the prevention of CVEs and atherosclerosis progression was largely investigated. Vitamin E was the most studied molecule among the antioxidant vitamins (vitamins $\mathrm{A}, \mathrm{C}, \mathrm{E}$, and $\beta$-carotene). The strong interest for vitamin $\mathrm{E}$ was based on observational studies reporting an inverse association between vitamin $\mathrm{E}$ plasma levels, CHD, and incidence of CVEs (380). The WHO/MONICA project found an inverse correlation between CHD mortality and vitamin E plasma levels (121). Conversely, no association was observed between CHD and other vitamins (vitamin $\mathrm{A}, \mathrm{C}$, and $\beta$-carotene). Similarly, Singh et al. found that in a population of 595 urban Indians, plasma levels of vitamins $\mathrm{C}$ and $\mathrm{E}$ were inversely related to CAD (340). Finally, blood vitamin E levels predicted CVEs in 1012 elderly AF patients during 27 months of follow-up (51). In addition to vitamin $\mathrm{E}$, low blood vitamin $\mathrm{C}$ levels were found to be predictive of cardiovascular mortality in an elderly British population (107).

At variance with this, meta-analyses of interventional trials with vitamin $C$ and E provided equivocal results (249) and, paradoxically, potentially harmful effects as enhanced risk of all-cause mortality $(31,32)$ or hemorrhagic stroke (322). However, in many trials, a combination of antioxidant vitamins was used on the assumption that more antioxidants could synergically enhance the antioxidant status potentially achievable by a single antioxidant (296). Actually, a combination of antioxidants may negatively influence the activity of a single antioxidant. For instance, a combination of vitamin $\mathrm{E}$ with vitamin $\mathrm{C}$ was shown to be not effective for cardiovascular prevention in The Physicians' Health Study II (329); this negative effect might depend on the fact that vitamin $\mathrm{C}$ may exert a pro-oxidant activity when orally administered to humans, thus impairing vitamin $\mathrm{E}$ antioxidant property $(291,296)$. A harmful effect was even detected by combining vitamin $\mathrm{E}$ with beta-carotene, which was, in fact, associated with enhanced risk of total mortality (388). The fact that vitamin $\mathrm{E}$ could be useful when given alone is suggested by a more recent meta-analysis, where vitamin $\mathrm{E}$ supplementation seemed to be associated to a reduction of MI (212).

Other reasons for inconsistency of interventional trials with antioxidant vitamins rely on methodological issues. Thus, potential bias of the interventional studies with vitamin E could be dependent on the concomitant use of statins, which were given in association with vitamin $\mathrm{E}$ in about one 


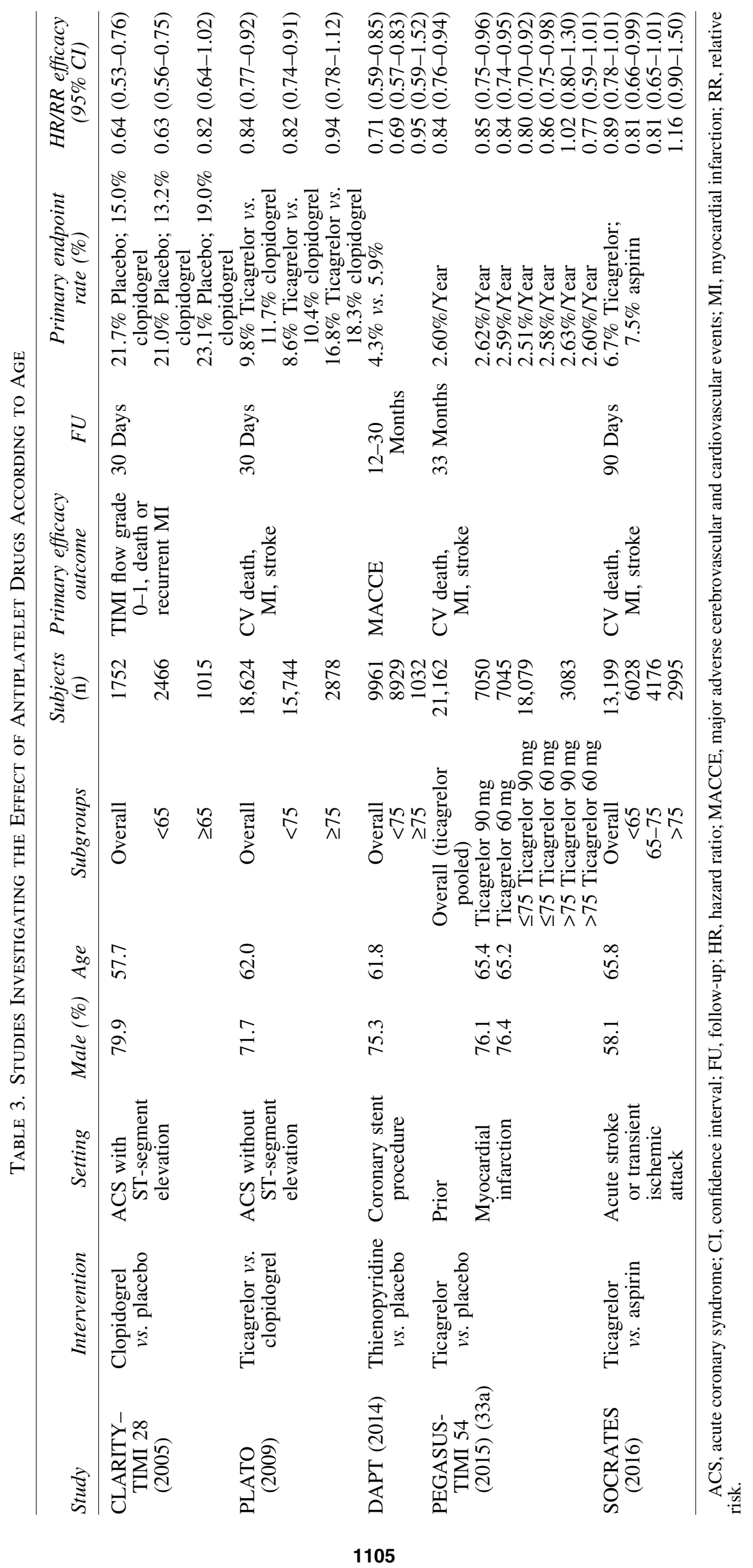


out of three patients (388). Thus, an experimental study demonstrated that statins reduce oxidative stress and improve circulating levels of vitamin $\mathrm{E}$, thus minimizing its putative antioxidant benefit (388). Further, interventional trials did not take into account that vitamin $\mathrm{E}$ is poorly absorbed if not assumed with meals (156). This issue has never been considered by interventional trials as scarce data regarding vitamin E bioavailability have been reported. In the absence of such information, it cannot be excluded that a poor bioavailability of vitamin E may represent another explanation for its lack of efficacy. Finally, none of the interventional trials measured the antioxidant status at baseline; therefore, it could not be appreciated whether patients included in the studies disclosed low levels of vitamins and actually needed antioxidant supplementation.

Several epidemiological studies showed that a diet rich in polyphenols reduces CVEs and cardiovascular mortality (9, $25,44,45)$. These beneficial effects have been observed particularly with the Mediterranean Diet (Med-Diet), which is rich in polyphenols for its high content of fruit, vegetables, extra-virgin olive oil (EVOO), and moderate red wine consumption. Thus, in the Seven Countries study (172), Ancel Keys described for the first time that people from the Mediterranean area (Greece, Italy) experienced a lower mortality rate for CVD, when compared with populations living in Northern Europe (172). The Lyon Diet Heart Study, which was the first interventional trial that studied the effect of MedDiet on CVD in patients affected by MI, showed that MedDiet reduced cardiovascular complications by $50 \%$ (80). Recently, the PREDIMED trial investigated the effect of Med-Diet on CVEs (99) by randomizing 7447 people at high vascular risk to Med-Diet supplemented with EVOO, mixed nuts, or control diet (99). Med-Diet reduced the risk of CVD complications by $30 \%$ over a follow-up of about 5 years in the two arms supplemented with EVOO or nuts (99). Of note, a subgroup analysis of PREDIMED showed that, compared with control diet, Med-Diet was particularly effective in preventing major CVEs in people $>70$ years (99). Consistent with this finding, we recently demonstrated that adherence to Med-Diet reduced the risk of CVE in an elderly population affected by AF (264).

Cocoa is another polyphenol-rich nutrient that seems to possess beneficial effects on the cardiovascular system (213). The Iowa Women's Health Study reported an inverse relationship between chocolate intake and CHD mortality in postmenopausal women (239). Accordingly, the European Prospective Investigation into Cancer and Nutrition (45) showed a lower rate of MI and stroke in subjects with the highest chocolate consumption. Moreover, an observational trial in elderly people, the Zutphen Study, showed that cocoa intake was inversely related to cardiovascular mortality (44). Finally, the Stockholm Heart Epidemiology Program (160) reported a reduction of cardiovascular mortality in a population of nondiabetic subjects with previous MI taking a high amount of chocolate. However, due the observational nature of these findings, the effect of polyphenols contained in cocoa on cardiovascular protection needs further evaluation by interventional randomized trials (213).

Another polyphenol largely studied for its antioxidant property is resveratrol, which is mostly contained in red wine. The "French paradox" ascribed to resveratrol the beneficial cardiovascular effects provided by red wine (305). However, this hypothesis was not confirmed in elderly people by the "Invecchiare In Chianti (inChianti) Study" that did not find any effect on mortality risk and CVD in 783 subjects who regularly drink red wine (327). Further investigation on the possible beneficial effect of resveratrol on CVD is, however, needed considering that, as for other antioxidants, interventional trials provided likely inconsistent results for several reasons, including study methodology, dosage, and subjects' selection (29).

Green and black tea are other polyphenol-rich nutrients that are believed to exert cardiovascular protection (346). Epidemiological studies in the elderly showed that tea consumption reduces the risk of CVD and total mortality (142, 347). However, a meta-analysis of 17 studies by Peters et al. did not find an association between tea intake and CVD (277). Large prospective and interventional studies are necessary to evaluate the effect of tea on the cardiovascular system.

\section{Future Perspectives and Conclusions}

Data here reported suggest that platelet and clotting activation along with endothelial dysfunction are typical features of the elderly population, which contribute toward enhancing the risk of cardiac and cerebral ischemic complications. Even if the modern approach to treat or prevent thrombosis with single or dual antiplatelet agents or with NOACs achieved positive results in terms of reduction of CVD, an elevated residual risk still remains. In this context, experimental and clinical data are in favor of the hypothesis that systemic inflammation and oxidative stress tends to worsen with advancing age and can precipitate acute events via activation of the platelet and clotting system. As classic atherosclerotic risk factors are recognized as the most important triggers of systemic inflammation and oxidative stress and, considering that they frequently overlap in the elderly population, careful attention should be given to optimize adherence to antiatherosclerotic treatments. This issue deserves careful attention as the drug's compliance is drastically reduced in case of multiple treatments as shown; for instance, adherence to aspirin prescription was significantly lowered when patients were treated with $>5$ pills/day (282).

Gut microbiota is another emergent risk factor that was recently proposed as contributing to systemic inflammation and oxidative stress with at least two different mechanisms: (i) gastrointestinal colonization of bacteria-producing inflammatory molecules; (ii) enhanced gut permeability due to abnormal changes of local circulation with ensuing translocation into systemic circulation of pro-inflammatory and prooxidant molecules such as TMAO or LPS. Although changes of gut microbiota occurring in the elderly have been described, no data regarding blood levels of TMAO or LPS in the elderly population have been reported. Due to the relevance of diet and changes of gut composition by advancing age, these data would be of particular interest also in view of developing new approaches to lower the risk of CVD in the elderly population.

Systemic inflammation and oxidative stress could also be counteracted by targeting specific oxidant pathways that are potentially implicated in atherothrombosis. Among them, an intriguing attractive approach is represented by the inhibition of Nox2, which is upregulated and is associated with platelet activation in the elderly (Fig. 9). Thus, experimental studies 
FIG. 9. Potential targets to slow aging. Several factors can favor atherothrombosis in the elderly: redox status (anti-oxidants and pro-oxidants pathways), atherosclerotic risk factors, gut dysbiosis, and endothelial dysfunction. In addition to antiplatelet and anticoagulants drugs, other potential targets to slow aging may include prevention/management of atherosclerotic risk factors, reduction of Nox2 upregulation, modulation of gut microbiota composition, and improving antioxidant status with an antioxidantrich diet (i.e., Mediterranean diet). To see this illustration in color, the reader is referred to the web version of this article at www.liebertpub .com/ars

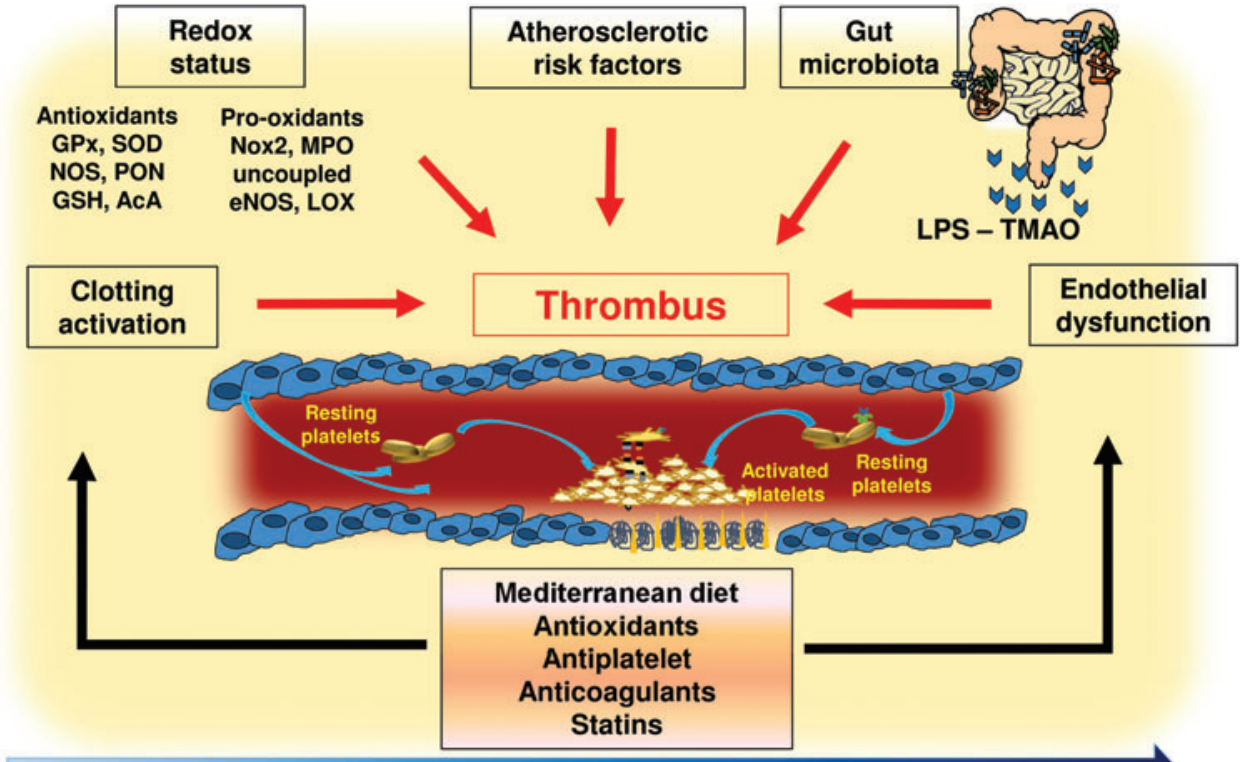

\section{Potential targets to slow aging}

To be reduced

Atherosclerotic risk factors

Nox2, MPO, uncoupled eNOS, LOX

Platelet activation

Gut dysbiosis
To be increased:

Antioxidant status (GPx, eNOS, GSH, AcA) Adherence to Mediterranean Diet demonstrated that inhibition of Nox 2 results in delayed thrombus growth, suggesting Nox2 as a target to modulate platelet function. A matter of concern is represented, however, by the role played by Nox 2 in the innate system, as a complete suppression of Nox 2 activity is associated to serious life-threatening infection disease as depicted by clinical history of patients with Nox2 hereditary deficiency (280). It is interesting, however, that in case of $50 \%$ reduction of Nox2 activity, as observed in Nox 2 deficiency carriers, platelet inhibition was similar to that found in patients with complete Nox 2 absence, in the absence of serious infection complications. Thus, it might be possible that $50 \%$ Nox 2 inhibition would be appropriate to achieve effective platelet inhibition and be clinically safe (55).

Among drugs modulating platelet function by interfering with Nox2, statins represent a promising candidate as these drugs inhibit the activity of the Nox2 subunit RAC1 (281). Thus, in a randomized study in hypercolesterolemic patients, $40 \mathrm{mg}$ atorvastatin ingestion was associated to immediate downregulation of Nox2, along with inhibition of platelet isoprostanes (281). Similar results were obtained by using rosuvastatin, another powerful lipid-lowering molecule (279). However, prospective studies are needed to investigate whether the protective effects of statins against CVD are also attributable to Nox 2 inhibition. Another therapeutic option could be represented by apocynin, a molecule that reduces $\mathrm{p} 47^{\mathrm{phox}}$ translocation to the catalytic site of Nox2. This approach would have less negative impact on the innate immune system as indicated by the more favorable clinical history of patients with hereditary deficiency of $\mathrm{p} 47^{\text {phox }}$ (185). Few studies analyzed the effects of apocynin in humans. In these studies, apocynin was nebulized and administered by inhalation to healthy subjects or asthmatics to examine its effect on
ROS levels in exhaled breath condensate (276, 348, 349). In each study, apocynin administration for a few hours was well tolerated, and it effectively reduced exhaled ROS levels (276, $348,349)$. Up to now, chronic systemic administration of apocynin in human has never been tested.

Another factor contributing to atherothrombosis in the elderly is the continuous decline of antioxidant status. Theoretically, increasing antioxidant status may represent a novel therapeutic option but, as reported earlier, data on supplementation with antioxidant vitamins are equivocal. However, other potential therapeutic options include supplementation with GSH precursors, which is reduced in the elderly and is predictive of CVEs. In this regard, a potential therapeutic approach is represented by $\mathrm{N}$-acetylcysteine (NAC), a direct precursor to GSH synthesis frequently proposed as a cardio-protective agent $(95,381)$. This compound is a nutritional supplement that acts by raising the intracellular concentration of cysteine/GSH, and by scavenging oxidant species (95). Its pharmacological actions include restoration of cellular antioxidant potential by replenishing GSH depleted by ROS scavenging and inhibition of neutrophil activity and $\mathrm{TNF} \alpha$ production (95). Preliminary data suggest a potential role of NAC in preventing postsurgery AF (381), but further data are necessary to explore the effect of NAC on CVEs. An alternative approach would consider upregulation of specific enzymatic pathways that exert antioxidant effects by scavenging intracellular oxidant species (78). In this regard, an experimental study provided interesting data, as GPx 1 overexpression resulted in impaired platelet activation and thrombus growth (78). Therefore, upregulating GPx or other antioxidant enzymes such as PON1, NOS, or HO may represent an option to be considered in future. 
We have interesting information, however, on the effect of an antioxidant-rich diet such as Med-Diet on oxidative stress and platelet function. Indeed, adherence to Med-Diet was associated with an antioxidant effect in a large prospective cohort study including elderly AF patients, by reduced Nox 2 activity and urinary 8 -iso-PGF $2 \alpha$ levels (264). Of note, adherence to Med-Diet was also associated to impaired production of $\mathrm{TxB}_{2}$, suggesting that downregulating Nox2-derived oxidative stress would result in impaired platelet activation (285). Taking into account that Nox2 upregulation and platelet overactivation are coincident in the elderly population, this diet could be advised particularly in the elderly population. It is still unclear, however, whether such beneficial effects may be attributed to the Med-Diet per se, or to its specific nutrients. EVOO could be effective through several mechanisms, including an antidiabetic, antioxidant, or antiplatelet effect. Regarding the first point, intake of EVOO has been shown to improve postprandial glycemic control with a mechanism involving upregulation of glucagon-like peptide 1 and insulin secretion (54). Further, we found that EVOO exerts an antioxidant activity by downregulating Nox2-derived oxidative stress and that its intake is associated with impaired platelet activation (56). Thus, identification of EVOO components implicated in this antioxidant effect could lead to discovering new molecules to be used for anti-anti-atherosclerotic purposes.

Finally, considering the reduced availability and ability to migrate of EPCs in elderly with CVD, EPC cell therapy may be a promising approach for the treatment of CVDs. However, trials performed so far provided inconclusive results; this may be dependent on the age-dependent functional impairment in terms of proliferation, migration, and survival capacity of EPCs, which limits the efficacy of autologous EPCs in the treatment of CVDs. To overcome these limitations, several EPC enhancement strategies have been tested in experimental models [reviewed in detail in Rurali et al. (311)]. These approaches aim at enhancing proliferation, migration/homing, and/or differentiation of EPCs. They can be broadly classified into (i) strategies that can improve EPC function, operating at the ischemic tissue levels (namely in vivo conditioning), and (ii) approaches acting directly on EPCs before their in vivo administration (namely ex vivo priming). Despite the potential interest for this approach, clinical studies are needed to support the beneficial effects.

In conclusion, the elderly population is characterized by a pro-thrombotic phenotype that is dependent on platelet and clotting activation and artery dysfunction. An imbalance between ROS formation and antioxidant status occurs by aging and may contribute to this pro-thrombotic status. Targeting specific pathways implicated in ROS formation or counteracting age-related decline of specific antioxidant enzymes would represent a novel approach to assess whether oxidative stress is a mere mirror of vascular disease or is actually implicated in promoting atherosclerosis and thrombosis.

\section{Acknowledgment}

The authors would like to thank Dr. Vittoria Cammisotto for assistance in the preparation of figures.

\section{References}

1. Abbate R, Prisco D, Rostagno C, Boddi M, and Gensini GF. Age-related changes in the hemostatic system. Int $J$ Clin Lab Res 23: 1-3, 1993.

2. Ahmed E, Trifunovic J, Stegmayr B, Hallmans G, and Lefvert AK. Autoantibodies against oxidatively modified LDL do not constitute a risk factor for stroke: a nested case-control study. Stroke 30: 2541-2546, 1999.

3. Aiello RJ, Bourassa PA, Lindsey S, Weng W, Freeman A, and Showell HJ. Leukotriene B4 receptor antagonism reduces monocytic foam cells in mice. Arterioscler Thromb Vasc Biol 22: 443-449, 2002.

4. Alberti KG, Eckel RH, Grundy SM, Zimmet PZ, Cleeman JI, Donato KA, Fruchart JC, James WP, Loria CM, Smith SC, Jr., International Diabetes Federation Task Force on E, Prevention, Hational Heart L, Blood I, American Heart A, World Heart F, International Atherosclerosis S, and International Association for the Study of O. Harmonizing the metabolic syndrome: a joint interim statement of the International Diabetes Federation Task Force on Epidemiology and Prevention; National Heart, Lung, and Blood Institute; American Heart Association; World Heart Federation; International Atherosclerosis Society; and International Association for the Study of Obesity. Circulation 120: 1640-1645, 2009.

5. Alessandrini P, Avogaro P, Bittolo Bon G, Patrignani P, and Patrono C. Physiologic variables affecting thromboxane B2 production in human whole blood. Thromb Res 37: 1-8, 1985.

6. Ali Z, Sarcia P, Mosley TH, Jr., Kondragunta V, and Kullo IJ. Association of serum myeloperoxidase with the ankle-brachial index and peripheral arterial disease. Vasc Med 14: 215-220, 2009.

7. Antithrombotic Trialists C, Baigent C, Blackwell L, Collins R, Emberson J, Godwin J, Peto R, Buring J, Hennekens C, Kearney P, Meade T, Patrono C, Roncaglioni MC, and Zanchetti A. Aspirin in the primary and secondary prevention of vascular disease: collaborative meta-analysis of individual participant data from randomised trials. Lancet 373: 1849-1860, 2009.

8. Antoniades C, Tousoulis D, Tentolouris C, Toutouza M, Marinou K, Goumas G, Tsioufis C, Toutouzas P, and Stefanadis C. Effects of antioxidant vitamins $\mathrm{C}$ and $\mathrm{E}$ on endothelial function and thrombosis/fibrinolysis system in smokers. Thromb Haemost 89: 990-995, 2003.

9. Arts IC, Hollman PC, Feskens EJ, Bueno de Mesquita HB, and Kromhout D. Catechin intake might explain the inverse relation between tea consumption and ischemic heart disease: the Zutphen Elderly Study. Am J Clin Nutr 74: 227-232, 2001.

10. Ashfaq S, Abramson JL, Jones DP, Rhodes SD, Weintraub WS, Hooper WC, Vaccarino V, Harrison DG, and Quyyumi AA. The relationship between plasma levels of oxidized and reduced thiols and early atherosclerosis in healthy adults. J Am Coll Cardiol 47: 1005-1011, 2006.

11. Authors/Task Force M, Ryden L, Grant PJ, Anker SD, Berne C, Cosentino F, Danchin N, Deaton C, Escaned J, Hammes HP, Huikuri H, Marre M, Marx N, Mellbin L, Ostergren J, Patrono C, Seferovic P, Uva MS, Taskinen MR, Tendera M, Tuomilehto J, Valensi P, Zamorano JL, Guidelines ESCCfP, Zamorano JL, Achenbach S, Baumgartner H, Bax JJ, Bueno H, Dean V, Deaton C, Erol C, Fagard R, Ferrari R, Hasdai D, Hoes AW, Kirchhof P, Knuuti J, Kolh P, Lancellotti P, Linhart A, Nihoyanno- 
poulos P, Piepoli MF, Ponikowski P, Sirnes PA, Tamargo JL, Tendera M, Torbicki A, Wijns W, Windecker S, Document R, De Backer G, Sirnes PA, Ezquerra EA, Avogaro A, Badimon L, Baranova E, Baumgartner H, Betteridge J, Ceriello A, Fagard R, Funck-Brentano C, Gulba DC, Hasdai D, Hoes AW, Kjekshus JK, Knuuti J, Kolh P, Lev E, Mueller C, Neyses L, Nilsson PM, Perk J, Ponikowski P, Reiner Z, Sattar N, Schachinger V, Scheen A, Schirmer H, Stromberg A, Sudzhaeva S, Tamargo JL, Viigimaa $\mathrm{M}$, Vlachopoulos $\mathrm{C}$, and Xuereb RG. ESC Guidelines on diabetes, pre-diabetes, and cardiovascular diseases developed in collaboration with the EASD: the Task Force on diabetes, pre-diabetes, and cardiovascular diseases of the European Society of Cardiology (ESC) and developed in collaboration with the European Association for the Study of Diabetes (EASD). Eur Heart J 34: 30353087, 2013.

12. Aviram M, Rosenblat M, Billecke S, Erogul J, Sorenson R, Bisgaier CL, Newton RS, and La Du B. Human serum paraoxonase (PON 1) is inactivated by oxidized low density lipoprotein and preserved by antioxidants. Free Radic Biol Med 26: 892-904, 1999.

13. Aviram M, Rosenblat M, Bisgaier CL, Newton RS, Primo-Parmo SL, and La Du BN. Paraoxonase inhibits high-density lipoprotein oxidation and preserves its functions. A possible peroxidative role for paraoxonase. $J$ Clin Invest 101: 1581-1590, 1998.

14. Aviv H, Khan MY, Skurnick J, Okuda K, Kimura M, Gardner J, Priolo L, and Aviv A. Age dependent aneuploidy and telomere length of the human vascular endothelium. Atherosclerosis 159: 281-287, 2001.

15. Azumi H, Inoue N, Takeshita S, Rikitake Y, Kawashima $\mathrm{S}$, Hayashi $\mathrm{Y}$, Itoh $\mathrm{H}$, and Yokoyama M. Expression of NADH/NADPH oxidase p22phox in human coronary arteries. Circulation 100: 1494-1498, 1999.

16. Babaev VR, Li L, Shah S, Fazio S, Linton MF, and May JM. Combined vitamin $\mathrm{C}$ and vitamin $\mathrm{E}$ deficiency worsens early atherosclerosis in apolipoprotein E-deficient mice. Arterioscler Thromb Vasc Biol 30: 1751-1757, 2010.

17. Back M, Bu DX, Branstrom R, Sheikine Y, Yan ZQ, and Hansson GK. Leukotriene B4 signaling through NFkappaB-dependent BLT1 receptors on vascular smooth muscle cells in atherosclerosis and intimal hyperplasia. Proc Natl Acad Sci U S A 102: 17501-17506, 2005.

18. Ballinger SW, Patterson C, Knight-Lozano CA, Burow DL, Conklin CA, Hu Z, Reuf J, Horaist C, Lebovitz R, Hunter GC, McIntyre K, and Runge MS. Mitochondrial integrity and function in atherogenesis. Circulation 106: 544-549, 2002.

19. Banning A, Schnurr K, Bol GF, Kupper D, MullerSchmehl K, Viita H, Yla-Herttuala S, and Brigelius-Flohe $\mathrm{R}$. Inhibition of basal and interleukin-1-induced VCAM-1 expression by phospholipid hydroperoxide glutathione peroxidase and 15-lipoxygenase in rabbit aortic smooth muscle cells. Free Radic Biol Med 36: 135-144, 2004.

20. Barry-Lane PA, Patterson C, van der Merwe M, Hu Z, Holland SM, Yeh ET, and Runge MS. p47phox is required for atherosclerotic lesion progression in $\mathrm{ApoE}(-/-)$ mice. J Clin Invest 108: 1513-1522, 2001.

21. Bartels ED, Christoffersen C, Lindholm MW, and Nielsen LB. Altered metabolism of LDL in the arterial wall precedes atherosclerosis regression. Circ Res 117: 933-942, 2015.

22. Barton M, Cosentino F, Brandes RP, Moreau P, Shaw S, and Luscher TF. Anatomic heterogeneity of vascular ag- ing: role of nitric oxide and endothelin. Hypertension 30: 817-824, 1997.

23. Basu S. F2-isoprostanes in human health and diseases: from molecular mechanisms to clinical implications. Antioxid Redox Signal 10: 1405-1434, 2008.

24. Bauer KA, Weiss LM, Sparrow D, Vokonas PS, and Rosenberg RD. Aging-associated changes in indices of thrombin generation and protein $\mathrm{C}$ activation in humans. Normative Aging Study. J Clin Invest 80: 1527-1534, 1987.

25. Bayard V, Chamorro F, Motta J, and Hollenberg NK. Does flavanol intake influence mortality from nitric oxidedependent processes? Ischemic heart disease, stroke, diabetes mellitus, and cancer in Panama. Int J Med Sci 4: 53-58, 2007.

26. Beard JR, Officer A, de Carvalho IA, Sadana R, Pot AM, Michel JP, Lloyd-Sherlock P, Epping-Jordan JE, Peeters GM, Mahanani WR, Thiyagarajan JA, and Chatterji S. The World report on ageing and health: a policy framework for healthy ageing. Lancet 387: 2145-2154, 2016.

27. Belkner J, Stender H, and Kuhn H. The rabbit 15lipoxygenase preferentially oxygenates LDL cholesterol esters, and this reaction does not require vitamin E. J Biol Chem 273: 23225-23232, 1998.

28. Bell SP and Saraf A. Risk stratification in very old adults: how to best gauge risk as the basis of management choices for patients aged over 80. Prog Cardiovasc Dis 57: 197-203, 2014.

29. Bhullar KS and Udenigwe C. Clinical evidence of resveratrol bioactivity in cardiovascular disease. Curr Opin Food Sci 8: 68-73, 2016.

30. Biswas SK, Newby DE, Rahman I, and Megson IL. Depressed glutathione synthesis precedes oxidative stress and atherogenesis in Apo-E(-/-) mice. Biochem Biophys Res Commun 338: 1368-1373, 2005.

31. Bjelakovic G, Nikolova D, Gluud LL, Simonetti RG, and Gluud C. Mortality in randomized trials of antioxidant supplements for primary and secondary prevention: systematic review and meta-analysis. JAMA 297: 842-857, 2007.

32. Bjelakovic G, Nikolova D, Gluud LL, Simonetti RG, and Gluud C. Antioxidant supplements for prevention of mortality in healthy participants and patients with various diseases. Cochrane Database Syst Rev 3: CD007176, 2012.

33. Blankenberg S, Rupprecht HJ, Bickel C, Torzewski M, Hafner G, Tiret L, Smieja M, Cambien F, Meyer J, Lackner KJ, and AtheroGene I. Glutathione peroxidase 1 activity and cardiovascular events in patients with coronary artery disease. N Engl J Med 349: 1605-1613, 2003.

33a. Bonaca MP, Bhatt DL, Cohen M, Steg PG, Storey RF, Jensen EC, Magnani G, Bansilal S, Fish MP, Im K, Bengtsson O, Oude Ophuis T, Budaj A, Theroux P, Ruda M, Hamm C, Goto S, Spinar J, Nicolau JC, Kiss RG, Murphy SA, Wiviott SD, Held P, Braunwald E, Sabatine MS; PEGASUS-TIMI 54 Steering Committee and Investigators. Long-term use of ticagrelor in patients with prior myocardial infarction. N Engl J Med 372: 1791-1800, 2015.

34. Bragado P, Armesilla A, Silva A, and Porras A. Apoptosis by cisplatin requires p53 mediated p38alpha MAPK activation through ROS generation. Apoptosis 12: 1733-1742, 2007.

35. Brand MD. Uncoupling to survive? The role of mitochondrial inefficiency in ageing. Exp Gerontol 35: 811820, 2000.

36. Braun S, Ndrepepa $G$, von Beckerath N, Mehilli J, Gorchakova O, Vogt W, Schomig A, and Kastrati A. Lack of association between circulating levels of plasma oxidized low-density lipoproteins and clinical outcome after coronary stenting. Am Heart J 150: 550-556, 2005. 
37. Brennan ML, Anderson MM, Shih DM, Qu XD, Wang X, Mehta AC, Lim LL, Shi W, Hazen SL, Jacob JS, Crowley JR, Heinecke JW, and Lusis AJ. Increased atherosclerosis in myeloperoxidase-deficient mice. J Clin Invest 107: 419-430, 2001.

38. Brennan ML, Wu W, Fu X, Shen Z, Song W, Frost H, Vadseth C, Narine L, Lenkiewicz E, Borchers MT, Lusis AJ, Lee JJ, Lee NA, Abu-Soud HM, Ischiropoulos H, and Hazen SL. A tale of two controversies: defining both the role of peroxidases in nitrotyrosine formation in vivo using eosinophil peroxidase and myeloperoxidasedeficient mice, and the nature of peroxidase-generated reactive nitrogen species. J Biol Chem 277: 1741517427, 2002.

39. Breton-Romero R, Gonzalez de Orduna C, Romero N, Sanchez-Gomez FJ, de Alvaro C, Porras A, RodriguezPascual F, Laranjinha J, Radi R, and Lamas S. Critical role of hydrogen peroxide signaling in the sequential activation of p38 MAPK and eNOS in laminar shear stress. Free Radic Biol Med 52: 1093-1100, 2012.

40. Brevetti G, Schiano V, Laurenzano E, Giugliano G, Petretta $\mathrm{M}$, Scopacasa F, and Chiariello M. Myeloperoxidase, but not $\mathrm{C}$-reactive protein, predicts cardiovascular risk in peripheral arterial disease. Eur Heart $J$ 29: 224-230, 2008.

41. Bridges AB, Scott NA, Pringle TH, McNeill GP, and Belch JJ. Relationship between the extent of coronary artery disease and indicators of free radical activity. Clin Cardiol 15: 169-174, 1992.

42. Brosnan JT and Brosnan ME. The sulfur-containing amino acids: an overview. J Nutr 136: 1636S-1640S, 2006.

43. Brown DI and Griendling KK. Nox proteins in signal transduction. Free Radic Biol Med 47: 1239-1253, 2009.

44. Buijsse B, Feskens EJ, Kok FJ, and Kromhout D. Cocoa intake, blood pressure, and cardiovascular mortality: the Zutphen Elderly Study. Arch Intern Med 166: 411-417, 2006.

45. Buijsse B, Weikert C, Drogan D, Bergmann M, and Boeing $\mathrm{H}$. Chocolate consumption in relation to blood pressure and risk of cardiovascular disease in German adults. Eur Heart J 31: 1616-1623, 2010.

46. Buttery LD, Springall DR, Chester AH, Evans TJ, Standfield EN, Parums DV, Yacoub MH, and Polak JM. Inducible nitric oxide synthase is present within human atherosclerotic lesions and promotes the formation and activity of peroxynitrite. Lab Invest 75: 77-85, 1996.

47. Cadroy Y, Dupouy D, Boneu B, and Plaisancie H. Polymorphonuclear leukocytes modulate tissue factor production by mononuclear cells: role of reactive oxygen species. J Immunol 164: 3822-3828, 2000.

48. Caliendo G, Cirino G, Santagada V, and Wallace JL. Synthesis and biological effects of hydrogen sulfide $\left(\mathrm{H}_{2} \mathrm{~S}\right)$ : development of $\mathrm{H}_{2} \mathrm{~S}$-releasing drugs as pharmaceuticals. J Med Chem 53: 6275-6286, 2010.

49. Callegari A, Liu Y, White CC, Chait A, Gough P, Raines EW, Cox D, Kavanagh TJ, and Rosenfeld ME. Gain and loss of function for glutathione synthesis: impact on advanced atherosclerosis in apolipoprotein E-deficient mice. Arterioscler Thromb Vasc Biol 31: 2473-2482, 2011.

50. Camici GG, Savarese G, Akhmedov A, and Luscher TF. Molecular mechanism of endothelial and vascular aging: implications for cardiovascular disease. Eur Heart J 36: 3392-3403, 2015.
51. Cangemi R, Pignatelli P, Carnevale R, Corazza GR, Pastori D, Farcomeni A, Basili S, Davi G, Ferro D, Hiatt WR, Licata G, Lip GY, Loffredo L, Mannucci PM, Vestri A, Violi F, and group APs. Cholesterol-adjusted vitamin E serum levels are associated with cardiovascular events in patients with non-valvular atrial fibrillation. Int J Cardiol 168: 3241-3247, 2013.

52. Cardoso MHM, Morganti RP, Lilla S, Murad F, De Nucci G, Antunes E, and Marcondes S. The role of superoxide anion in the inhibitory effect of SIN-1 in thrombinactivated human platelet adhesion. Eur J Pharmacol 627: 229-234, 2010.

53. Carnevale R, Iuliano L, Nocella C, Bartimoccia S, Trape S, Russo R, Gentile MC, Cangemi R, Loffredo L, Pignatelli P, Violi F, and group I. Relationship between platelet and urinary 8-iso-PGF ${ }_{2 \text { alpha }}$ levels in subjects with different degrees of NOX2 regulation. J Am Heart Assoc 2: e000198, 2013.

54. Carnevale R, Loffredo L, Del Ben M, Angelico F, Nocella C, Petruccioli A, Bartimoccia S, Monticolo R, Cava E, and Violi F. Extra virgin olive oil improves post-prandial glycemic and lipid profile in patients with impaired fasting glucose. Clin Nutr 36: 782-787, 2017.

55. Carnevale R, Loffredo L, Sanguigni V, Plebani A, Rossi P, Pignata C, Martire B, Finocchi A, Pietrogrande MC, Azzari C, Soresina AR, Martino S, Cirillo E, Martino F, Pignatelli P, and Violi F. Different degrees of NADPH oxidase 2 regulation and in vivo platelet activation: lesson from chronic granulomatous disease. J Am Heart Assoc 3: e000920, 2014.

56. Carnevale R, Pignatelli P, Nocella C, Loffredo L, Pastori D, Vicario T, Petruccioli A, Bartimoccia S, and Violi F. Extra virgin olive oil blunt post-prandial oxidative stress via NOX2 down-regulation. Atherosclerosis 235: 649658, 2014.

57. Carr AC, McCall MR, and Frei B. Oxidation of LDL by myeloperoxidase and reactive nitrogen species: reaction pathways and antioxidant protection. Arterioscler Thromb Vasc Biol 20: 1716-1723, 2000.

58. Castellani LW, Chang JJ, Wang X, Lusis AJ, and Reynolds WF. Transgenic mice express human MPO-463G/A alleles at atherosclerotic lesions, developing hyperlipidemia and obesity in -463G males. J Lipid Res 47: 13661377, 2006.

59. Cathcart MK. Regulation of superoxide anion production by NADPH oxidase in monocytes/macrophages: contributions to atherosclerosis. Arterioscler Thromb Vasc Biol 24: 23-28, 2004.

60. Celermajer DS, Sorensen KE, Spiegelhalter DJ, Georgakopoulos D, Robinson J, and Deanfield JE. Aging is associated with endothelial dysfunction in healthy men years before the age-related decline in women. $J$ Am Coll Cardiol 24: 471-476, 1994.

61. Channon KM. Tetrahydrobiopterin: regulator of endothelial nitric oxide synthase in vascular disease. Trends Cardiovasc Med 14: 323-327, 2004.

62. Cheng YJ, Imperatore G, Geiss LS, Wang J, Saydah SH, Cowie CC, and Gregg EW. Secular changes in the agespecific prevalence of diabetes among U.S. adults: 19882010. Diabetes Care 36: 2690-2696, 2013.

63. Cherki M, Berrougui H, Isabelle M, Cloutier M, Koumbadinga GA, and Khalil A. Effect of PON1 polymorphism on HDL antioxidant potential is blunted with aging. Exp Gerontol 42: 815-824, 2007. 
64. Cho CG, Kim HJ, Chung SW, Jung KJ, Shim KH, Yu BP, Yodoi J, and Chung HY. Modulation of glutathione and thioredoxin systems by calorie restriction during the aging process. Exp Gerontol 38: 539-548, 2003.

65. Cipollone F, Ciabattoni G, Patrignani P, Pasquale M, Di Gregorio D, Bucciarelli T, Davi G, Cuccurullo F, and Patrono C. Oxidant stress and aspirin-insensitive thromboxane biosynthesis in severe unstable angina. Circulation 102: 1007-1013, 2000.

66. Cipollone F, Mezzetti A, Porreca E, Di Febbo C, Nutini M, Fazia M, Falco A, Cuccurullo F, and Davi G. Association between enhanced soluble CD40L and prothrombotic state in hypercholesterolemia: effects of statin therapy. Circulation 106: 399-402, 2002.

67. Cook-Mills JM, Marchese ME, and Abdala-Valencia H. Vascular cell adhesion molecule-1 expression and signaling during disease: regulation by reactive oxygen species and antioxidants. Antioxid Redox Signal 15: 16071638, 2011.

68. Csanyi G, Taylor WR, and Pagano PJ. NOX and inflammation in the vascular adventitia. Free Radic Biol Med 47: 1254-1266, 2009.

69. Cunha FM, Caldeira da Silva CC, Cerqueira FM, and Kowaltowski AJ. Mild mitochondrial uncoupling as a therapeutic strategy. Curr Drug Targets 12: 783-789, 2011.

70. Cyrus T, Pratico D, Zhao L, Witztum JL, Rader DJ, Rokach J, FitzGerald GA, and Funk CD. Absence of 12/15lipoxygenase expression decreases lipid peroxidation and atherogenesis in apolipoprotein e-deficient mice. Circulation 103: 2277-2282, 2001.

71. Cyrus T, Yao Y, Ding T, Dogne JM, and Pratico D. Thromboxane receptor blockade improves the antiatherogenic effect of thromboxane A2 suppression in LDLR KO mice. Blood 109: 3291-3296, 2007.

72. Dal-Ros S, Bronner C, Auger C, and Schini-Kerth VB. Red wine polyphenols improve an established agingrelated endothelial dysfunction in the mesenteric artery of middle-aged rats: role of oxidative stress. Biochem Biophys Res Commun 419: 381-387, 2012.

73. Dal-Ros S, Zoll J, Lang AL, Auger C, Keller N, Bronner C, Geny B, and Schini-Kerth VB. Chronic intake of red wine polyphenols by young rats prevents aging-induced endothelial dysfunction and decline in physical performance: role of NADPH oxidase. Biochem Biophys Res Commun 404: 743-749, 2011.

74. Davì G, Ciabattoni G, Consoli A, Mezzetti A, Falco A, Santarone S, Pennese E, Vitacolonna E, Bucciarelli T, Costantini F, Capani F, and Patrono C. In vivo formation of 8-iso-prostaglandin f2alpha and platelet activation in diabetes mellitus: effects of improved metabolic control and vitamin E supplementation. Circulation 99: 224-229, 1999.

75. Davi G and Patrono C. Platelet activation and atherothrombosis. N Engl J Med 357: 2482-2494, 2007.

76. Davignon J and Ganz P. Role of endothelial dysfunction in atherosclerosis. Circulation 109: III27-III32, 2004.

77. Dayal S, Gu SX, Hutchins RD, Wilson KM, Wang Y, Fu $X$, and Lentz SR. Deficiency of superoxide dismutase impairs protein $\mathrm{C}$ activation and enhances susceptibility to experimental thrombosis. Arterioscler Thromb Vasc Biol 35: 1798-1804, 2015.

78. Dayal S, Wilson KM, Motto DG, Miller FJ, Jr., Chauhan AK, and Lentz SR. Hydrogen peroxide promotes aging- related platelet hyperactivation and thrombosis. Circulation 127: 1308-1316, 2013.

79. de Haan JB, Bladier C, Lotfi-Miri M, Taylor J, Hutchinson P, Crack PJ, Hertzog P, and Kola I. Fibroblasts derived from Gpx1 knockout mice display senescent-like features and are susceptible to $\mathrm{H}_{2} \mathrm{O}_{2}$-mediated cell death. Free Radic Biol Med 36: 53-64, 2004.

80. De Lorgeril M, Salen P, Martin JL, Mamelle N, Monjaud I, Touboul P, and Delaye J. Effect of a mediterranean type of diet on the rate of cardiovascular complications in patients with coronary artery disease. Insights into the cardioprotective effect of certain nutriments. $J$ Am Coll Cardiol 28: 1103-1108, 1996.

81. de Oliveira RM. Klotho RNAi induces premature senescence of human cells via a p53/p21 dependent pathway. FEBS Lett 580: 5753-5758, 2006.

82. Del Ben M, Fabiani M, Loffredo L, Polimeni L, Carnevale R, Baratta F, Brunori M, Albanese F, Augelletti T, Violi F, and Angelico F. Oxidative stress mediated arterial dysfunction in patients with obstructive sleep apnoea and the effect of continuous positive airway pressure treatment. BMC Pulm Med 12: 36, 2012.

83. Del Principe D, Menichelli A, De Matteis W, Di Giulio S, Giordani M, Savini I, and Agro AF. Hydrogen peroxide is an intermediate in the platelet activation cascade triggered by collagen, but not by thrombin. Thromb Res 62: 365375, 1991.

84. Dennery PA. Regulation and role of heme oxygenase in oxidative injury. Curr Top Cell Regul 36: 181-199, 2000.

85. Devarajan A, Bourquard N, Hama S, Navab M, Grijalva VR, Morvardi S, Clarke CF, Vergnes L, Reue K, Teiber JF, and Reddy ST. Paraoxonase 2 deficiency alters mitochondrial function and exacerbates the development of atherosclerosis. Antioxid Redox Signal 14: 341-351, 2011.

86. Dikalova AE, Gongora MC, Harrison DG, Lambeth JD, Dikalov S, and Griendling KK. Upregulation of Nox1 in vascular smooth muscle leads to impaired endotheliumdependent relaxation via eNOS uncoupling. Am J Physiol Heart Circ Physiol 299: H673-H679, 2010.

87. Dinkova-Kostova AT and Talalay P. Direct and indirect antioxidant properties of inducers of cytoprotective proteins. Mol Nutr Food Res 52 Suppl 1: S128-S138, 2008.

88. Dobrian AD, Lieb DC, Cole BK, Taylor-Fishwick DA, Chakrabarti SK, and Nadler JL. Functional and pathological roles of the 12- and 15-lipoxygenases. Prog Lipid Res 50: 115-131, 2011.

89. Douglas G, Bendall JK, Crabtree MJ, Tatham AL, Carter $\mathrm{EE}$, Hale $\mathrm{AB}$, and Channon KM. Endothelial-specific Nox2 overexpression increases vascular superoxide and macrophage recruitment in ApoE(-)/(-) mice. Cardiovasc Res 94: 20-29, 2012.

90. Driver JA, Djousse L, Logroscino G, Gaziano JM, and Kurth T. Incidence of cardiovascular disease and cancer in advanced age: prospective cohort study. BMJ 337: a2467, 2008.

91. Drummond GR and Sobey CG. Endothelial NADPH oxidases: which NOX to target in vascular disease? Trends Endocrinol Metab 25: 452-463, 2014.

92. Du J, Zhou Y, Su X, Yu JJ, Khan S, Jiang H, Kim J, Woo J, Kim JH, Choi BH, He B, Chen W, Zhang S, Cerione RA, Auwerx J, Hao Q, and Lin H. Sirt5 is a NADdependent protein lysine demalonylase and desuccinylase. Science 334: 806-809, 2011. 
93. Eikelboom JW, Hankey GJ, Thom J, Bhatt DL, Steg PG, Montalescot G, Johnston SC, Steinhubl SR, Mak KH, Easton JD, Hamm C, Hu T, Fox KA, Topol EJ, Clopidogrel for High Atherothrombotic R, Ischemic Stabilization $\mathrm{M}$, and Avoidance I. Incomplete inhibition of thromboxane biosynthesis by acetylsalicylic acid: determinants and effect on cardiovascular risk. Circulation 118: 1705-1712, 2008.

94. El Assar M, Angulo J, and Rodriguez-Manas L. Oxidative stress and vascular inflammation in aging. Free Radic Biol Med 65: 380-401, 2013.

95. Elbini Dhouib I, Jallouli M, Annabi A, Gharbi N, Elfazaa $\mathrm{S}$, and Lasram MM. A minireview on $\mathrm{N}$-acetylcysteine: an old drug with new approaches. Life Sci 151: 359-363, 2016.

96. Elchuri S, Oberley TD, Qi W, Eisenstein RS, Jackson Roberts L, Van Remmen H, Epstein CJ, and Huang TT. CuZnSOD deficiency leads to persistent and widespread oxidative damage and hepatocarcinogenesis later in life. Oncogene 24: 367-380, 2005.

97. Elosua R, Lluis-Ganella C, Subirana I, Havulinna A, Lall K, Lucas G, Sayols-Baixeras S, Pietila A, Alver M, Cabrera de Leon A, Senti M, Siscovick D, Mellander O, Fischer K, Salomaa V, and Marrugat J. Cardiovascular risk factors and ischemic heart disease: is the confluence of risk factors greater than the parts? A genetic approach. Circ Cardiovasc Genet 9: 279-286, 2016.

98. Ervin RB. Prevalence of metabolic syndrome among adults 20 years of age and over, by sex, age, race and ethnicity, and body mass index: United States, 20032006. Natl Health Stat Report 5: 1-7, 2009.

99. Estruch R, Ros E, Salas-Salvado J, Covas MI, Corella D, Aros F, Gomez-Gracia E, Ruiz-Gutierrez V, Fiol M, Lapetra J, Lamuela-Raventos RM, Serra-Majem L, Pinto X, Basora J, Munoz MA, Sorli JV, Martinez JA, MartinezGonzalez MA, and Investigators PS. Primary prevention of cardiovascular disease with a Mediterranean diet. $N$ Engl J Med 368: 1279-1290, 2013.

100. Exner M, Schillinger M, Minar E, Mlekusch W, Schlerka G, Haumer M, Mannhalter C, and Wagner O. Heme oxygenase-1 gene promoter microsatellite polymorphism is associated with restenosis after percutaneous transluminal angioplasty. J Endovasc Ther 8: 433-440, 2001.

101. Fan Q, Chen M, Fang X, Lau WB, Xue L, Zhao L, Zhang H, Liang YH, Bai X, Niu HY, Ye J, Chen Q, Yang X, and Liu M. Aging might augment reactive oxygen species (ROS) formation and affect reactive nitrogen species (RNS) level after myocardial ischemia/reperfusion in both humans and rats. Age (Dordr) 35: 1017-1026, 2013.

102. Farro I, Bia D, Zocalo Y, Torrado J, Farro F, Florio L, Lluberas R, and Armentano RL. Aging-related changes and reference values for the carotid intima-media thickness in a Uruguayan population. Conf Proc IEEE Eng Med Biol Soc 2012: 5622-5625, 2012.

103. Favaloro EJ, Franchini M, and Lippi G. Aging hemostasis: changes to laboratory markers of hemostasis as we age-a narrative review. Semin Thromb Hemost 40: 621-633, 2014.

104. Ferro D, Basili S, Alessandri C, Cara D, and Violi F. Inhibition of tissue-factor-mediated thrombin generation by simvastatin. Atherosclerosis 149: 111-116, 2000.

105. Ferro D, Basili S, Pratico D, Iuliano L, FitzGerald GA, and Violi F. Vitamin E reduces monocyte tissue factor expression in cirrhotic patients. Blood 93: 2945-2950, 1999.
106. Fleg JL, O'Connor F, Gerstenblith G, Becker LC, Clulow J, Schulman SP, and Lakatta EG. Impact of age on the cardiovascular response to dynamic upright exercise in healthy men and women. $J$ Appl Physiol (1985) 78: 890-900, 1995.

107. Fletcher AE, Breeze E, and Shetty PS. Antioxidant vitamins and mortality in older persons: findings from the nutrition add-on study to the Medical Research Council Trial of Assessment and Management of Older People in the Community. Am J Clin Nutr 78: 999-1010, 2003.

108. Focks JJ, van Schaik A, Clappers N, van Dijk EG, van Oijen MG, Verheugt FW, and Peters WH. Assessment of plasma aminothiol levels and the association with recurrent atherothrombotic events in patients hospitalized for an acute coronary syndrome: a prospective study. Clin Chem Lab Med 51: 2187-2193, 2013.

109. Fogelstrand $\mathrm{P}$ and Boren J. Retention of atherogenic lipoproteins in the artery wall and its role in atherogenesis. Nutr Metab Cardiovasc Dis 22: 1-7, 2012.

110. Forman HJ. Glutathione-from antioxidant to posttranslational modifier. Arch Biochem Biophys 595: 64-67, 2016.

111. Fougere B, Boulanger E, Nourhashemi F, Guyonnet S, and Cesari M. Chronic inflammation: accelerator of biological aging. J Gerontol A Biol Sci Med Sci 72: 12181225, 2017.

112. Franchini M. Hemostasis and aging. Crit Rev Oncol Hematol 60: 144-151, 2006.

113. Freedman JE, Loscalzo J, Benoit SE, Valeri CR, Barnard MR, and Michelson AD. Decreased platelet inhibition by nitric oxide in two brothers with a history of arterial thrombosis. J Clin Invest 97: 979-987, 1996.

114. Fukai T and Ushio-Fukai M. Superoxide dismutases: role in redox signaling, vascular function, and diseases. Antioxid Redox Signal 15: 1583-1606, 2011.

115. Funk CD, Chen XS, Johnson EN, and Zhao L. Lipoxygenase genes and their targeted disruption. Prostaglandins Other Lipid Mediat 68-69: 303-312, 2002.

116. Galley HF and Webster NR. Physiology of the endothelium. Br J Anaesth 93: 105-113, 2004.

117. Gammelmark A, Nielsen MS, Lundbye-Christensen S, Tjonneland A, Schmidt EB, and Overvad K. Common polymorphisms in the 5-lipoxygenase pathway and risk of incident myocardial infarction: a Danish case-cohort study. PLoS One 11: e0167217, 2016.

118. Ganji SH, Qin S, Zhang L, Kamanna VS, and Kashyap ML. Niacin inhibits vascular oxidative stress, redoxsensitive genes, and monocyte adhesion to human aortic endothelial cells. Atherosclerosis 202: 68-75, 2009.

119. Gautam N, Das S, Kar Mahapatra S, Chakraborty SP, Kundu PK, and Roy S. Age associated oxidative damage in lymphocytes. Oxid Med Cell Longev 3: 275-282, 2010.

120. Gertow K, Nobili E, Folkersen L, Newman JW, Pedersen TL, Ekstrand J, Swedenborg J, Kuhn H, Wheelock CE, Hansson GK, Hedin U, Haeggstrom JZ, and Gabrielsen A. 12- and 15-Lipoxygenases in human carotid atherosclerotic lesions: associations with cerebrovascular symptoms. Atherosclerosis 215: 411-416, 2011.

121. Gey KF, Puska P, Jordan P, and Moser UK. Inverse correlation between plasma vitamin $\mathrm{E}$ and mortality from ischemic heart disease in cross-cultural epidemiology. Am J Clin Nutr 53: 326S-334S, 1991.

122. Gladyshev VN. The free radical theory of aging is dead. Long live the damage theory! Antioxid Redox Signal 20: 727-731, 2014. 
123. Goldschmidt-Clermont PJ. Loss of bone marrow-derived vascular progenitor cells leads to inflammation and atherosclerosis. Am Heart J 146: S5-S12, 2003.

124. Goldschmidt-Clermont PJ, Creager MA, Losordo DW, Lam GK, Wassef M, and Dzau VJ. Atherosclerosis 2005: recent discoveries and novel hypotheses. Circulation 112: 3348-3353, 2005.

125. Gross M, Steffes M, Jacobs DR, Jr., Yu X, Lewis L, Lewis CE, and Loria CM. Plasma F2-isoprostanes and coronary artery calcification: the CARDIA Study. Clin Chem 51: 125-131, 2005.

126. Group DS. Age- and sex-specific prevalences of diabetes and impaired glucose regulation in 13 European cohorts. Diabetes Care 26: 61-69, 2003.

127. Gu M, Love H, Schofield D, Turkie W, Odom N, and Braganza JM. A pilot study of blood antioxidant and free radical marker profiles in patients awaiting coronary artery bypass grafting. Clin Chim Acta 252: 181-195, 1996.

128. Guagnano MT, Ferroni P, Santilli F, Paoletti V, Manigrasso MR, Pescara L, Cuccurullo C, Ciabattoni G, and Davi G. Determinants of platelet activation in hypertensives with microalbuminuria. Free Radic Biol Med 46: 922-927, 2009.

129. Guiding Principles for the Care of Older Adults with Multimorbidity: An Approach for Clinicians. Guiding principles for the care of older adults with multimorbidity: an approach for clinicians: American Geriatrics Society Expert Panel on the Care of Older Adults with Multimorbidity. J Am Geriatr Soc 60: E1-E25, 2012.

130. Guo Z, Ran Q, Roberts LJ, 2nd, Zhou L, Richardson A, Sharan C, Wu D, and Yang H. Suppression of atherogenesis by overexpression of glutathione peroxidase- 4 in apolipoprotein E-deficient mice. Free Radic Biol Med 44: 343-352, 2008

131. Guzik TJ, Sadowski J, Guzik B, Jopek A, Kapelak B, Przybylowski P, Wierzbicki K, Korbut R, Harrison DG, and Channon KM. Coronary artery superoxide production and nox isoform expression in human coronary artery disease. Arterioscler Thromb Vasc Biol 26: 333-339, 2006.

132. Han L, Li M, Liu Y, Han C, and Ye P. Atorvastatin may delay cardiac aging by upregulating peroxisome proliferator-activated receptors in rats. Pharmacology 89: 74-82, 2012.

133. Harats D, Shaish A, George J, Mulkins M, Kurihara H, Levkovitz H, and Sigal E. Overexpression of 15lipoxygenase in vascular endothelium accelerates early atherosclerosis in LDL receptor-deficient mice. Arterioscler Thromb Vasc Biol 20: 2100-2105, 2000.

134. Harkewicz R, Hartvigsen K, Almazan F, Dennis EA, Witztum JL, and Miller YI. Cholesteryl ester hydroperoxides are biologically active components of minimally oxidized low density lipoprotein. J Biol Chem 283: 10241-10251, 2008.

135. Harman D. Aging: a theory based on free radical and radiation chemistry. J Gerontol 11: 298-300, 1956.

136. Hayek SS, MacNamara J, Tahhan AS, Awad M, Yadalam A, Ko YA, Healy S, Hesaroieh I, Ahmed H, Gray B, Sher SS, Ghasemzadeh N, Patel R, Kim J, Waller EK, and Quyyumi AA. Circulating progenitor cells identify peripheral arterial disease in patients with coronary artery disease. Circ Res 119: 564-571, 2016.

137. Hayflick L. The limited in vitro lifetime of human diploid cell strains. Exp Cell Res 37: 614-636, 1965.
138. He T, Joyner MJ, and Katusic ZS. Aging decreases expression and activity of glutathione peroxidase- 1 in human endothelial progenitor cells. Microvasc Res 78: 447452, 2009.

139. Heller R, Munscher-Paulig F, Grabner R, and Till U. LAscorbic acid potentiates nitric oxide synthesis in endothelial cells. J Biol Chem 274: 8254-8260, 1999.

140. Herkert O, Diebold I, Brandes RP, Hess J, Busse R, and Gorlach A. NADPH oxidase mediates tissue factordependent surface procoagulant activity by thrombin in human vascular smooth muscle cells. Circulation 105: 2030-2036, 2002.

141. Hersberger M. Potential role of the lipoxygenase derived lipid mediators in atherosclerosis: leukotrienes, lipoxins and resolvins. Clin Chem Lab Med 48: 1063-1073, 2010.

142. Hertog MG, Feskens EJ, Hollman PC, Katan MB, and Kromhout D. Dietary antioxidant flavonoids and risk of coronary heart disease: the Zutphen Elderly Study. Lancet 342: 1007-1011, 1993.

143. Heslop CL, Frohlich JJ, and Hill JS. Myeloperoxidase and C-reactive protein have combined utility for long-term prediction of cardiovascular mortality after coronary angiography. J Am Coll Cardiol 55: 1102-1109, 2010.

144. Hill JM, Zalos G, Halcox JP, Schenke WH, Waclawiw MA, Quyyumi AA, and Finkel T. Circulating endothelial progenitor cells, vascular function, and cardiovascular risk. N Engl J Med 348: 593-600, 2003.

145. Holbrook A, Schulman S, Witt DM, Vandvik PO, Fish J, Kovacs MJ, Svensson PJ, Veenstra DL, Crowther M, Guyatt GH, and American College of Chest P. Evidencebased management of anticoagulant therapy: Antithrombotic Therapy and Prevention of Thrombosis, 9th ed: American College of Chest Physicians Evidence-Based Clinical Practice Guidelines. Chest 141: e152S-e184S, 2012.

146. Hollman PC, Cassidy A, Comte B, Heinonen M, Richelle M, Richling E, Serafini M, Scalbert A, Sies H, and Vidry $\mathrm{S}$. The biological relevance of direct antioxidant effects of polyphenols for cardiovascular health in humans is not established. J Nutr 141: 989S-1009S, 2011.

147. Holvoet P, Kritchevsky SB, Tracy RP, Mertens A, Rubin SM, Butler J, Goodpaster B, and Harris TB. The metabolic syndrome, circulating oxidized LDL, and risk of myocardial infarction in well-functioning elderly people in the health, aging, and body composition cohort. Diabetes 53: 1068-1073, 2004.

148. Holvoet P, Vanhaecke J, Janssens S, Van de Werf F, and Collen D. Oxidized LDL and malondialdehyde-modified LDL in patients with acute coronary syndromes and stable coronary artery disease. Circulation 98: 14871494, 1998.

149. Howard G, Sharrett AR, Heiss G, Evans GW, Chambless LE, Riley WA, and Burke GL. Carotid artery intimalmedial thickness distribution in general populations as evaluated by B-mode ultrasound. ARIC Investigators. Stroke 24: 1297-1304, 1993.

150. Hull TD, Agarwal A, and George JF. The mononuclear phagocyte system in homeostasis and disease: a role for heme oxygenase-1. Antioxid Redox Signal 20: 1770-1788, 2014.

151. Huveneers S, Daemen MJ, and Hordijk PL. Between Rho(k) and a hard place: the relation between vessel wall stiffness, endothelial contractility, and cardiovascular disease. Circ Res 116: 895-908, 2015. 
152. Huxley RR, Filion KB, Konety S, and Alonso A. Metaanalysis of cohort and case-control studies of type 2 diabetes mellitus and risk of atrial fibrillation. Am J Cardiol 108: 56-62, 2011.

153. Ingenbleek $Y$ and Kimura $H$. Nutritional essentiality of sulfur in health and disease. Nutr Rev 71: 413-432, 2013.

154. Italiano D, Lena AM, Melino G, and Candi E. Identification of NCF2/p67phox as a novel p53 target gene. Cell Cycle 11: 4589-4596, 2012.

155. Iuliano L, Mauriello A, Sbarigia E, Spagnoli LG, and Violi F. Radiolabeled native low-density lipoprotein injected into patients with carotid stenosis accumulates in macrophages of atherosclerotic plaque: effect of vitamin $\mathrm{E}$ supplementation. Circulation 101: 1249-1254, 2000.

156. Iuliano L, Micheletta F, Maranghi M, Frati G, Diczfalusy $\mathrm{U}$, and Violi F. Bioavailability of vitamin $\mathrm{E}$ as function of food intake in healthy subjects: effects on plasma peroxide-scavenging activity and cholesterol-oxidation products. Arterioscler Thromb Vasc Biol 21: E34-E37, 2001.

157. Iuliano L, Pratico D, Greco C, Mangieri E, Scibilia G, FitzGerald GA, and Violi F. Angioplasty increases coronary sinus F2-isoprostane formation: evidence for in vivo oxidative stress during PTCA. J Am Coll Cardiol 37: 7680, 2001

158. Jain SK, Krueger KS, McVie R, Jaramillo JJ, Palmer M, and Smith T. Relationship of blood thromboxane-B2 $\left(\mathrm{TxB}_{2}\right)$ with lipid peroxides and effect of vitamin $\mathrm{E}$ and placebo supplementation on $\mathrm{TxB}_{2}$ and lipid peroxide levels in type 1 diabetic patients. Diabetes Care 21: 15111516, 1998.

159. Jaiswal S, Natarajan P, Silver AJ, Gibson CJ, Bick AG, Shvartz E, McConkey M, Gupta N, Gabriel S, Ardissino D, Baber U, Mehran R, Fuster V, Danesh J, Frossard P, Saleheen D, Melander O, Sukhova GK, Neuberg D, Libby $\mathrm{P}$, Kathiresan S, and Ebert BL. Clonal hematopoiesis and risk of atherosclerotic cardiovascular disease. $N$ Engl $J$ Med 377: 111-121, 2017.

160. Janszky I, Mukamal KJ, Ljung R, Ahnve S, Ahlbom A, and Hallqvist J. Chocolate consumption and mortality following a first acute myocardial infarction: the Stockholm Heart Epidemiology Program. J Intern Med 266: 248-257, 2009.

161. Jialal I and Grundy SM. Preservation of the endogenous antioxidants in low density lipoprotein by ascorbate but not probucol during oxidative modification. J Clin Invest 87: 597-601, 1991.

162. Jin RC, Mahoney CE, Coleman Anderson L, Ottaviano F, Croce K, Leopold JA, Zhang YY, Tang SS, Handy DE, and Loscalzo J. Glutathione peroxidase-3 deficiency promotes platelet-dependent thrombosis in vivo. Circulation 123: 1963-1973, 2011.

163. Johnston N, Jernberg T, Lagerqvist B, Siegbahn A, and Wallentin L. Oxidized low-density lipoprotein as a predictor of outcome in patients with unstable coronary artery disease. Int J Cardiol 113: 167-173, 2006.

164. Johnston SC, Amarenco P, Albers GW, Denison H, Easton JD, Evans SR, Held P, Jonasson J, Minematsu K, Molina CA, Wang Y, Wong KS, Committee SS, and Investigators. Ticagrelor versus aspirin in acute stroke or transient ischemic attack. $N$ Engl J Med 375: 35-43, 2016.

165. Jones DP, Mody VC, Jr., Carlson JL, Lynn MJ, and Sternberg P, Jr. Redox analysis of human plasma allows separation of pro-oxidant events of aging from decline in antioxidant defenses. Free Radic Biol Med 33: 12901300, 2002.

166. Jonsson AL and Backhed F. Role of gut microbiota in atherosclerosis. Nat Rev Cardiol 14: 79-87, 2017.

167. Jorgensen KA, Dyerberg J, Olesen AS, and Stoffersen E. Acetylsalicylic acid, bleeding time and age. Thromb Res 19: 799-805, 1980.

168. Judkins CP, Diep H, Broughton BR, Mast AE, Hooker EU, Miller AA, Selemidis S, Dusting GJ, Sobey CG, and Drummond GR. Direct evidence of a role for Nox2 in superoxide production, reduced nitric oxide bioavailability, and early atherosclerotic plaque formation in $\mathrm{ApoE}^{-/-}$ mice. Am J Physiol Heart Circ Physiol 298: H24-H32, 2010.

169. Kamzalov S and Sohal RS. Effect of age and caloric restriction on coenzyme Q and alpha-tocopherol levels in the rat. Exp Gerontol 39: 1199-1205, 2004.

170. Kannel WB and McGee DL. Update on some epidemiologic features of intermittent claudication: the Framingham Study. J Am Geriatr Soc 33: 13-18, 1985.

171. Karra R, Vemullapalli S, Dong C, Herderick EE, Song X, Slosek K, Nevins JR, West M, Goldschmidt-Clermont PJ, and Seo D. Molecular evidence for arterial repair in atherosclerosis. Proc Natl Acad Sci U S A 102: 16789-16794, 2005.

172. Keys A, Menotti A, Karvonen MJ, Aravanis C, Blackburn H, Buzina R, Djordjevic BS, Dontas AS, Fidanza F, Keys $\mathrm{MH}$, et al. The diet and 15-year death rate in the seven countries study. Am J Epidemiol 124: 903-915, 1986.

173. Khatri JJ, Johnson C, Magid R, Lessner SM, Laude KM, Dikalov SI, Harrison DG, Sung HJ, Rong Y, and Galis ZS. Vascular oxidant stress enhances progression and angiogenesis of experimental atheroma. Circulation 109: 520$525,2004$.

174. Kilic U, Gok O, Erenberk U, Dundaroz MR, Torun E, Kucukardali Y, Elibol-Can B, Uysal O, and Dundar T. A remarkable age-related increase in SIRT1 protein expression against oxidative stress in elderly: SIRT1 gene variants and longevity in human. PLoS One 10: e0117954, 2015.

175. Kim JY, Hyun YJ, Jang Y, Lee BK, Chae JS, Kim SE, Yeo HY, Jeong TS, Jeon DW, and Lee JH. Lipoproteinassociated phospholipase $A_{2}$ activity is associated with coronary artery disease and markers of oxidative stress: a case-control study. Am J Clin Nutr 88: 630-637, 2008.

176. Kim YC, Masutani H, Yamaguchi Y, Itoh K, Yamamoto $\mathrm{M}$, and Yodoi J. Hemin-induced activation of the thioredoxin gene by Nrf2. A differential regulation of the antioxidant responsive element by a switch of its binding factors. J Biol Chem 276: 18399-18406, 2001.

177. Koenig W, Karakas M, Zierer A, Herder C, Baumert J, Meisinger $\mathrm{C}$, and Thorand $\mathrm{B}$. Oxidized LDL and the risk of coronary heart disease: results from the MONICA/ KORA Augsburg Study. Clin Chem 57: 1196-1200, 2011.

178. Koide S, Kugiyama K, Sugiyama S, Nakamura S, Fukushima H, Honda O, Yoshimura M, and Ogawa H. Association of polymorphism in glutamate-cysteine ligase catalytic subunit gene with coronary vasomotor dysfunction and myocardial infarction. J Am Coll Cardiol 41: 539-545, 2003.

179. Konior A, Schramm A, Czesnikiewicz-Guzik M, and Guzik TJ. NADPH oxidases in vascular pathology. Antioxid Redox Signal 20: 2794-2814, 2014. 
180. Kovacic JC, Moreno P, Nabel EG, Hachinski V, and Fuster V. Cellular senescence, vascular disease, and aging: part 2 of a 2-part review: clinical vascular disease in the elderly. Circulation 123: 1900-1910, 2011.

181. Kroger K, Stang A, Kondratieva J, Moebus S, Beck E, Schmermund A, Mohlenkamp S, Dragano N, Siegrist J, Jockel KH, Erbel R, and Heinz Nixdorf Recall Study G. Prevalence of peripheral arterial disease-results of the Heinz Nixdorf recall study. Eur J Epidemiol 21: 279-285, 2006.

182. Kuhlencordt PJ, Chen J, Han F, Astern J, and Huang PL. Genetic deficiency of inducible nitric oxide synthase reduces atherosclerosis and lowers plasma lipid peroxides in apolipoprotein E-knockout mice. Circulation 103: 30993104, 2001.

183. Kuhlencordt PJ, Gyurko R, Han F, Scherrer-Crosbie M, Aretz TH, Hajjar R, Picard MH, and Huang PL. Accelerated atherosclerosis, aortic aneurysm formation, and ischemic heart disease in apolipoprotein E/endothelial nitric oxide synthase double-knockout mice. Circulation 104: 448-454, 2001.

184. Kuhlencordt PJ, Hotten S, Schodel J, Rutzel S, Hu K, Widder J, Marx A, Huang PL, and Ertl G. Atheroprotective effects of neuronal nitric oxide synthase in apolipoprotein e knockout mice. Arterioscler Thromb Vasc Biol 26: 1539-1544, 2006.

185. Kuhns DB, Alvord WG, Heller T, Feld JJ, Pike KM, Marciano BE, Uzel G, DeRavin SS, Priel DA, Soule BP, Zarember KA, Malech HL, Holland SM, and Gallin JI. Residual NADPH oxidase and survival in chronic granulomatous disease. $N$ Engl J Med 363: 2600-2610, 2010.

186. Kumar S and Bandyopadhyay U. Free heme toxicity and its detoxification systems in human. Toxicol Lett 157: 175-188, 2005.

187. Kural KC, Tandon N, Skoblov M, Kel-Margoulis OV, and Baranova AV. Pathways of aging: comparative analysis of gene signatures in replicative senescence and stress induced premature senescence. BMC Genomics 17: 1030, 2016.

188. Kuro-o M. Klotho and aging. Biochim Biophys Acta 1790: 1049-1058, 2009.

189. Kwak JY, Takeshige K, Cheung BS, and Minakami S. Bilirubin inhibits the activation of superoxide-producing NADPH oxidase in a neutrophil cell-free system. Biochim Biophys Acta 1076: 369-373, 1991.

190. Lafont AM, Chai YC, Cornhill JF, Whitlow PL, Howe $\mathrm{PH}$, and Chisolm GM. Effect of alpha-tocopherol on restenosis after angioplasty in a model of experimental atherosclerosis. J Clin Invest 95: 1018-1025, 1995.

191. Laggner H, Muellner MK, Schreier S, Sturm B, Hermann M, Exner M, Gmeiner BM, and Kapiotis S. Hydrogen sulphide: a novel physiological inhibitor of LDL atherogenic modification by HOCl. Free Radic Res 41: 741-747, 2007.

192. Lakatta EG and Levy D. Arterial and cardiac aging: major shareholders in cardiovascular disease enterprises: Part I: aging arteries: a "set up" for vascular disease. Circulation 107: 139-146, 2003.

193. Lang CA, Naryshkin S, Schneider DL, Mills BJ, and Lindeman RD. Low blood glutathione levels in healthy aging adults. J Lab Clin Med 120: 720-725, 1992.

194. Langbein H, Brunssen C, Hofmann A, Cimalla P, Brux M, Bornstein SR, Deussen A, Koch E, and Morawietz H. NADPH oxidase 4 protects against development of en- dothelial dysfunction and atherosclerosis in LDL receptor deficient mice. Eur Heart J 37: 1753-1761, 2016.

195. Lapenna D, de Gioia S, Ciofani G, Mezzetti A, Ucchino S, Calafiore AM, Napolitano AM, Di Ilio C, and Cuccurullo F. Glutathione-related antioxidant defenses in human atherosclerotic plaques. Circulation 97: 1930-1934, 1998.

196. Laukkanen MO, Lehtolainen P, Turunen P, Aittomaki S, Oikari P, Marklund SL, and Yla-Herttuala S. Rabbit extracellular superoxide dismutase: expression and effect on LDL oxidation. Gene 254: 173-179, 2000.

197. LeLeiko RM, Vaccari CS, Sola S, Merchant N, Nagamia $\mathrm{SH}$, Thoenes M, and Khan BV. Usefulness of elevations in serum choline and free F2)-isoprostane to predict 30-day cardiovascular outcomes in patients with acute coronary syndrome. Am J Cardiol 104: 638-643, 2009.

198. Lesniewski LA, Connell ML, Durrant JR, Folian BJ, Anderson MC, Donato AJ, and Seals DR. B6D2F1 Mice are a suitable model of oxidative stress-mediated impaired endothelium-dependent dilation with aging. J Gerontol A Biol Sci Med Sci 64: 9-20, 2009.

199. $\mathrm{Li} \mathrm{H}$ and Forstermann U. Nitric oxide in the pathogenesis of vascular disease. J Pathol 190: 244-254, 2000.

200. Li JM, Fan LM, Christie MR, and Shah AM. Acute tumor necrosis factor alpha signaling via NADPH oxidase in microvascular endothelial cells: role of p47phox phosphorylation and binding to TRAF4. Mol Cell Biol 25: 2320-2330, 2005.

201. Li JM, Fan LM, George VT, and Brooks G. Nox2 regulates endothelial cell cycle arrest and apoptosis via p21cip1 and p53. Free Radic Biol Med 43: 976-986, 2007.

202. Li S, Chen W, Srinivasan SR, Bond MG, Tang R, Urbina EM, and Berenson GS. Childhood cardiovascular risk factors and carotid vascular changes in adulthood: the Bogalusa Heart Study. JAMA 290: 2271-2276, 2003.

203. Li SH, Tian HB, Zhao HJ, Chen LH, and Cui LQ. The acute effects of grape polyphenols supplementation on endothelial function in adults: meta-analyses of controlled trials. PLoS One 8: e69818, 2013.

204. Liao D, Arnett DK, Tyroler HA, Riley WA, Chambless LE, Szklo M, and Heiss G. Arterial stiffness and the development of hypertension. The ARIC study. Hypertension 34: 201-206, 1999.

205. Lip GY, Nieuwlaat R, Pisters R, Lane DA, and Crijns HJ. Refining clinical risk stratification for predicting stroke and thromboembolism in atrial fibrillation using a novel risk factor-based approach: the euro heart survey on atrial fibrillation. Chest 137: 263-272, 2010.

206. Liu Y, Davidson BP, Yue Q, Belcik T, Xie A, Inaba Y, McCarty OJ, Tormoen GW, Zhao Y, Ruggeri ZM, Kaufmann BA, and Lindner JR. Molecular imaging of inflammation and platelet adhesion in advanced atherosclerosis effects of antioxidant therapy with NADPH oxidase inhibition. Circ Cardiovasc Imaging 6: 74-82, 2013.

207. Loffredo L, Carnevale R, Cangemi R, Angelico F, Augelletti T, Di Santo S, Calabrese CM, Della Volpe L, Pignatelli P, Perri L, Basili S, and Violi F. NOX2 upregulation is associated with artery dysfunction in patients with peripheral artery disease. Int J Cardiol 165: 184-192, 2013.

208. Loffredo L, Carnevale R, Perri L, Catasca E, Augelletti T, Cangemi R, Albanese F, Piccheri C, Nocella C, Pignatelli $\mathrm{P}$, and Violi $\mathrm{F}$. NOX2-mediated arterial dysfunction in smokers: acute effect of dark chocolate. Heart 97: 17761781, 2011. 
209. Loffredo L, Carnevale R, Sanguigni V, Plebani A, Rossi P, Pignata C, De Mattia D, Finocchi A, Martire B, Pietrogrande MC, Martino S, Gambineri E, Giardino G, Soresina AR, Martino F, Pignatelli P, and Violi F. Does NADPH oxidase deficiency cause artery dilatation in humans? Antioxid Redox Signal 18: 1491-1496, 2013.

210. Loffredo L, Martino F, Carnevale R, Pignatelli P, Catasca E, Perri L, Calabrese CM, Palumbo MM, Baratta F, Del Ben M, Angelico F, and Violi F. Obesity and hypercholesterolemia are associated with NOX2 generated oxidative stress and arterial dysfunction. J Pediatr 161: 10041009, 2012.

211. Loffredo L, Perri L, Catasca E, Pignatelli P, Brancorsini M, Nocella C, De Falco E, Bartimoccia S, Frati G, Carnevale R, and Violi F. Dark chocolate acutely improves walking autonomy in patients with peripheral artery disease. J Am Heart Assoc 3: e001072, 2014.

212. Loffredo L, Perri L, Di Castelnuovo A, Iacoviello L, De Gaetano G, and Violi F. Supplementation with vitamin E alone is associated with reduced myocardial infarction: a meta-analysis. Nutr Metab Cardiovasc Dis 25: 354-363, 2015.

213. Loffredo L, Perri L, Nocella C, and Violi F. Antioxidant and antiplatelet activity by polyphenol-rich nutrients: focus on extra virgin olive oil and cocoa. $\mathrm{Br} J$ Clin Pharmacol 83: 96-102, 2017.

214. Loffredo L, Zicari AM, Occasi F, Perri L, Carnevale R, Angelico F, Del Ben M, Martino F, Nocella C, Savastano V, Cesoni Marcelli A, Duse M, and Violi F. Endothelial dysfunction and oxidative stress in children with sleep disordered breathing: role of NADPH oxidase. Atherosclerosis 240: 222-227, 2015.

215. Lorenz MW, Markus HS, Bots ML, Rosvall M, and Sitzer M. Prediction of clinical cardiovascular events with carotid intima-media thickness: a systematic review and meta-analysis. Circulation 115: 459-467, 2007.

216. Lyte JM, Gabler NK, and Hollis JH. Postprandial serum endotoxin in healthy humans is modulated by dietary fat in a randomized, controlled, cross-over study. Lipids Health Dis 15: 186, 2016.

217. Madamanchi NR, Moon SK, Hakim ZS, Clark S, Mehrizi A, Patterson C, and Runge MS. Differential activation of mitogenic signaling pathways in aortic smooth muscle cells deficient in superoxide dismutase isoforms. Arterioscler Thromb Vasc Biol 25: 950-956, 2005.

218. Madonna R, Novo G, and Balistreri CR. Cellular and molecular basis of the imbalance between vascular damage and repair in ageing and age-related diseases: as biomarkers and targets for new treatments. Mech Ageing Dev 159: 22-30, 2016.

219. Malle E, Waeg G, Schreiber R, Grone EF, Sattler W, and Grone HJ. Immunohistochemical evidence for the myeloperoxidase $/ \mathrm{H}_{2} \mathrm{O}_{2}$ /halide system in human atherosclerotic lesions: colocalization of myeloperoxidase and hypochloritemodified proteins. Eur J Biochem 267: 4495-4503, 2000.

220. Mangoni AA, Zinellu A, Carru C, Attia JR, and McEvoy M. Serum thiols and cardiovascular risk scores: a combined assessment of transsulfuration pathway components and substrate/product ratios. J Transl Med 11: 99, 2013.

221. Mani S, Li H, Untereiner A, Wu L, Yang G, Austin RC, Dickhout JG, Lhotak S, Meng QH, and Wang R. Decreased endogenous production of hydrogen sulfide accelerates atherosclerosis. Circulation 127: 2523-2534, 2013.
222. Mani S, Untereiner $\mathrm{A}, \mathrm{Wu} \mathrm{L}$, and Wang R. Hydrogen sulfide and the pathogenesis of atherosclerosis. Antioxid Redox Signal 20: 805-817, 2014.

223. Marchegiani F, Marra M, Spazzafumo L, James RW, Boemi M, Olivieri F, Cardelli M, Cavallone L, Bonfigli $\mathrm{AR}$, and Franceschi C. Paraoxonase activity and genotype predispose to successful aging. J Gerontol A Biol Sci Med Sci 61: 541-546, 2006.

224. Marletta MA. Nitric oxide synthase: aspects concerning structure and catalysis. Cell 78: 927-930, 1994.

225. Martin A and Frei B. Both intracellular and extracellular vitamin $\mathrm{C}$ inhibit atherogenic modification of LDL by human vascular endothelial cells. Arterioscler Thromb Vasc Biol 17: 1583-1590, 1997.

226. Martino F, Loffredo L, Carnevale R, Sanguigni V, Martino E, Catasca E, Zanoni C, Pignatelli P, and Violi F. Oxidative stress is associated with arterial dysfunction and enhanced intima-media thickness in children with hypercholesterolemia: the potential role of nicotinamideadenine dinucleotide phosphate oxidase. Pediatrics 122: e648-e655, 2008.

227. Maruhashi T, Soga J, Fujimura N, Idei N, Mikami S, Iwamoto Y, Kajikawa M, Matsumoto T, Hidaka T, Kihara Y, Chayama K, Noma K, Nakashima A, Goto C, Tomiyama H, Takase B, Yamashina A, and Higashi Y. Relationship between flow-mediated vasodilation and cardiovascular risk factors in a large community-based study. Heart 99: 1837-1842, 2013.

228. Matsumoto K, Sera Y, Nakamura H, Ueki Y, and Miyake S. Correlation between common carotid arterial wall thickness and ischemic stroke in patients with type 2 diabetes mellitus. Metabolism 51: 244-247, 2002.

229. Matsuno K, Yamada H, Iwata K, Jin D, Katsuyama M, Matsuki M, Takai S, Yamanishi K, Miyazaki M, Matsubara $\mathrm{H}$, and Yabe-Nishimura C. Nox 1 is involved in angiotensin II-mediated hypertension: a study in Nox1-deficient mice. Circulation 112: 2677-2685, 2005.

230. Mauri L, Kereiakes DJ, Yeh RW, Driscoll-Shempp P, Cutlip DE, Steg PG, Normand SL, Braunwald E, Wiviott SD, Cohen DJ, Holmes DR, Jr., Krucoff MW, Hermiller J, Dauerman HL, Simon DI, Kandzari DE, Garratt KN, Lee DP, Pow TK, Ver Lee P, Rinaldi MJ, Massaro JM, and Investigators DS. Twelve or 30 months of dual antiplatelet therapy after drug-eluting stents. $N$ Engl J Med 371: 2155-2166, 2014.

231. May JM and Harrison FE. Role of vitamin C in the function of the vascular endothelium. Antioxid Redox Signal 19: 2068-2083, 2013.

232. May JM, Qu ZC, Whitesell RR, and Cobb CE. Ascorbate recycling in human erythrocytes: role of GSH in reducing dehydroascorbate. Free Radic Biol Med 20: 543-551, 1996.

233. Mekonnen G, Hayek SS, Mehta PK, Li Q, Mahar E, Mou L, Kenkre TS, Petersen JW, Azarbal B, Samuels B, Anderson RD, Sedlak T, Zaya M, Agarwal M, Haftbaradaran A, Minissian M, Handberg E, Pepine CJ, Cogle CR, Bairey Merz CN, Waller EK, and Quyyumi AA. Circulating progenitor cells and coronary microvascular dysfunction: results from the NHLBI-sponsored Women's Ischemia Syndrome Evaluation-Coronary Vascular Dysfunction Study (WISE-CVD). Atherosclerosis 253: 111-117, 2016.

234. Meuwese MC, Stroes ES, Hazen SL, van Miert JN, Kuivenhoven JA, Schaub RG, Wareham NJ, Luben R, Kas- 
telein JJ, Khaw KT, and Boekholdt SM. Serum myeloperoxidase levels are associated with the future risk of coronary artery disease in apparently healthy individuals: the EPIC-Norfolk Prospective Population Study. J Am Coll Cardiol 50: 159-165, 2007.

235. Michelsen KS, Wong MH, Shah PK, Zhang W, Yano J, Doherty TM, Akira S, Rajavashisth TB, and Arditi M. Lack of Toll-like receptor 4 or myeloid differentiation factor 88 reduces atherosclerosis and alters plaque phenotype in mice deficient in apolipoprotein E. Proc Natl Acad Sci U S A 101: 10679-10684, 2004.

236. Migliaccio E, Giorgio M, Mele S, Pelicci G, Reboldi P, Pandolfi PP, Lanfrancone L, and Pelicci PG. The p66shc adaptor protein controls oxidative stress response and life span in mammals. Nature 402: 309-313, 1999.

237. Miller AA, De Silva TM, Judkins CP, Diep H, Drummond GR, and Sobey CG. Augmented superoxide production by Nox2-containing NADPH oxidase causes cerebral artery dysfunction during hypercholesterolemia. Stroke 41: 784$789,2010$.

238. Milochevitch $\mathrm{C}$ and Khalil A. Study of the paraoxonase and platelet-activating factor acetylhydrolase activities with aging. Prostaglandins Leukot Essent Fatty Acids 65: 241-246, 2001.

239. Mink PJ, Scrafford CG, Barraj LM, Harnack L, Hong CP, Nettleton JA, and Jacobs DR, Jr. Flavonoid intake and cardiovascular disease mortality: a prospective study in postmenopausal women. Am J Clin Nutr 85: 895-909, 2007.

240. Mitchell JA, Ali F, Bailey L, Moreno L, and Harrington LS. Role of nitric oxide and prostacyclin as vasoactive hormones released by the endothelium. Exp Physiol 93: 141-147, 2008.

241. Miyamoto S, Kawano H, Takazoe K, Soejima H, Sakamoto T, Hokamaki J, Yoshimura M, Nakamura H, Yodoi $\mathrm{J}$, and Ogawa $\mathrm{H}$. Vitamin $\mathrm{E}$ improves fibrinolytic activity in patients with coronary spastic angina. Thromb Res 113: 345-351, 2004.

242. Miyoshi T, Li Y, Shih DM, Wang X, Laubach VE, Matsumoto AH, Helm GA, Lusis AJ, and Shi W. Deficiency of inducible NO synthase reduces advanced but not early atherosclerosis in apolipoprotein E-deficient mice. Life Sci 79: 525-531, 2006.

243. Mohebali D, Kaplan D, Carlisle M, Supiano MA, and Rondina MT. Alterations in platelet function during aging: clinical correlations with thromboinflammatory disease in older adults. J Am Geriatr Soc 62: 529-535, 2014.

244. Mondoro TH, Shafer BC, and Vostal JG. Peroxynitriteinduced tyrosine nitration and phosphorylation in human platelets. Free Radic Biol Med 22: 1055-1063, 1997.

245. Montezano AC and Touyz RM. Reactive oxygen species and endothelial function-role of nitric oxide synthase uncoupling and Nox family nicotinamide adenine dinucleotide phosphate oxidases. Basic Clin Pharmacol Toxicol 110: 87-94, 2012.

246. Morrow JD. Quantification of isoprostanes as indices of oxidant stress and the risk of atherosclerosis in humans. Arterioscler Thromb Vasc Biol 25: 279-286, 2005.

247. Mozaffarian D, Benjamin EJ, Go AS, Arnett DK, Blaha MJ, Cushman M, de Ferranti S, Despres JP, Fullerton HJ, Howard VJ, Huffman MD, Judd SE, Kissela BM, Lackland DT, Lichtman JH, Lisabeth LD, Liu S, Mackey RH, Matchar DB, McGuire DK, Mohler ER, 3rd, Moy CS, Muntner P, Mussolino ME, Nasir K, Neumar RW, Nichol
G, Palaniappan L, Pandey DK, Reeves MJ, Rodriguez CJ, Sorlie PD, Stein J, Towfighi A, Turan TN, Virani SS, Willey JZ, Woo D, Yeh RW, Turner MB, American Heart Association Statistics C, and Stroke Statistics S. Heart disease and stroke statistics-2015 update: a report from the American Heart Association. Circulation 131: e29e322, 2015.

248. Munoz-Sanchez J and Chanez-Cardenas ME. A review on hemeoxygenase-2: focus on cellular protection and oxygen response. Oxid Med Cell Longev 2014: 604981, 2014.

249. Myung SK, Ju W, Cho B, Oh SW, Park SM, Koo BK, and Park BJ. Efficacy of vitamin and antioxidant supplements in prevention of cardiovascular disease: systematic review and meta-analysis of randomised controlled trials. $B M J$ 346: f10, 2013

250. Najjar SS, Scuteri A, and Lakatta EG. Arterial aging: is it an immutable cardiovascular risk factor? Hypertension 46: 454-462, 2005.

251. Nakamura S, Kugiyama K, Sugiyama S, Miyamoto S, Koide S, Fukushima H, Honda O, Yoshimura M, and Ogawa H. Polymorphism in the 5 '-flanking region of human glutamate-cysteine ligase modifier subunit gene is associated with myocardial infarction. Circulation 105: 2968-2973, 2002.

252. Nakamura YK and Omaye ST. Age-related changes of serum lipoprotein oxidation in rats. Life Sci 74: 12651275, 2004

253. Napoli C, Martin-Padura I, de Nigris F, Giorgio M, Mansueto G, Somma P, Condorelli M, Sica G, De Rosa G, and Pelicci P. Deletion of the p66Shc longevity gene reduces systemic and tissue oxidative stress, vascular cell apoptosis, and early atherogenesis in mice fed a high-fat diet. Proc Natl Acad Sci U S A 100: 2112-2116, 2003.

254. Navab M, Fogelman AM, Berliner JA, Territo MC, Demer LL, Frank JS, Watson AD, Edwards PA, and Lusis AJ. Pathogenesis of atherosclerosis. Am J Cardiol 76: 18C23C, 1995.

255. Nimni ME, Han B, and Cordoba F. Are we getting enough sulfur in our diet? Nutr Metab (Lond) 4: 24, 2007.

256. Nishiyama SK, Wray DW, and Richardson RS. Aging affects vascular structure and function in a limb-specific manner. J Appl Physiol (1985) 105: 1661-1670, 2008.

257. Nwankwo T, Yoon SS, Burt V, and Gu Q. Hypertension among adults in the United States: National Health and Nutrition Examination Survey, 2011-2012. NCHS Data Brief 133: 1-8, 2013.

258. Obrador E, Benlloch M, Pellicer JA, Asensi M, and Estrela JM. Intertissue flow of glutathione (GSH) as a tumor growth-promoting mechanism: interleukin 6 induces GSH release from hepatocytes in metastatic B16 melanomabearing mice. J Biol Chem 286: 15716-15727, 2011.

259. Oelze M, Kroller-Schon S, Steven S, Lubos E, Doppler C, Hausding M, Tobias S, Brochhausen C, Li H, Torzewski M, Wenzel P, Bachschmid M, Lackner KJ, Schulz E, Munzel T, and Daiber A. Glutathione peroxidase-1 deficiency potentiates dysregulatory modifications of endothelial nitric oxide synthase and vascular dysfunction in aging. Hypertension 63: 390-396, 2014.

260. Offermanns S. Activation of platelet function through $G$ protein-coupled receptors. Circ Res 99: 1293-1304, 2006.

261. Orozco LD, Kapturczak MH, Barajas B, Wang X, Weinstein MM, Wong J, Deshane J, Bolisetty S, Shaposhnik Z, Shih DM, Agarwal A, Lusis AJ, and Araujo JA. Heme oxygenase-1 expression in macrophages plays a 
beneficial role in atherosclerosis. Circ Res 100: 1703 1711, 2007.

262. Orr WC and Sohal RS. Extension of life-span by overexpression of superoxide dismutase and catalase in Drosophila melanogaster. Science 263: 1128-1130, 1994.

263. Palareti $G$ and Cosmi B. Bleeding with anticoagulation therapy - who is at risk, and how best to identify such patients. Thromb Haemost 102: 268-278, 2009.

264. Pastori D, Carnevale R, Bartimoccia S, Nocella C, Tanzilli G, Cangemi R, Vicario T, Catena M, Violi F, and Pignatelli P. Does Mediterranean diet reduce cardiovascular events and oxidative stress in atrial fibrillation? Antioxid Redox Signal 23: 682-687, 2015.

265. Pastori D, Carnevale R, Nocella C, Novo M, Santulli M, Cammisotto V, Menichelli D, Pignatelli P, and Violi F. Gut-derived serum lipopolysaccharides are associated with enhanced risk of major adverse cardiovascular events in atrial fibrillation: Effect of adherence to Mediterranean diet. J Am Heart Assoc 6: e005784, 2017.

266. Pastori D, Farcomeni A, Poli D, Antonucci E, Angelico F, Del Ben M, Cangemi R, Tanzilli G, Lip GY, Pignatelli P, and Violi F. Cardiovascular risk stratification in patients with non-valvular atrial fibrillation: the 2MACE score. Intern Emerg Med 11: 199-204, 2016.

267. Pastori D, Pignatelli P, Angelico F, Farcomeni A, Del Ben M, Vicario T, Bucci T, Raparelli V, Cangemi R, Tanzilli G, Lip GY, and Violi F. Incidence of myocardial infarction and vascular death in elderly patients with atrial fibrillation taking anticoagulants: relation to atherosclerotic risk factors. Chest 147: 1644-1650, 2015.

268. Pastori D, Pignatelli P, Farcomeni A, Menichelli D, Nocella C, Carnevale R, and Violi F. Aging-related decline of glutathione peroxidase 3 and risk of cardiovascular events in patients with atrial fibrillation. J Am Heart Assoc 5: e003682, 2016.

269. Pastori D, Pignatelli P, Farcomeni A, Nocella C, Bartimoccia S, Carnevale R, and Violi F. Age-related increase of thromboxane B2 and risk of cardiovascular disease in atrial fibrillation. Oncotarget 7: 39143-39147, 2016.

270. Patel RS, Al Mheid I, Morris AA, Ahmed Y, Kavtaradze N, Ali S, Dabhadkar K, Brigham K, Hooper WC, Alexander RW, Jones DP, and Quyyumi AA. Oxidative stress is associated with impaired arterial elasticity. Atherosclerosis 218: 90-95, 2011.

271. Patrignani P, Panara MR, Tacconelli S, Seta F, Bucciarelli T, Ciabattoni G, Alessandrini P, Mezzetti A, Santini G, Sciulli MG, Cipollone F, Davi G, Gallina P, Bon GB, and Patrono C. Effects of vitamin E supplementation on $\mathrm{F}(2)$ isoprostane and thromboxane biosynthesis in healthy cigarette smokers. Circulation 102: 539-545, 2000.

272. Pechlaner R, Willeit P, Summerer M, Santer P, Egger G, Kronenberg F, Demetz E, Weiss G, Tsimikas S, Witztum JL, Willeit K, Iglseder B, Paulweber B, Kedenko L, Haun M, Meisinger C, Gieger C, Muller-Nurasyid M, Peters A, Willeit J, and Kiechl S. Heme oxygenase-1 gene promoter microsatellite polymorphism is associated with progressive atherosclerosis and incident cardiovascular disease. Arterioscler Thromb Vasc Biol 35: 229-236, 2015.

273. Peluzio MC, Homem AP, Cesar GC, Azevedo GS, Amorim R, Cara DC, Saliba H, Vieira EC, Arantes RE, and Alvarez-Leite J. Influences of alpha-tocopherol on cholesterol metabolism and fatty streak development in apolipoprotein E-deficient mice fed an atherogenic diet. Braz J Med Biol Res 34: 1539-1545, 2001.
274. Peluzio MC, Miguel E, Jr., Drumond TC, Cesar GC, Santiago HC, Teixeira MM, Vieira EC, Arantes RM, and Alvarez-Leite JI. Monocyte chemoattractant protein-1 involvement in the alpha-tocopherol-induced reduction of atherosclerotic lesions in apolipoprotein $\mathrm{E}$ knockout mice. Br J Nutr 90: 3-11, 2003.

275. Perez VI, Van Remmen H, Bokov A, Epstein CJ, Vijg J, and Richardson A. The overexpression of major antioxidant enzymes does not extend the lifespan of mice. Aging Cell 8: 73-75, 2009.

276. Peters EA, Hiltermann JT, and Stolk J. Effect of apocynin on ozone-induced airway hyperresponsiveness to methacholine in asthmatics. Free Radic Biol Med 31: 14421447, 2001.

277. Peters U, Poole C, and Arab L. Does tea affect cardiovascular disease? A meta-analysis. Am J Epidemiol 154: 495-503, 2001.

278. Pignatelli P, Carnevale R, Cangemi R, Loffredo L, Sanguigni V, Stefanutti C, Basili S, and Violi F. Atorvastatin inhibits gp91phox circulating levels in patients with hypercholesterolemia. Arterioscler Thromb Vasc Biol 30: 360-367, 2010.

279. Pignatelli P, Carnevale R, Di Santo S, Bartimoccia S, Nocella C, Vicario T, Loffredo L, Angelico F, and Violi F. Rosuvastatin reduces platelet recruitment by inhibiting NADPH oxidase activation. Biochem Pharmacol 84: 1635-1642, 2012.

280. Pignatelli P, Carnevale R, Di Santo S, Bartimoccia S, Sanguigni V, Lenti L, Finocchi A, Mendolicchio L, Soresina AR, Plebani A, and Violi F. Inherited human gp91phox deficiency is associated with impaired isoprostane formation and platelet dysfunction. Arterioscler Thromb Vasc Biol 31: 423-434, 2011.

281. Pignatelli P, Carnevale R, Pastori D, Cangemi R, Napoleone L, Bartimoccia S, Nocella C, Basili S, and Violi F. Immediate antioxidant and antiplatelet effect of atorvastatin via inhibition of Nox2. Circulation 126: 92-103, 2012.

282. Pignatelli P, Di Santo S, Barilla F, Gaudio C, and Violi F. Multiple anti-atherosclerotic treatments impair aspirin compliance: effects on aspirin resistance. J Thromb Haemost 6: 1832-1834, 2008.

283. Pignatelli P, Pastori D, Bartimoccia S, Menichelli D, Vicario T, Nocella C, Carnevale R, and Violi F. Anti Xa oral anticoagulants inhibit in vivo platelet activation by modulating glycoprotein VI shedding. Pharmacol Res 113: 484-489, 2016.

284. Pignatelli P, Pastori D, Carnevale R, Farcomeni A, Cangemi R, Nocella C, Bartimoccia S, Vicario T, Saliola M, Lip GY, and Violi F. Serum NOX2 and urinary isoprostanes predict vascular events in patients with atrial fibrillation. Thromb Haemost 113: 617-624, 2015.

285. Pignatelli P, Pastori D, Farcomeni A, Nocella C, Bartimoccia S, Vicario T, Bucci T, Carnevale R, and Violi F. Mediterranean diet reduces thromboxane A2 production in atrial fibrillation patients. Clin Nutr 34: 899-903, 2015.

286. Pignatelli P, Pulcinelli FM, Lenti L, Gazzaniga PP, and Violi F. Hydrogen peroxide is involved in collageninduced platelet activation. Blood 91: 484-490, 1998.

287. Pignatelli P, Pulcinelli FM, Lenti L, Gazzaniga PP, and Violi F. Vitamin E inhibits collagen-induced platelet activation by blunting hydrogen peroxide. Arterioscler Thromb Vasc Biol 19: 2542-2547, 1999. 
288. Pignatelli P, Sanguigni V, Lenti L, Ferro D, Finocchi A, Rossi P, and Violi F. gp91phox-dependent expression of platelet CD40 ligand. Circulation 110: 1326-1329, 2004.

289. Pignatelli P, Sanguigni V, Paola SG, Lo Coco E, Lenti L, and Violi F. Vitamin $\mathrm{C}$ inhibits platelet expression of CD40 ligand. Free Radic Biol Med 38: 1662-1666, 2005.

290. Pinton P, Rimessi A, Marchi S, Orsini F, Migliaccio E, Giorgio M, Contursi C, Minucci S, Mantovani F, Wieckowski MR, Del Sal G, Pelicci PG, and Rizzuto R. Protein kinase $\mathrm{C}$ beta and prolyl isomerase 1 regulate mitochondrial effects of the life-span determinant p66Shc. Science 315: 659-663, 2007.

291. Podmore ID, Griffiths HR, Herbert KE, Mistry N, Mistry $\mathrm{P}$, and Lunec J. Vitamin C exhibits pro-oxidant properties. Nature 392: 559, 1998.

292. Polidori MC, Mariani E, Baggio G, Deiana L, Carru C, Pes GM, Cecchetti R, Franceschi C, Senin U, and Mecocci P. Different antioxidant profiles in Italian centenarians: the Sardinian peculiarity. Eur J Clin Nutr 61: 922-924, 2007.

293. Pratico D. Prostanoid and isoprostanoid pathways in atherogenesis. Atherosclerosis 201: 8-16, 2008.

294. Pratico D, Iuliano L, Mauriello A, Spagnoli L, Lawson JA, Rokach J, Maclouf J, Violi F, and FitzGerald GA. Localization of distinct F2-isoprostanes in human atherosclerotic lesions. J Clin Invest 100: 2028-2034, 1997.

295. Predmore BL, Lefer DJ, and Gojon G. Hydrogen sulfide in biochemistry and medicine. Antioxid Redox Signal 17: 119-140, 2012.

296. Pryor WA. Vitamin E and heart disease: basic science to clinical intervention trials. Free Radic Biol Med 28: 141164,2000

297. Pugliese G, Solini A, Bonora E, Fondelli C, Orsi E, Nicolucci A, Penno G, and Group RS. Chronic kidney disease in type 2 diabetes: lessons from the Renal Insufficiency And Cardiovascular Events (RIACE) Italian Multicentre Study. Nutr Metab Cardiovasc Dis 24: 815$822,2014$.

298. Quesada IM, Lucero A, Amaya C, Meijles DN, Cifuentes ME, Pagano PJ, and Castro C. Selective inactivation of NADPH oxidase 2 causes regression of vascularization and the size and stability of atherosclerotic plaques. Atherosclerosis 242: 469-475, 2015.

299. Qureshi AA, Karpen CW, Qureshi N, Papasian CJ, Morrison DC, and Folts JD. Tocotrienols-induced inhibition of platelet thrombus formation and platelet aggregation in stenosed canine coronary arteries. Lipids Health Dis 10: 58, 2011.

300. Randrianarisoa E, Lehn-Stefan A, Wang X, Hoene M, Peter A, Heinzmann SS, Zhao X, Konigsrainer I, Konigsrainer A, Balletshofer B, Machann J, Schick F, Fritsche A, Haring HU, Xu G, Lehmann R, and Stefan N. Relationship of serum trimethylamine N-oxide (TMAO) levels with early atherosclerosis in humans. Sci Rep 6: 26745, 2016.

301. Rauscher FM, Goldschmidt-Clermont PJ, Davis BH, Wang T, Gregg D, Ramaswami P, Pippen AM, Annex $\mathrm{BH}$, Dong C, and Taylor DA. Aging, progenitor cell exhaustion, and atherosclerosis. Circulation 108: 457-463, 2003.

302. Ravandi A, Boekholdt SM, Mallat Z, Talmud PJ, Kastelein JJ, Wareham NJ, Miller ER, Benessiano J, Tedgui A, Witztum JL, Khaw KT, and Tsimikas S. Relationship of IgG and IgM autoantibodies and immune complexes to oxidized LDL with markers of oxidation and inflammation and cardiovascular events: results from the EPICNorfolk Study. J Lipid Res 52: 1829-1836, 2011.

303. Ravikumar P, Ye J, Zhang J, Pinch SN, Hu MC, Kuro-o $\mathrm{M}$, Hsia CC, and Moe OW. alpha-Klotho protects against oxidative damage in pulmonary epithelia. Am J Physiol Lung Cell Mol Physiol 307: L566-L575, 2014.

304. Reilly IA and FitzGerald GA. Eicosenoid biosynthesis and platelet function with advancing age. Thromb Res 41: 545-554, 1986.

305. Renaud S and de Lorgeril M. Wine, alcohol, platelets, and the French paradox for coronary heart disease. Lancet 339: 1523-1526, 1992.

306. Roest M, Voorbij HA, Van der Schouw YT, Peeters PH, Teerlink T, and Scheffer PG. High levels of urinary F2isoprostanes predict cardiovascular mortality in postmenopausal women. J Clin Lipidol 2: 298-303, 2008.

307. Romero MJ, Platt DH, Tawfik HE, Labazi M, El-Remessy AB, Bartoli M, Caldwell RB, and Caldwell RW. Diabetesinduced coronary vascular dysfunction involves increased arginase activity. Circ Res 102: 95-102, 2008.

308. Rose AH and Hoffmann PR. Selenoproteins and cardiovascular stress. Thromb Haemost 113: 494-504, 2015.

309. Rosenblat M, Coleman R, and Aviram M. Increased macrophage glutathione content reduces cell-mediated oxidation of LDL and atherosclerosis in apolipoprotein Edeficient mice. Atherosclerosis 163: 17-28, 2002.

310. Rosenblat M, Coleman R, Reddy ST, and Aviram M. Paraoxonase 2 attenuates macrophage triglyceride accumulation via inhibition of diacylglycerol acyltransferase 1 . J Lipid Res 50: 870-879, 2009.

311. Rurali E, Bassetti B, Perrucci GL, Zanobini M, Malafronte C, Achilli F, and Gambini E. BM ageing: implication for cell therapy with EPCs. Mech Ageing Dev 159: 4-13, 2016.

312. Ryoo S, Gupta G, Benjo A, Lim HK, Camara A, Sikka G, Lim HK, Sohi J, Santhanam L, Soucy K, Tuday E, Baraban E, Ilies M, Gerstenblith G, Nyhan D, Shoukas A, Christianson DW, Alp NJ, Champion HC, Huso D, and Berkowitz DE. Endothelial arginase II: a novel target for the treatment of atherosclerosis. Circ Res 102: 923-932, 2008.

313. Saad MJ, Santos A, and Prada PO. Linking gut microbiota and inflammation to obesity and insulin resistance. Physiology (Bethesda) 31: 283-293, 2016.

314. Sabatine MS, Cannon CP, Gibson CM, Lopez-Sendon JL, Montalescot G, Theroux P, Claeys MJ, Cools F, Hill KA, Skene AM, McCabe $\mathrm{CH}$, Braunwald $\mathrm{E}$, and Investigators C-T. Addition of clopidogrel to aspirin and fibrinolytic therapy for myocardial infarction with ST-segment elevation. $N$ Engl J Med 352: 1179-1189, 2005.

315. Sakkinen PA, Cushman M, Psaty BM, Rodriguez B, Boineau R, Kuller LH, and Tracy RP. Relationship of plasmin generation to cardiovascular disease risk factors in elderly men and women. Arterioscler Thromb Vasc Biol 19: 499-504, 1999.

316. Salama R, Sadaie M, Hoare M, and Narita M. Cellular senescence and its effector programs. Genes Dev 28: 99114, 2014.

317. Salazar N, Valdes-Varela L, Gonzalez S, Gueimonde M, and de Los Reyes-Gavilan CG. Nutrition and the gut microbiome in the elderly. Gut Microbes 8: 82-97, 2017.

318. Santilli F, Mucci L, and Davi G. TP receptor activation and inhibition in atherothrombosis: the paradigm of diabetes mellitus. Intern Emerg Med 6: 203-212, 2011. 
319. Santos Franco S, Raveh-Amit H, Kobolak J, Alqahtani $\mathrm{MH}$, Mobasheri A, and Dinnyes A. The crossroads between cancer stem cells and aging. BMC Cancer $15 \mathrm{Suppl}$ 1: S1, 2015.

320. Sawabe M. Vascular aging: from molecular mechanism to clinical significance. Geriatr Gerontol Int 10 Suppl 1: S213-S220, 2010.

321. Scapagnini G, Vasto S, Abraham NG, Caruso C, Zella D, and Fabio G. Modulation of Nrf2/ARE pathway by food polyphenols: a nutritional neuroprotective strategy for cognitive and neurodegenerative disorders. Mol Neurobiol 44: 192-201, 2011.

322. Schurks M, Glynn RJ, Rist PM, Tzourio C, and Kurth T. Effects of vitamin $\mathrm{E}$ on stroke subtypes: meta-analysis of randomised controlled trials. BMJ 341: c5702, 2010.

323. Schurmann C, Rezende F, Kruse C, Yasar Y, Lowe O, Fork C, van de Sluis B, Bremer R, Weissmann N, Shah AM, Jo H, Brandes RP, and Schroder K. The NADPH oxidase Nox4 has anti-atherosclerotic functions. Eur Heart J 36: 3447-3456, 2015.

324. Schwedhelm E, Bartling A, Lenzen H, Tsikas D, Maas R, Brummer J, Gutzki FM, Berger J, Frolich JC, and Boger RH. Urinary 8-iso-prostaglandin F2alpha as a risk marker in patients with coronary heart disease: a matched casecontrol study. Circulation 109: 843-848, 2004.

325. Schwenke DC, Rudel LL, Sorci-Thomas MG, and Thomas MJ. Alpha-tocopherol protects against diet induced atherosclerosis in New Zealand white rabbits. J Lipid Res 43: 1927-1938, 2002.

326. Seals DR, Jablonski KL, and Donato AJ. Aging and vascular endothelial function in humans. Clin Sci (Lond) 120: 357-375, 2011.

327. Semba RD, Ferrucci L, Bartali B, Urpi-Sarda M, ZamoraRos R, Sun K, Cherubini A, Bandinelli S, and AndresLacueva C. Resveratrol levels and all-cause mortality in older community-dwelling adults. JAMA Intern Med 174: 1077-1084, 2014.

328. Sentman ML, Granstrom M, Jakobson H, Reaume A, Basu S, and Marklund SL. Phenotypes of mice lacking extracellular superoxide dismutase and copper- and zinccontaining superoxide dismutase. J Biol Chem 281: 69046909, 2006.

329. Sesso HD, Buring JE, Christen WG, Kurth T, Belanger C, MacFadyen J, Bubes V, Manson JE, Glynn RJ, and Gaziano JM. Vitamins $\mathrm{E}$ and $\mathrm{C}$ in the prevention of cardiovascular disease in men: the Physicians' Health Study II randomized controlled trial. JAMA 300: 2123-2133, 2008.

330. Shen H, Kreisel D, and Goldstein DR. Processes of sterile inflammation. J Immunol 191: 2857-2863, 2013.

331. Shih DM, Gu L, Xia YR, Navab M, Li WF, Hama S, Castellani LW, Furlong CE, Costa LG, Fogelman AM, and Lusis AJ. Mice lacking serum paraoxonase are susceptible to organophosphate toxicity and atherosclerosis. Nature 394: 284-287, 1998.

332. Shih DM, Xia YR, Wang XP, Miller E, Castellani LW, Subbanagounder G, Cheroutre H, Faull KF, Berliner JA, Witztum JL, and Lusis AJ. Combined serum paraoxonase knockout/apolipoprotein E knockout mice exhibit increased lipoprotein oxidation and atherosclerosis. $J$ Biol Chem 275: 17527-17535, 2000.

333. Shih DM, Xia YR, Wang XP, Wang SS, Bourquard N, Fogelman AM, Lusis AJ, and Reddy ST. Decreased obesity and atherosclerosis in human paraoxonase 3 transgenic mice. Circ Res 100: 1200-1207, 2007.
334. Shimada K, Mokuno H, Matsunaga E, Miyazaki T, Sumiyoshi K, Miyauchi K, and Daida H. Circulating oxidized low-density lipoprotein is an independent predictor for cardiac event in patients with coronary artery disease. Atherosclerosis 174: 343-347, 2004.

335. Shimizu H, Kiyohara Y, Kato I, Kitazono T, Tanizaki Y, Kubo M, Ueno H, Ibayashi S, Fujishima M, and Iida M. Relationship between plasma glutathione levels and cardiovascular disease in a defined population: the Hisayama study. Stroke 35: 2072-2077, 2004.

336. Shishehbor $\mathrm{MH}$, Zhang $\mathrm{R}$, Medina $\mathrm{H}$, Brennan $\mathrm{ML}$, Brennan DM, Ellis SG, Topol EJ, and Hazen SL. Systemic elevations of free radical oxidation products of arachidonic acid are associated with angiographic evidence of coronary artery disease. Free Radic Biol Med 41: 16781683, 2006.

337. Sibley CT, Estwick T, Zavodni A, Huang CY, Kwan AC, Soule BP, Long Priel DA, Remaley AT, Rudman Spergel AK, Turkbey EB, Kuhns DB, Holland SM, Malech HL, Zarember KA, Bluemke DA, and Gallin JI. Assessment of atherosclerosis in chronic granulomatous disease. Circulation 130: 2031-2039, 2014.

338. Sigala F, Kotsinas A, Savari P, Filis K, Markantonis S, Iliodromitis EK, Gorgoulis VG, and Andreadou I. Oxidized LDL in human carotid plaques is related to symptomatic carotid disease and lesion instability. J Vasc Surg 52: 704-713, 2010.

339. Signorelli SS, Li Volsi G, Fiore V, Mangiafico M, Barbagallo I, Parenti R, Rizzo M, and Li Volti G. Plasma heme oxygenase- 1 is decreased in peripheral artery disease patients. Mol Med Rep 14: 3459-3463, 2016.

340. Singh RB, Ghosh S, Niaz MA, Singh R, Beegum R, Chibo $\mathrm{H}$, Shoumin Z, and Postiglione A. Dietary intake, plasma levels of antioxidant vitamins, and oxidative stress in relation to coronary artery disease in elderly subjects. Am J Cardiol 76: 1233-1238, 1995.

341. Singh S and Bajorek B. Defining 'elderly' in clinical practice guidelines for pharmacotherapy. Pharm Pract (Granada) 12: 489, 2014.

342. Smith TL and Kummerow FA. Effect of dietary vitamin E on plasma lipids and atherogenesis in restricted ovulator chickens. Atherosclerosis 75: 105-109, 1989.

343. Soliman EZ, Safford MM, Muntner P, Khodneva Y, Dawood FZ, Zakai NA, Thacker EL, Judd S, Howard VJ, Howard G, Herrington DM, and Cushman M. Atrial fibrillation and the risk of myocardial infarction. JAMA Intern Med 174: 107-114, 2014.

344. Son TG, Zou Y, Yu BP, Lee J, and Chung HY. Aging effect on myeloperoxidase in rat kidney and its modulation by calorie restriction. Free Radic Res 39: 283-289, 2005.

345. Stables MJ and Gilroy DW. Old and new generation lipid mediators in acute inflammation and resolution. Prog $\mathrm{Li}$ pid Res 50: 35-51, 2011.

346. Stangl V, Dreger H, Stangl K, and Lorenz M. Molecular targets of tea polyphenols in the cardiovascular system. Cardiovasc Res 73: 348-358, 2007.

347. Stangl V, Lorenz M, and Stangl K. The role of tea and tea flavonoids in cardiovascular health. Mol Nutr Food Res 50: 218-228, 2006.

348. Stefanska J, Sarniak A, Wlodarczyk A, Sokolowska M, Pniewska E, Doniec Z, Nowak D, and Pawliczak R. Apocynin reduces reactive oxygen species concentrations in exhaled breath condensate in asthmatics. Exp Lung Res 38: 90-99, 2012. 
349. Stefanska J, Sokolowska M, Sarniak A, Wlodarczyk A, Doniec Z, Nowak D, and Pawliczak R. Apocynin decreases hydrogen peroxide and nitrate concentrations in exhaled breath in healthy subjects. Pulm Pharmacol Ther 23: 48-54, 2010.

350. Stein S, Lohmann C, Schafer N, Hofmann J, Rohrer L, Besler C, Rothgiesser KM, Becher B, Hottiger MO, Boren J, McBurney MW, Landmesser U, Luscher TF, and Matter CM. SIRT1 decreases Lox-1-mediated foam cell formation in atherogenesis. Eur Heart J 31: 2301-2309, 2010.

351. Stocker R and Keaney JF, Jr. Role of oxidative modifications in atherosclerosis. Physiol Rev 84: 1381-1478, 2004.

352. Subbarao K, Jala VR, Mathis S, Suttles J, Zacharias W, Ahamed J, Ali H, Tseng MT, and Haribabu B. Role of leukotriene B4 receptors in the development of atherosclerosis: potential mechanisms. Arterioscler Thromb Vasc Biol 24: 369-375, 2004.

353. Sverdlov AL, Ngo DT, Chan WP, Chirkov YY, and Horowitz JD. Aging of the nitric oxide system: are we as old as our NO? J Am Heart Assoc 3: e000973, 2014.

354. This reference has been deleted.

355. Swiatkowska M, Szemraj J, Al-Nedawi KN, and Pawlowska Z. Reactive oxygen species upregulate expression of PAI-1 in endothelial cells. Cell Mol Biol Lett 7: 10651071, 2002.

356. t Hoen PA, Van der Lans CA, Van Eck M, Bijsterbosch MK, Van Berkel TJ, and Twisk J. Aorta of ApoE-deficient mice responds to atherogenic stimuli by a prelesional increase and subsequent decrease in the expression of antioxidant enzymes. Circ Res 93: 262-269, 2003.

357. Tabas I. Macrophage death and defective inflammation resolution in atherosclerosis. Nat Rev Immunol 10: 36-46, 2010.

358. Tabas I. 2016 Russell Ross memorial lecture in vascular biology: molecular-cellular mechanisms in the progression of atherosclerosis. Arterioscler Thromb Vasc Biol 37: 183-189, 2017

359. Takatsu H, Tasaki H, Kim HN, Ueda S, Tsutsui M, Yamashita K, Toyokawa T, Morimoto Y, Nakashima Y, and Adachi T. Overexpression of EC-SOD suppresses endothelial-cell-mediated LDL oxidation. Biochem Biophys Res Commun 285: 84-91, 2001.

360. Tang WH and Hazen SL. Microbiome, trimethylamine Noxide, and cardiometabolic disease. Transl Res 179: 108115,2017

361. Tang WH, Wu Y, Nicholls SJ, and Hazen SL. Plasma myeloperoxidase predicts incident cardiovascular risks in stable patients undergoing medical management for coronary artery disease. Clin Chem 57: 33-39, 2011.

362. Tatchum-Talom R, and Martin DS. Tempol improves vascular function in the mesenteric vascular bed of senescent rats. Can J Physiol Pharmacol 82: 200-207, 2004.

363. Taub J, Lau JF, Ma C, Hahn JH, Hoque R, Rothblatt J, and Chalfie M. A cytosolic catalase is needed to extend adult lifespan in C. elegans daf-C and clk-1 mutants. Nature 399: 162-166, 1999.

364. Thijssen DH, Black MA, Pyke KE, Padilla J, Atkinson G, Harris RA, Parker B, Widlansky ME, Tschakovsky ME, and Green DJ. Assessment of flow-mediated dilation in humans: a methodological and physiological guideline. Am J Physiol Heart Circ Physiol 300: H2-H12, 2011.

365. Torzewski M, Ochsenhirt V, Kleschyov AL, Oelze M, Daiber A, Li H, Rossmann H, Tsimikas S, Reifenberg K,
Cheng F, Lehr HA, Blankenberg S, Forstermann U, Munzel T, and Lackner KJ. Deficiency of glutathione peroxidase-1 accelerates the progression of atherosclerosis in apolipoprotein E-deficient mice. Arterioscler Thromb Vasc Biol 27: 850-857, 2007.

366. Touboul PJ, Vicaut E, Labreuche J, Acevedo M, Torres V, Ramirez-Martinez J, Vinueza R, Silva H, Champagne B, Hernandez-Hernandez R, Wilson E, and Schargrodsky H. Common carotid artery intima-media thickness: the Cardiovascular Risk Factor Multiple Evaluation in Latin America (CARMELA) study results. Cerebrovasc Dis 31: 43-50, 2011.

367. Townsend DM, Tew KD, and Tapiero H. The importance of glutathione in human disease. Biomed Pharmacother 57: 145-155, 2003.

368. Tracz MJ, Alam J, and Nath KA. Physiology and pathophysiology of heme: implications for kidney disease. J Am Soc Nephrol 18: 414-420, 2007.

369. Tsao R. Chemistry and biochemistry of dietary polyphenols. Nutrients 2: 1231-1246, 2010.

370. Tsimikas S, Kiechl S, Willeit J, Mayr M, Miller ER, Kronenberg F, Xu Q, Bergmark C, Weger S, Oberhollenzer F, and Witztum JL. Oxidized phospholipids predict the presence and progression of carotid and femoral atherosclerosis and symptomatic cardiovascular disease: fiveyear prospective results from the Bruneck study. $J$ Am Coll Cardiol 47: 2219-2228, 2006.

371. Turgeon J, Haddad P, Dussault S, Groleau J, Maingrette F, Perez G, and Rivard A. Protection against vascular aging in Nox2-deficient mice: impact on endothelial progenitor cells and reparative neovascularization. Atherosclerosis 223: 122-129, 2012.

372. Tyner SD, Venkatachalam S, Choi J, Jones S, Ghebranious N, Igelmann $\mathrm{H}$, Lu X, Soron G, Cooper B, Brayton C, Park SH, Thompson T, Karsenty G, Bradley A, and Donehower LA. p53 Mutant mice that display early ageing-associated phenotypes. Nature 415: 45-53, 2002.

373. Tzou WS, Douglas PS, Srinivasan SR, Bond MG, Tang R, Chen W, Berenson GS, and Stein JH. Increased subclinical atherosclerosis in young adults with metabolic syndrome: the Bogalusa Heart Study. J Am Coll Cardiol 46: 457-463, 2005.

374. Valko M, Rhodes CJ, Moncol J, Izakovic M, and Mazur M. Free radicals, metals and antioxidants in oxidative stressinduced cancer. Chem Biol Interact 160: 1-40, 2006.

375. van Lieshout EM and Peters WH. Age and gender dependent levels of glutathione and glutathione Stransferases in human lymphocytes. Carcinogenesis 19: 1873-1875, 1998.

376. Vassalle C, Petrozzi L, Botto N, Andreassi MG, and Zucchelli GC. Oxidative stress and its association with coronary artery disease and different atherogenic risk factors. J Intern Med 256: 308-315, 2004.

377. Venkateshappa C, Harish G, Mythri RB, Mahadevan A, Bharath MM, and Shankar SK. Increased oxidative damage and decreased antioxidant function in aging human substantia nigra compared to striatum: implications for Parkinson's disease. Neurochem Res 37: 358-369, 2012.

378. Verlangieri AJ and Bush MJ. Effects of d-alpha-tocopherol supplementation on experimentally induced primate atherosclerosis. J Am Coll Nutr 11: 131-138, 1992.

379. Violi F, Basili S, Nigro C, and Pignatelli P. Role of NADPH oxidase in atherosclerosis. Future Cardiol 5: 8392, 2009. 
380. Violi F, Loffredo L, Musella L, and Marcoccia A. Should antioxidant status be considered in interventional trials with antioxidants? Heart 90: 598-602, 2004.

381. Violi F, Pastori D, Pignatelli P, and Loffredo L. Antioxidants for prevention of atrial fibrillation: a potentially useful future therapeutic approach? A review of the literature and meta-analysis. Europace 16: 1107-1116, 2014.

382. Violi F and Pignatelli P. Platelet NOX, a novel target for anti-thrombotic treatment. Thromb Haemost 111: 817823, 2014.

383. Violi F and Pignatelli P. Clinical application of NOX activity and other oxidative biomarkers in cardiovascular disease: a critical review. Antioxid Redox Signal 23: 514 532, 2015.

384. Violi F, Pignatelli P, Pignata C, Plebani A, Rossi P, Sanguigni V, Carnevale R, Soresina A, Finocchi A, Cirillo E, Catasca E, Angelico F, and Loffredo L. Reduced atherosclerotic burden in subjects with genetically determined low oxidative stress. Arterioscler Thromb Vasc Biol 33: 406-412, 2013.

385. Violi F, Sanguigni V, Carnevale R, Plebani A, Rossi P, Finocchi A, Pignata C, De Mattia D, Martire B, Pietrogrande MC, Martino S, Gambineri E, Soresina AR, Pignatelli P, Martino F, Basili S, and Loffredo L. Hereditary deficiency of gp91(phox) is associated with enhanced arterial dilatation: results of a multicenter study. Circulation 120: 1616-1622, 2009.

386. Violi F, Soliman EZ, Pignatelli P, and Pastori D. Atrial fibrillation and myocardial infarction: a systematic review and appraisal of pathophysiologic mechanisms. J Am Heart Assoc 5: e003347, 2016.

387. Virmani R, Avolio AP, Mergner WJ, Robinowitz M, Herderick EE, Cornhill JF, Guo SY, Liu TH, Ou DY, and O'Rourke M. Effect of aging on aortic morphology in populations with high and low prevalence of hypertension and atherosclerosis. Comparison between occidental and Chinese communities. Am J Pathol 139: 1119-1129, 1991.

388. Vivekananthan DP, Penn MS, Sapp SK, Hsu A, and Topol EJ. Use of antioxidant vitamins for the prevention of cardiovascular disease: meta-analysis of randomised trials. Lancet 361: 2017-2023, 2003.

389. Vogel ME, Idelman G, Konaniah ES, and Zucker SD. Bilirubin prevents atherosclerotic lesion formation in lowdensity lipoprotein receptor-deficient mice by inhibiting endothelial VCAM-1 and ICAM-1 signaling. J Am Heart Assoc 6: e004820, 2017.

390. Wallace JL, Vaughan D, Dicay M, MacNaughton WK, and de Nucci G. Hydrogen Sulfide-Releasing Therapeutics: translation to the Clinic. Antioxid Redox Signal 2017 [Epub ahead of print]; DOI: 10.1089/ars.2017.7068.

391. Wallentin L, Becker RC, Budaj A, Cannon CP, Emanuelsson H, Held C, Horrow J, Husted S, James S, Katus H, Mahaffey KW, Scirica BM, Skene A, Steg PG, Storey RF, Harrington RA, Investigators P, Freij A, and Thorsen M. Ticagrelor versus clopidogrel in patients with acute coronary syndromes. N Engl J Med 361: 1045-1057, 2009.

392. Wang B, Pan J, Wang L, Zhu H, Yu R, and Zou Y. Associations of plasma 8-isoprostane levels with the presence and extent of coronary stenosis in patients with coronary artery disease. Atherosclerosis 184: 425-430, 2006.
393. Wang HM, Chen TC, Jiang SQ, Liu YJ, and Tian JW. Association of conventional risk factors for cardiovascular disease with IMT in middle-aged and elderly Chinese. Int J Cardiovasc Imaging 30: 759-768, 2014.

394. Wang XL, Adachi T, Sim AS, and Wilcken DE. Plasma extracellular superoxide dismutase levels in an Australian population with coronary artery disease. Arterioscler Thromb Vasc Biol 18: 1915-1921, 1998.

395. Wang Y, Zhao X, Jin H, Wei H, Li W, Bu D, Tang X, Ren $\mathrm{Y}$, Tang C, and Du J. Role of hydrogen sulfide in the development of atherosclerotic lesions in apolipoprotein $\mathrm{E}$ knockout mice. Arterioscler Thromb Vasc Biol 29: 173179, 2009.

396. Wang Z, Nicholls SJ, Rodriguez ER, Kummu O, Horkko S, Barnard J, Reynolds WF, Topol EJ, DiDonato JA, and Hazen SL. Protein carbamylation links inflammation, smoking, uremia and atherogenesis. Nat Med 13: 11761184, 2007.

397. Ward NC, Croft KD, Blacker D, Hankey GJ, Barden A, Mori TA, Puddey IB, and Beer CD. Cytochrome P450 metabolites of arachidonic acid are elevated in stroke patients compared with healthy controls. Clin Sci (Lond) 121: 501-507, 2011.

398. Watanabe K, Shibuya S, Ozawa Y, Nojiri H, Izuo N, Yokote K, and Shimizu T. Superoxide dismutase 1 loss disturbs intracellular redox signaling, resulting in global age-related pathological changes. Biomed Res Int 2014: 140165, 2014

399. Wever R, Stroes E, and Rabelink TJ. Nitric oxide and hypercholesterolemia: a matter of oxidation and reduction? Atherosclerosis 137 Suppl: S51-S60, 1998.

400. Whiteman M, Li L, Rose P, Tan CH, Parkinson DB, and Moore PK. The effect of hydrogen sulfide donors on lipopolysaccharide-induced formation of inflammatory mediators in macrophages. Antioxid Redox Signal 12: 1147-1154, 2010.

401. Williams RJ, Motteram JM, Sharp CH, and Gallagher PJ. Dietary vitamin E and the attenuation of early lesion development in modified Watanabe rabbits. Atherosclerosis 94: 153-159, 1992.

402. Wilson PW, Ben-Yehuda O, McNamara J, Massaro J, Witztum J, and Reaven PD. Autoantibodies to oxidized LDL and cardiovascular risk: the Framingham Offspring Study. Atherosclerosis 189: 364-368, 2006.

403. Wolff JL, Starfield B, and Anderson G. Prevalence, expenditures, and complications of multiple chronic conditions in the elderly. Arch Intern Med 162: 2269-2276, 2002.

404. Woods AA, Linton SM, and Davies MJ. Detection of $\mathrm{HOCl}-$ mediated protein oxidation products in the extracellular matrix of human atherosclerotic plaques. Biochem J 370: 729-735, 2003.

405. Woodward M, Croft KD, Mori TA, Headlam H, Wang XS, Suarna C, Raftery MJ, MacMahon SW, and Stocker R. Association between both lipid and protein oxidation and the risk of fatal or non-fatal coronary heart disease in a human population. Clin Sci (Lond) 116: 53-60, 2009.

406. Wu T, Willett WC, Rifai N, Shai I, Manson JE, and Rimm EB. Is plasma oxidized low-density lipoprotein, measured with the widely used antibody 4E6, an independent predictor of coronary heart disease among U.S. men and women? J Am Coll Cardiol 48: 973-979, 2006.

407. Wykretowicz A, Adamska K, Krauze T, Guzik P, Szczepanik A, Rutkowska A, and Wysoki H. The plasma 
concentration of advanced oxidation protein products and arterial stiffness in apparently healthy adults. Free Radic Res 41: 645-649, 2007.

408. Xia N, Daiber A, Forstermann U, and Li H. Antioxidant effects of resveratrol in the cardiovascular system. $\mathrm{Br} \mathrm{J}$ Pharmacol 174: 1633-1646, 2017.

409. Xie S, Wang Q, Wu H, Cogswell J, Lu L, Jhanwar-Uniyal $\mathrm{M}$, and Dai W. Reactive oxygen species-induced phosphorylation of p53 on serine 20 is mediated in part by polo-like kinase-3. J Biol Chem 276: 36194-36199, 2001.

410. Yachie A, Niida Y, Wada T, Igarashi N, Kaneda H, Toma T, Ohta K, Kasahara Y, and Koizumi S. Oxidative stress causes enhanced endothelial cell injury in human heme oxygenase-1 deficiency. J Clin Invest 103: 129-135, 1999.

411. Yamamoto K, Takeshita K, Kojima T, Takamatsu J, and Saito H. Aging and plasminogen activator inhibitor-1 (PAI-1) regulation: implication in the pathogenesis of thrombotic disorders in the elderly. Cardiovasc Res 66: 276-285, 2005.

412. Yamamoto M, Clark JD, Pastor JV, Gurnani P, Nandi A, Kurosu H, Miyoshi M, Ogawa Y, Castrillon DH, Rosenblatt KP, and Kuro-o M. Regulation of oxidative stress by the anti-aging hormone klotho. J Biol Chem 280: 3802938034, 2005.

413. Yang H, Roberts LJ, Shi MJ, Zhou LC, Ballard BR, Richardson A, and Guo ZM. Retardation of atherosclerosis by overexpression of catalase or both $\mathrm{Cu} / \mathrm{Zn}$-superoxide dismutase and catalase in mice lacking apolipoprotein E. Circ Res 95: 1075-1081, 2004.

414. Yang J, Zhou X, Fan XR, Xiao M, Yang DH, Liang B, Dai M, Shan LL, Lu JB, Lin ZQ, Liu R, Liu J, Wang LP, Zhong M, Jiang Y, and Bai XC. mTORC1 promotes aging-related venous thrombosis in mice via elevation of platelet volume and activation. Blood 128: 615-624, 2016.

415. Yeh JK and Wang CY. Telomeres and telomerase in cardiovascular diseases. Genes (Basel) 7: 58, 2016.

416. Yoon JH, Kim JY, Park JK, and Ko SB. Oxidative damage markers are significantly associated with the carotid artery intima-media thickness after controlling for conventional risk factors of atherosclerosis in men. PLoS One 10: e0119731, 2015.

417. Yoshida T and Migita CT. Mechanism of heme degradation by heme oxygenase. J Inorg Biochem 82: 33-41, 2000.

418. Yuan S, Shen X, and Kevil CG. Beyond a gasotransmitter: hydrogen sulfide and polysulfide in cardiovascular health and immune response. Antioxid Redox Signal 27: 634653, 2017.

419. Zalba G, Beloqui O, San Jose G, Moreno MU, Fortuno A, and Diez J. NADPH oxidase-dependent superoxide production is associated with carotid intima-media thickness in subjects free of clinical atherosclerotic disease. Arterioscler Thromb Vasc Biol 25: 1452-1457, 2005.

420. Zhang Q, Malik P, Pandey D, Gupta S, Jagnandan D, Belin de Chantemele E, Banfi B, Marrero MB, Rudic RD, Stepp DW, and Fulton DJ. Paradoxical activation of endothelial nitric oxide synthase by NADPH oxidase. Arterioscler Thromb Vasc Biol 28: 1627-1633, 2008.

421. Zhang QJ, Wang Z, Chen HZ, Zhou S, Zheng W, Liu G, Wei YS, Cai H, Liu DP, and Liang CC. Endotheliumspecific overexpression of class III deacetylase SIRT1 decreases atherosclerosis in apolipoprotein E-deficient mice. Cardiovasc Res 80: 191-199, 2008.

422. Zhang R, Brennan ML, Fu X, Aviles RJ, Pearce GL, Penn MS, Topol EJ, Sprecher DL, and Hazen SL. Association between myeloperoxidase levels and risk of coronary artery disease. JAMA 286: 2136-2142, 2001.

423. Zhang R, Brennan ML, Shen Z, MacPherson JC, Schmitt D, Molenda CE, and Hazen SL. Myeloperoxidase functions as a major enzymatic catalyst for initiation of lipid peroxidation at sites of inflammation. J Biol Chem 277: 46116-46122, 2002.

Address correspondence to: Prof. Francesco Violi I Clinica Medica

Department of Internal Medicine and Medical Specialties Sapienza University of Rome Viale del Policlinico 155 Roma 00161 Italy

E-mail: francesco.violi@uniroma1.it

Date of first submission to ARS Central, December 1, 2016; date of acceptance, August 7, 2017.

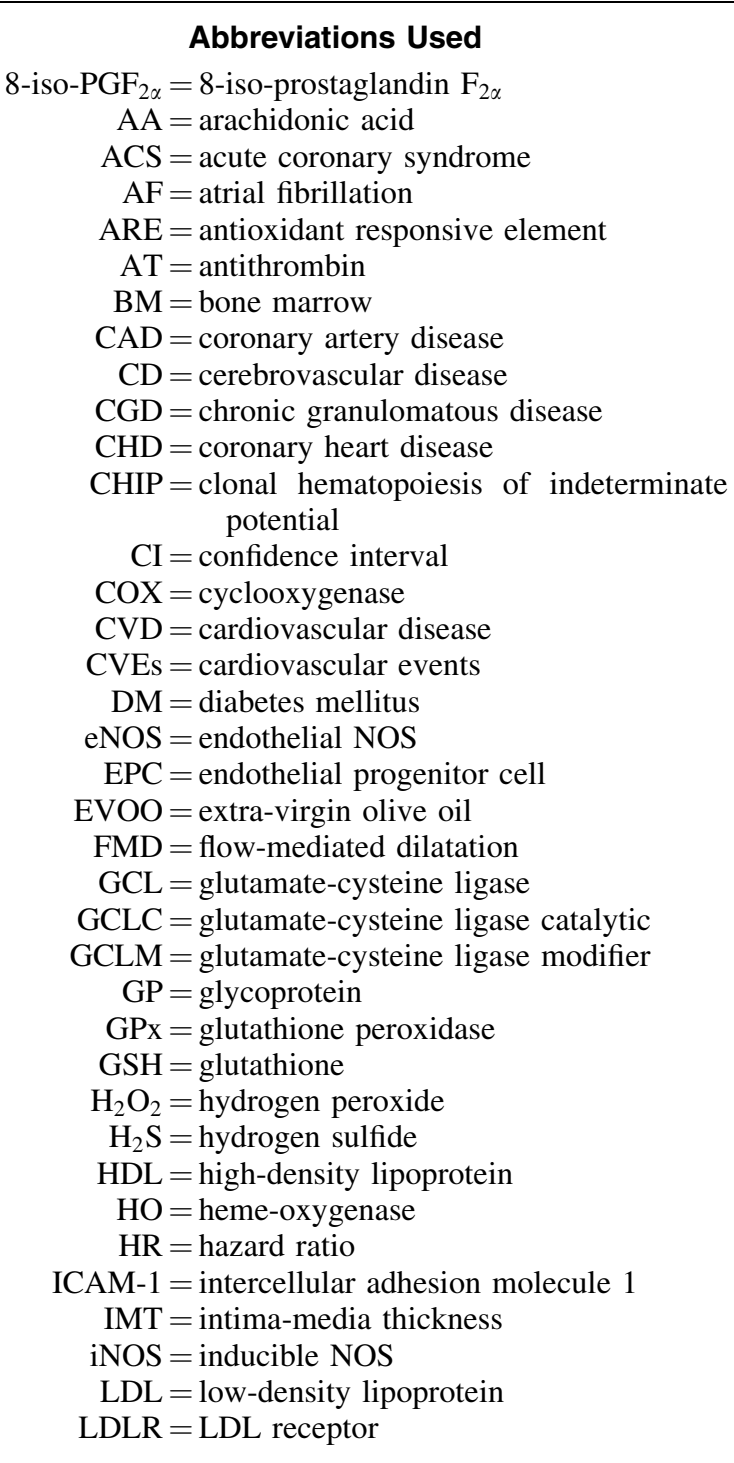




\begin{aligned} & \hline Abbreviations Used (Cont.) \\ & LOX $=$ lipoxygenase \\ & $\mathrm{LPS}=$ lipopolysaccharide \\ & $\mathrm{MAPK}=$ mitogen activated protein kinase \\ & $\mathrm{MCP}-1=$ monocyte chemoattractant protein \\ & $\mathrm{Med}-\mathrm{Diet}=$ Mediterranean Diet \\ & $\mathrm{MetS}=$ metabolic syndrome \\ & $\mathrm{MI}=$ myocardial infarction \\ & $\mathrm{MONICA}=$ Monitoring of Trends and Determinants \\ & $\mathrm{MPO}=$ myeloperoxidase \\ & $\mathrm{mRNA}=$ messenger RNA \\ & $\mathrm{NAC}=$ N-acetylcysteine \\ & $\mathrm{NADPH}=$ nicotinamide adenine dinucleotide \\ & phosphate \\ & $\mathrm{NF}-\kappa \mathrm{B}=$ nuclear factor kappa-light-chain- \\ &$\quad$ enhancer of activated B cells \\ & $\mathrm{nNOS}=$ neuronal NOS \\ & $\mathrm{NO}=$ nitric oxide \\ & $\mathrm{NOACs}=$ non-vitamin K oral anticoagulants \\ & $\mathrm{NOS}=$ NO synthase \\ & $\mathrm{Nox}=$ NADPH oxidase \end{aligned}

$\begin{aligned} \mathrm{Nrf} 2 & =\text { NF-E2-related factor } 2 \\ \mathrm{O}_{2}{ }^{-} & =\text {superoxide anion } \\ \text { ox-LDs } & =\text { oxidized LDLs } \\ \mathrm{PAD} & =\text { peripheral artery disease } \\ \mathrm{PAI}-1 & =\text { plasminogen activator inhibitor } 1 \\ \mathrm{PC} & =\text { progenitor cell } \\ \mathrm{PG} & =\text { prostaglandin } \\ \mathrm{PLA} & =\text { phospholipase } \mathrm{A}_{2} \\ \mathrm{PON} & =\text { paraoxonase } \\ \mathrm{PWV} & =\text { pulse wave velocity } \\ \mathrm{ROS} & =\text { reactive oxygen species } \\ \mathrm{RS} & =\text { replicative senescence } \\ \mathrm{SIPS} & =\text { stress-induced premature senescence } \\ \mathrm{SIRT} & =\text { sirtuin } \\ \mathrm{sNox} 2-\mathrm{dp} & =\text { soluble Nox2-derived peptide } \\ \mathrm{SOD} & =\text { superoxide dismutase } \\ \mathrm{TF} & =\text { tissue factor } \\ \mathrm{TMAO} & =\text { trimethylamine N-oxide } \\ \mathrm{TNF} \alpha & =\text { tumor necrosis factor } \alpha \\ \mathrm{Tx} & =\text { thromboxane } \\ \mathrm{VCAM}-1 & =\text { vascular cell adhesion molecule } 1 \\ \mathrm{VSMCs} & =\text { vascular smooth muscles cells }\end{aligned}$

